\title{
AVALIAÇÃO DA ESTABILIDADE DAS MEDIDAS CEFALOMÉTRICAS APÓS CINCO ANOS EM PACIENTES COM O ÂNGULO ANB MAIOR QUE 4ㅁ, TRATADOS ORTODONTICAMENTE COM EXTRAÇÕES DOS QUATRO PRIMEIROS PRÉ-MOLARES
}

\section{ANA CARLA RAPHAELLI NAHÁS}

Dissertação apresentada à Faculdade de Odontologia de Bauru, da Universidade de São Paulo, como parte dos requisitos para a obtenção do título de Mestre em Odontologia, área de Ortodontia.

(Edição Revisada)

Bauru

2000 


\section{AVALIAÇÃO DA ESTABILIDADE DAS MEDIDAS CEFALOMÉTRICAS APÓS CINCO ANOS EM PACIENTES COM O ÂNGULO ANB MAIOR QUE 4, TRATADOS ORTODONTICAMENTE COM EXTRAÇÕES DOS QUATRO PRIMEIROS PRÉ-MOLARES}

\section{ANA CARLA RAPHAELLI NAHÁS}

Dissertação apresentada à Faculdade de Odontologia de Bauru, da Universidade de São Paulo, como parte dos requisitos para a obtenção do título de Mestre em Odontologia, área de Ortodontia.

\section{(Edição Revisada)}

Orientador:

Prof. Dr. Marcos Roberto de Freitas

Bauru 
Nahás, Ana Carla Raphaelli

$\mathrm{N} 14 a \quad$ Avaliação da estabilidade das medidas cefalométricas após cinco anos em pacientes com o ângulo ANB maior que $4^{\circ}$, tratados ortodonticamente com extrações dos quatro primeiros pré-molares / Ana Carla Raphaelli Nahás.- Bauru, 2000.

123p.: il.; 29,7cm.

Dissertação. (Mestrado) - Faculdade de Odontologia de Bauru. USP.

Orientador: Prof. Dr. Marcos Roberto de Freitas

Autorizo, exclusivamente para fins acadêmicos e científicos, a reprodução total ou parcial desta dissertação, por processos fotocopiadores e/ou meios eletrônicos.

Assinatura do autor:

Data: 


\section{ANA CARLA RAPHAELLI NAHÁS}

28 de agosto de 1974

São Paulo - SP

Deoclécio Nahás e

Maria Lúcia Raphaelli Nahás

$1993-1996$

$1998-1999$

Associações
Nascimento.

Filiação.

Curso de Graduação em Odontologia - Universidade do Sagrado Coração de Jesus (USC) - SP.

Curso de Pós-Graduação em Odontologia, na área de Ortodontia, em nível de Mestrado, na Faculdade de Odontologia de Bauru, da Universidade de São Paulo.

Associação

Paulista

de Cirurgiões Dentistas. 
“No Universo do conhecimento, o âmago está em todo lugar." 


\section{A Deus,}

pela vida que a cada segundo amo em desfrutá-la, 
Aos meus maiores e eternos mestres, meus pais,

\section{Deoclécio e Maria Lúcia}

que com amor ao longo dos anos ensinaram-me o valor da vida, 
As minhas queridas irmãs,

Ana Lúcia e Carmen Lúcia,

pela alegria e amizade sempre transmitidas,

E a você, Cesar, pelo carinho, compreensão e apoio,

Dedico este trabalho, com meu mais profundo afeto. 
Meus sinceros agradecimentos aos Professores Doutores

Décio Rodrigues Martins,

Arnaldo Pinzan,

José Fernando Castanha Henriques, Guilherme dos Reis Pereira Janson, Renato Rodrigues de Almeida e em especial, ao meu orientador, MARCOS ROBERTO DE FREITAS,

pela convivência nestes anos, pelos ensinamentos e confiança em mim depositada. 
Agradeço ainda:

A todos os meus familiares: avós, tios e primos pelo incentivo e carinho constante;

Às minhas grandes amigas Mariana Mondelli e Claudia Maio Gagliardi pela amizade sincera e convívio durante minha vida;

"As pessoas entram em nossa vida por acaso, mas não é por acaso que elas permanecem"

Aos amigos do Curso de Mestrado em Ortodontia: Ana Claudia de Castro Ferreira Conti, Daniela Gamba Garib Carrera, Danilo Furquim Siqueira, Fausto Silva Bramante, Karyna Martins do Valle, Karina Santana Cruz, Paulo Eduardo Guedes Carvalho, Renata Rodrigues de Almeida e Roberto Bombonatti, pelo crescimento humano e profissional nesta jornada;

A todos os amigos de Pós-Graduação, desta Faculdade, pelos momentos gostosos que passamos e que deixarão saudades;

A todos os professores do Curso de Pós-Graduação em Ortodontia;

Aos funcionários da Disciplina de Ortodontia: Luiz Sérgio Vieira, Maria José dos Santos Formenti, Vera Lúcia Rodrigues Purgato, Tereza Cristina Alves Camaforte Ducatti, Cristiane de Jesus Cano e Daniel Francisco Rascão Selmo pela dedicação e ajuda inestimável; 
A todos os funcionários da Biblioteca, da Pós-Graduação e da Associação de Pós-Graduação pelas orientações e auxílio sempre paciente;

À amiga Dra. Dina Maria D. Sottovia pelos conselhos e apoio presente;

Ao Dr. Arnaldo Pinzan e família pelo carinho e amizade recebida durante minha vida;

Ao jovem casal Eduardo Alvarez Dainesi e Marcia Yuri Kawauchi pela consideração e atenção que sempre me dispensaram;

Aos alunos da Graduação e pacientes das clínicas de Graduação e de Pós-Graduação, pela contribuição na minha formação;

Aos que participaram diretamente da elaboração deste trabalho com destreza e paciência:

Prof. Roberto Pereira Lauris, pela elaboração da análise estatística, o jovem Daniel Francisco Rascão Selmo pela configuração das figuras e ajuda na formatação,

Prof. Valdir João Afonso pela correção gramatical, e Mário Vinícius Zendron pelo auxílio na realização do abstract; 
Agradecimentos Institucionais:

À Faculdade de Odontologia de Bauru, da Universidade de São Paulo, representada pelo seu Diretor, o Prof. Dr. Aymar Pavarini, Ao Prof. Dr. Luiz Fernando Pegoraro, Presidente da Comissão de PósGraduação da Faculdade de Odontologia de Bauru, Ao Conselho Nacional de Desenvolvimento Científico e Tecnológico (CNPq), pela concessão da bolsa de estudos;

e a todos, que de uma forma ou outra, me ajudaram nesta caminhada. 
"Nenhuma riqueza é mais bela que a que se ganha com o próprio trabalho". 


\section{SUMÁRIO}

LISTA DE FIGURAS ................................................................................................

LISTA DE TABELAS …..................................................................................... XV

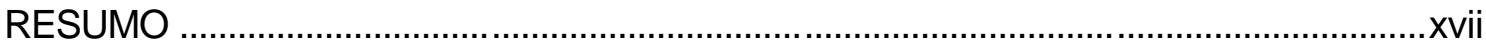

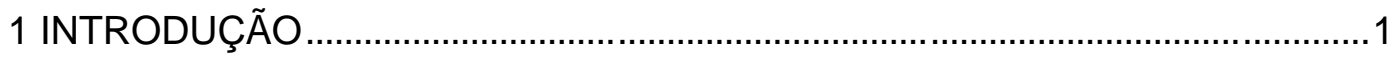

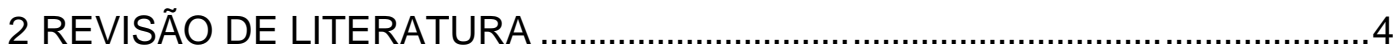



4 MATERIAL E MÉTODOS ............................................................................ 48

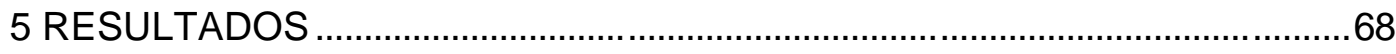

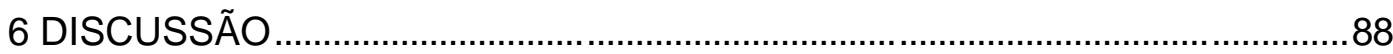

6.1 Discussão do material e métodos ........................................................90

6.2 Discussão dos resultados ..................................................................95

6.3 Discussão geral ..................................................................................103

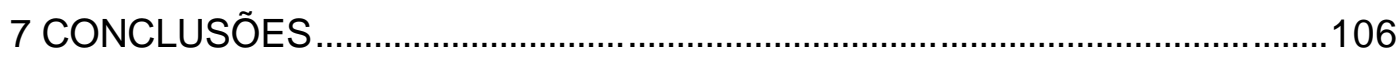

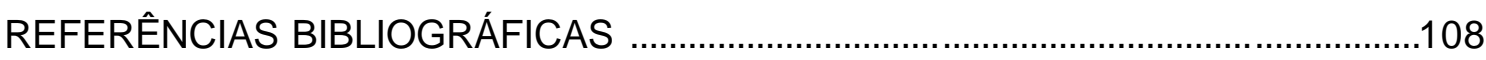

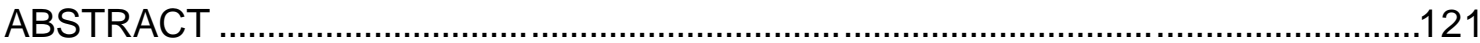

APÊNDICE. 


\section{LISTA DE FIGURAS}

FIGURA 2.1 - Ângulos que compõem o triângulo de TWEED ${ }^{90,91,92} \ldots . . . .15$

FIGURA 2.3 - Diagrama proposto por STEINER ${ }^{80,81,82,83}$, chamado de compromissos aceitáveis .............................................. 18

FIGURA 4.1 - Composição do desenho anatômico adotado .................. 53

FIGURA 4.2 - Pontos cefalométricos utilizados e suas localizações no desenho anatômico .................................................... 55

FIGURA 4.3 - Planos e linhas de referência que constituíram o traçado de orientação dos cefalogramas ........................ 57

FIGURA 4.4 - Medida Angular SNA …............................................... 58

FIGURA 4.5 - Medida Angular SNB …................................................... 59



FIGURA 4.7 - Medida Angular 1.NA …................................................. 60







FIGURA 4.11 - Medida Angular 1.ENP-ENA …….................................... 63

FIGURA 4.12 - Medida Linear 1-NA …......................................................... 64

FIGURA 4.13 - Medida Linear $\overline{1}$-NB ...................................................... 65

FIGURA 5.5 - $\quad$ Representação Gráfica - SNA ......................................... 72

FIGURA 5.8 - $\quad$ Representação Gráfica - SNB …..................................... 73

FIGURA 5.11 - Representação Gráfica - ANB .......................................... 74

FIGURA 5.14 - Representação Gráfica - 1.NA ……................................. 75

FIGURA 5.17 - Representação Gráfica - 1-NA .......................................... 76 
FIGURA 5.20 - Representação Gráfica - 1.NB ...................................... 77

FIGURA 5.23 - Representação Gráfica - 1-NB ........................................ 78

FIGURA 5.26 - Representação Gráfica - 1.ENP-ENA ........................... 79

FIGURA 5.29 - Representação Gráfica - IMPA ................................... 80

FIGURA 5.32 - Representação Gráfica - 1.1 ........................................ 81

FIGURA 5.35 - Representação gráfica do ângulo ANB, na fase $T_{3}$, para os gêneros masculino e feminino .................................. 84

FIGURA 5.36 - Representação gráfica do ângulo $\overline{1}$.NB, na fase $T_{3}$, para os gêneros masculino e feminino .................................... 84 


\section{LISTA DE TABELAS}

TABELA 2.2 - Tabela de valores preconizada por HOLDAWAY ${ }^{37}$ para orientar o posicionamento e a inclinação dentária quando a relação entre as bases apicais se encontra deficiente ........................................................................... 16

TABELA 2.4 - Alguns exemplos de medidas auferidas no trabalho de MARTINS et al. ${ }^{52}$, dispostas em tabela ............................ 44

TABELA 5.1 - Médias e desvios padrão calculados para cada variável cefalométrica nas diferentes fases do estudo

TABELA 5.2 - Médias e desvios padrão calculados das alterações ocorridas para cada variável cefalométrica nos intervalos interfases .......................................................... 70

TABELA 5.3 - $\quad$ Análise de Variância a um critério - SNA ......................... 72

TABELA 5.4 - Teste de Tukey - SNA ….................................................... 72

TABELA 5.6 - Análise de Variância a um critério - SNB ......................... 73

TABELA 5.7 - Teste de Tukey - SNB …................................................. 73

TABELA 5.9 - $\quad$ Análise de Variância a um critério - ANB ......................... 74

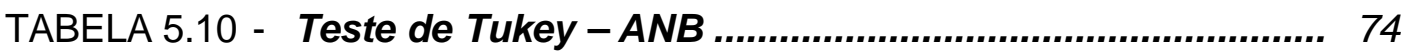

TABELA 5.12 - Análise de Variância a um critério - 1.NA ...................... 75

TABELA 5.13 - Teste de Tukey - 1.NA ............................................... 75

TABELA 5.15 - Análise de Variância a um critério - 1-NA ....................... 76

TABELA 5.16 - Teste de Tukey - 1-NA .................................................... 76

TABELA 5.18 - Análise de Variância a um critério - 1.NB ...................... 77

TABELA 5.19 - Teste de Tukey - 1.NB ............................................... 77 
TABELA 5.21 - Análise de Variância a um critério - 1-NB ....................... 78

TABELA 5.22 - Teste de Tukey - 1-NB ..................................................... 78

TABELA 5.24 - Análise de Variância a um critério - 1.ENP-ENA ............ 79

TABELA 5.25 - Teste de Tukey - 1.ENP-ENA ..................................... 79

TABELA 5.27 - Análise de Variância a um critério - IMPA ....................... 80

TABELA 5.28 - Teste de Tukey - IMPA .................................................. 80

TABELA 5.30 - Análise de Variância a um critério - 1.1 ......................... 81

TABELA $5.31 \quad$ Teste de Tukey - 1.1 ...................................................... 81

TABELA 5.33 - Coeficiente de correlação de Pearson .............................. 82

TABELA 5.34 - Médias, desvios padrão, valores de $\mathbf{t}$ e $\mathbf{p}$ para os gêneros nas diferentes fases de estudo .......................... 83

TABELA 5.37 - Erros sistemáticos das grandezas cefalométricas .......... 85

TABELA 5.38 - Erros casuais das grandezas cefalométricas ................. 87 


\section{RESUMO}

Este trabalho teve como objetivo avaliar cefalometricamente a estabilidade das medidas SNA, SNB, ANB, 1.NA, 1-NA, $\overline{1}$.NB, $\overline{1}$-NB, 1 .ENP-ENA, IMPA e $1 . \overline{1}$ a longo prazo, de pacientes tratados ortodonticamente com extrações dos quatro primeiros pré-molares e verificar, paralelamente a isto, se foram realizadas as compensações dentárias na mecânica ortodôntica e se estas foram preservadas cinco anos após o término do tratamento. Vinte e sete pacientes foram analisados no início $\left(T_{1}\right)$, no final $\left(T_{2}\right)$ e cinco anos após a finalização terapêutica $\left(\mathrm{T}_{3}\right)$. No início do tratamento, a idade média era de 13 anos e 5 meses e todos os componentes apresentavam o ângulo ANB maior que 4․․ Quatorze componentes apresentavam más oclusões Classe II, 1a divisão de Angle, 12 componentes apresentavam más oclusões Classe I e 1, má oclusão Classe II, $2^{a}$ divisão. Os casos foram tratados com a técnica Edgewise. Nas três fases de estudo os cefalogramas laterais foram realizados manualmente, obtendo-se as oito grandezas angulares e as duas lineares. A análise estatística indutiva envolveu a análise de variância a um critério para identificar as alterações interfases no valor de cada variável estudada, e o teste de Tukey para indicar, especificamente, entre quais fases de estudo estaria ocorrendo diferenças estatisticamente significantes. Utilizou-se o coeficiente de correlação de Pearson, no afã de relacionar a medida cefalométrica $1 . \overline{1}$ com as demais medidas nas três fases de estudo. De acordo com os resultados obtidos, todas as medidas estudadas entre as fases inicial e final se alteraram significantemente refletindo a influência da mecânica ortodôntica sobre os movimentos dentários e entre as fases final e cinco anos após, todas as medidas 
permaneceram estáveis. Obtiveram-se as compensações dentárias necessárias no final do tratamento ortodôntico e estas foram preservadas a longo prazo. 


\section{1 - INTRODUÇÃO}




\section{INTRODUÇÃO}

HOLLY BROADBENT, em $1931^{13}$, contribuiu para a ciência ortodôntica com o advento de uma técnica de estudo radiográfico, utilizando-a de modo ímpar no diagnóstico e planejamento dos casos, além de auxiliar nas análises das alterações resultantes do tratamento ativo ${ }^{35}$. Desde então, as inclinações no sentido vestibulolingual dos incisivos inferiores observadas nas radiografias cefalométricas de norma lateral, surpreenderam os pesquisadores ao verificarem as mudanças ocorridas entre as fases pré e pós-tratamento, o que era impossível pelos modelos ortodônticos de estudo e pela observação clínica. Atualmente, os ortodontistas estão cientes da importância de se movimentar estes dentes adequadamente, contribuindo para o alcance de resultados mais satisfatórios ${ }^{69,93}$. Apesar das inúmeras pesquisas realizadas na tentativa de se determinar os prognósticos da estabilidade ortodôntica a longo prazo, encontram-se poucas evidências na literatura de estudos relacionando as inclinações axiais dos dentes ântero-inferiores e a recidiva ortodôntica ${ }^{47}$.

O primeiro a incluir os incisivos inferiores no planejamento dos casos clínicos, como critério fundamental para a obtenção de uma oclusão normal, foi CHARLES H. TWEED, na década de $40^{31,87,88,89}$. Ele relatou que estes dentes deveriam formar cefalometricamente um ângulo de 90ำ com o osso basal. Tempos depois, CECIL C. STEINER ${ }^{81,82,83}$ preconizou uma análise baseada empiricamente no mecanismo compensatório dentoalveolar ${ }^{73}$, guiando e capacitando o profissional a tornar mais objetivo sua elaboração dos planos de tratamento. Estas descobertas 
foram essenciais para o avanço científico nessa área, sendo amplamente utilizadas até os dias atuais.

O mecanismo compensatório dentoalveolar é um sistema que, com o crescimento e o desenvolvimento craniofacial, tenta manter a relação interarcos normal, em variados relacionamentos entre as bases ósseas apicais nos planos sagital, vertical e transversal. Em pacientes que apresentam bom equilíbrio facial e suave deficiência no relacionamento sagital entre os maxilares, a própria natureza se encarrega de compensar as posições dentárias, diferentemente daqueles que, exibindo um ângulo ANB desfavorável (valor angular distante do considerado ideal = 2ำ entre as bases apicais), a prática ortodôntica tem como encargo corrigir, inclinando os incisivos superiores e os inferiores acuradamente com o propósito de disfarçar a discrepância existente ${ }^{10,73,74}$.

A realização deste estudo teve como objetivo principal avaliar cefalometricamente a estabilidade das medidas SNA, SNB, ANB, 1.NA, $\underline{1}-\mathrm{NA}, \overline{1} . \mathrm{NB}$, $\overline{1}-N B, \underline{1}$.ENP-ENA, IMPA e $\underline{1} \cdot \overline{1}$ após cinco anos a finalização do tratamento ortodôntico com a extração dos primeiros pré-molares de pacientes que apresentavam no início da terapêutica o ângulo ANB maior que $4^{\circ}$ e verificar se as compensações esqueléticas e dentárias foram realizadas na mecânica ortodôntica e se estas foram preservadas a longo prazo. 
2 - REVISÃO DE LITERATURA 


\section{REVISÃO DE LITERATURA}

A revisão literária, em seqüência cronológica, discorrerá sobre vários aspectos pertinentes a este trabalho, como a posição ideal dos incisivos inferiores ao final do tratamento ortodôntico e a sua estabilidade a longo prazo, os métodos de análises referentes ao posicionamento e à inclinação dentária, os mecanismos compensatórios dentoalveolares, as compensações dentárias realizadas mecanicamente relacionadas posteriormente ao sucesso da terapêutica ortodôntica pós-tratamento, a influência do equilíbrio muscular sobre o posicionamento dentário, os estudos de crescimento longitudinais e a importância do julgamento profissional na individualização dos casos ortodônticos.

MARGOLIS, em $1943^{51}$, demonstrou existir um relacionamento entre os incisivos inferiores e o plano mandibular, permitindo aos clínicos, de maneira mais precisa, a comparação do grau de inclinação destes dentes antes, durante e após o término do tratamento ortodôntico. No traçado cefalométrico, mediu-se o ângulo formado pela intersecção do longo eixo do incisivo central inferior com uma linha tangente à borda inferior da mandíbula, classificando-o da seguinte forma: obtuso, quando os incisivos se encontrassem vestibularizados; agudo, quando lingualizados; e reto $\left(90^{\circ} \pm 3^{\circ}\right)$, verticalizados com o osso basal. Para o autor, obtinham -se os melhores resultados de casos tratados ortodonticamente de crianças leucodermas, quando os incisivos inferiores se encontravam verticalizados ao plano mandibular. Entretanto, o profissional deveria variar necessariamente seu planejamento de 
acordo com seu próprio conceito de tipo e harmonia facial, bem como com a sua capacidade.

Em 1943, NOYES; RUSHING; SIMS $^{57}$ realizaram um estudo telerradiográfico de 30 jovens leucodermas com 18 anos de idade (21 do gênero masculino e 9 do feminino). Destes, 15 apresentavam má oclusão Classe II, $1^{\text {a }}$ divisão de Angle e 15 má oclusão Classe III de Angle. A medida cefalométrica angular obtida pela intersecção dos longos eixos dos incisivos centrais superiores com os incisivos centrais inferiores (ângulo interincisivos) mostrou-se similar entre os componentes da amostra, sugerindo uma tendência compensatória nos arcos dentários.

Em 1944, BRODIE ${ }^{14}$ examinou 36 casos de má oclusão Classe I de Angle, 43 de Classe II, $1^{\text {a }}$ divisão e 15 de Classe II, $2^{\text {a }}$ divisão, totalizando 104 casos. As telerradiografias tomadas anterior ao tratamento ortodôntico foram traçadas, enfatizando a grandeza angular do incisivo central inferior com a linha tangente à borda inferior da mandíbula. O ângulo médio para os casos de má oclusão Classe I foi de $90.9^{\circ}$, para os de Classe II, $1^{\text {a }}$ divisão, $89.3^{\circ}$ e $86.6^{\circ}$ aos pertencentes à má oclusão Classe II, $2^{\mathfrak{a}}$ divisão. Uma vez que sua amostra compôsse apenas de más oclusões, não se conseguiu muito significado em relação aos resultados, sendo que se presumia alguma correlação da má oclusão presente com a inclinação dos dentes ântero-inferiores. O autor deixa claro o possível fracasso em se empregar uma média como critério para o tratamento, sendo mais lógico concluir que a inclinação axial dos incisivos inferiores, como qualquer outra característica 
anatômica, varia consideravelmente de indivíduo para indivíduo. Erra-se ao insistir que todos os incisivos devam ficar verticalizados sobre o osso basal.

Com o propósito de analisar a inclinação axial vestibulolingual dos incisivos centrais inferiores de jovens com oclusões consideradas ideais, SPEIDEL; STONER, em $1944^{77}$, realizaram os traçados cefalométricos de 42 adolescentes do gênero masculino. Deu-se maior importância ao ângulo formado pelo longo eixo do incisivo central inferior com a tangente à borda inferior do corpo da mandíbula. Aproximadamente $80 \%$ destes ângulos variaram de $86^{\circ}$ a $99^{\circ}$, com uma inclinação média, de $92,64^{\circ}$. Apesar dos componentes desta amostra possuírem excelente relacionamento oclusal, verificou-se uma grande variação na configuração de seus ossos mandibulares, bem como nas inclinações dos incisivos centrais inferiores.

Como resultado de observações clínicas constantes, TWEED, na década de $40^{87}, 88,89$, convenceu-se de que para o sucesso do tratamento ortodôntico das más oclusões de Angle, Classe I e II e protrusão bimaxilar, os incisivos inferiores deveriam estar verticalizados sobre o osso basal possibilitando o equi líbrio mecânico-funcional. Ele considerou o relacionamento dos dentes ânteroinferiores com a base apical o mais acurado guia para o tratamento científico das más oclusões, estabelecendo que o ângulo formado por estes dentes e a borda inferior da mandíbula, deveria ser $90^{\circ} \mathrm{com}$ uma variação de $\pm 5^{\circ}$. Isto se aplicou apenas aos casos em que o padrão de crescimento se aproximava do normal, pois aqueles que apresentavam crescimento vertical, estes dentes deveriam ser posicionados com uma diferença de $-5^{\circ} \mathrm{a}-10^{\circ}$, em relação aos $90^{\circ}$ já citados. Além disso, estabeleceu-se que havendo discrepância negativa de modelo, quatro pré- 
molares seriam extraídos com o objetivo de ganhar espaço para a correção das inclinações axiais e posições dentárias.

Em 1947, CORLETT ${ }^{22}$ objetivou em seu trabalho analisar o relacionamento dos dentes ântero-inferiores com o osso basal mandibular, especificamente com o mento ósseo. O material consistiu de telerradiografias padronizadas de 452 pacientes leucodermas de ortodontia da Universidade de lowa. Trezentos e setenta e três eram pertencentes ao grupo A (oclusão normal e má oclusão Classe I de Angle) e 79 ao grupo B (má oclusão Classe II de Angle). A idade cronológica variou de 4 a 25 anos. De cada radiografia, o incisivo central inferior e o corpo da mandíbula foram traçados. Procedeutse com a realização de duas linhas: uma tangente à borda inferior da mandíbula e a outra tangente ao mento, formando um ângulo reto entre as duas. Mediu-se a menor distância entre a superfície vestibular do ncisivo inferior e a última linha designada. Todas as medidas foram expressas em milímetros. Padronizou-se como valor zero os valores coincidentes com a linha vertical tangente ao mento, como valores positivos todas as medidas à frente desta linha, e negativos todas as que estiverem atrás da mesma. Perante os dados coletados, observou-se uma similaridade entre os jovens dos grupos A e B que apresentavam os incisivos inferiores posicionados em média 8mm atrás da linha de referência, concluindo que estes dentes se posicionam de forma parecida, independe se for má oclusão classe I, II ou oclusão normal.

MARGOLIS, em $1947^{00}$, introduziu o triângulo maxilofacial, cujos lados são: a linha da base craniana, a linha facial e a linha mandibular. Ele analisou 100 crianças de 6 a 19 anos de idade, observando as características deste triângulo e 
verificou que em faces bem desenvolvidas, o ângulo formado pelo incisivo central inferior e a linha mandibular se manteve em $90^{\circ}$, com uma variação de $3^{\circ}$.

COLE, em $1948^{20}$, com o propósito de avaliar as mudanças ocorridas nas inclinações axiais dos dentes ântero-inferiores no período pós-contenção, selecionou 21 pacientes que apresentavam oclusões deficientes. Tratou todos os casos com a técnica Edgewise, com a extração dos primeiros pré-molares superiores e inferiores. Realizaram-se os cefalogramas, de radiografias em norma lateral, obtidos no início do tratamento, no final e no mínimo um ano após a remoção de toda a contenção. A medida angular de escolha para analisar as alterações nas inclinações dos incisivos inferiores foi o ângulo formado pelo longo eixo do incisivo central inferior esquerdo com o plano mandibular (GoMe). Da segunda para a terceira fase de avaliação, em 11 casos, as inclinações dos incisivos inferiores retornaram 34\% da distância de movimentação, em direção a suas posições originais. Em seis casos, os resultados permaneceram estáveis e nos demais a tendência de movimento continuou em direção a do tratamento mecânico. Estes dados sugerem existir uma forte tendência das inclinações axiais dos incisivos inferiores em retornarem para os seus relacionamentos de origem, com o plano mandibular, subseqüente à remoção do aparelho de contenção; entretanto o tratamento com extração foi bem sucedido no estabelecimento de posições mais verticais destes dentes.

Com a mesma linha de pesquisa do estudo anterior de $\operatorname{COLE}^{20}$, em 1948, LITOWITZ ${ }^{49}$ investigou as alterações das inclinações dentárias do segmento ântero-inferior ocorridas a longo prazo. Vinte pacientes (15 classificados em má 
oclusão Classe I de Angle e 5 em Classe II) foram tratados com a mecânica do arco de canto com a finalização do tratamento ortodôntico considerada aparentemente bem sucedida. As fases de avaliação abrangeram o início do tratamento, o final e um a cinco anos após a retirada de toda a contenção. Utilizou-se tanto o auxílio cefalométrico (os planos mandibulares e as sínfises dos traçados foram superpostos), como o estudo em modelos. De acordo com os resultados obtidos, naqueles em que a mecânica resultou em um aumento da inclinação axial dos incisivos inferiores, metade deste grupo apresentou uma tendência em retornar a sua relação original e a outra metade tornou-se mais vestibularizada. Já naqueles em que se deu a diminuição da inclinação, a maior parte apresentou uma diminuição adicional no período pós-contenção.

DOWNS, em $1948^{24}$, com a utilização de uma amostra de 40 casos controles de oclusão normal conferiu a inclinação axial do incisivo central inferior em relação ao plano mandibular, obtendo uma média de $91.4^{\circ}$. O autor explicou a diferença encontrada entre este valor, obtido em seu estudo, com o padrão normal de $90^{\circ}$ devido ao método de localização do plano mandibular. Aferiu-se também o ângulo interincisivos obtendo uma média de $135.4^{\circ}$, variando de $130^{\circ}$ a $150.5^{\circ}$.

Evidenciando-se as mudanças ocorridas quanto à inclinação axial dos dentes anteriores subseqüente ao tratamento da má oclusão, surgiram dúvidas se estas mudanças seriam ou não encontradas em todos os pacientes em fase de crescimento. Portanto, SCHAEFFER, em $1949^{69}$, realizou um estudo longitudinal onde as alterações pertinentes ao crescimento individual foram acompanhadas. Relacionou-se o incisivo superior com o plano palatino (traçou-se uma linha 
passando pelos pontos espinha nasal anterior e posterior), o incisivo inferior com o plano mandibular (determinado pelos pontos gônio e gnátio), os incisivos entre si (ângulo interincisivos), e o plano palatino com o plano mandibular, para determinar se ou não mudanças ocorridas no relacionamento dos incisivos superiores com os inferiores poderiam ser atribuídas às mudanças entre os planos de referência. A seleção da amostra foi aleatória consistindo de 47 séries de telerradiografias de casos não tratados. Todos os pacientes apresentavam má oclusão Classe I de Angle, exceto seis que eram Classe II. Dos 47 componentes, 18 eram do gênero feminino e 29 do masculino. Perante os resultados encontrados, existiu uma grande variação nas grandezas angulares auferidas. Empregar medidas exatas como critério absoluto no planejamento e prognóstico do tratamento ortodôntico seria impossível de acordo com este estudo. Cada um dos três primeiros ângulos citados pode aumentar, diminuir ou permanecer estável durante o crescimento. Não se observou também diferenças entre os gêneros.

Em 1950, RIEDEL ${ }^{65}$ verificou uma tendência, clara, dos incisivos superiores e inferiores em estarem mais verticalizados, em pacientes que apresentassem perfis considerados bons (agradáveis esteticamente - com o ângulo ANB não excedendo a $2.5^{\circ}$ ).

Após dois anos, RIEDEL ${ }^{66}$ estudou as relações da maxila, com a base craniana e com a mandíbula. A amostra selecionada foi constituída de 52 adultos (18 anos a 36 anos de idade) e 24 crianças ( 7 anos a 11 anos) que apresentavam excelentes oclusões; 38 indivíduos com más oclusões Classe II, 1a divisão de Angle, 10 com más oclusões Classe II, $2^{\underline{a}}$ divisão e 9, Classe III. Grandezas angulares e 
lineares foram obtidas a partir das telerradiografias. Com a medida da posição relativa ântero-posterior da maxila em relação à base craniana, pode-se construir o ângulo Sela-Násio ao ponto A (SNA). Nenhuma diferença significante existiu entre os pacientes apresentando excelentes oclusões e más oclusões dentárias. Evidenciou-se uma tendência da maxila em tornar-se mais protruída com o crescimento, ao comparar os grupos formados por adolescentes e os formados por adultos. A posição relativa ântero-posterior da mandíbula em relação à base do crânio foi medida pelo ângulo Sela-Násio ao ponto B (SNB), encontrando uma diferença significante entre os pacientes que exibiam excelentes oclusões e os que exibiam más oclusões dentárias. Nas más oclusões Classe II, $1^{\text {a }}$ divisão de Angle, a mandíbula se mostrava menos protruída, tornando-se com o crescimento menos retruída. Considerou-se a relação ântero-posterior entre os pontos $A$ (na maxila) e B (na mandíbula), o resultado mais significante do estudo, sendo mensurável pela subtração do ângulo SNB do ângulo SNA (em oclusões normais o ângulo ANB é aproximadamente $2^{\circ}$ ). Obtiveram-se outras medidas, entre elas 0 ângulo interincisivos, com uma média de $130.98^{\circ}$ para os adultos e $130.40^{\circ}$ para as crianças.

\section{Em 1952, LANDE $^{45}$ averiguou cefalometricamente as mudanças} ocorridas na forma do perfil facial em três intervalos de tempo: radiografias obtidas de 3 a 7 anos de idade, de 7 a 12 e de 12 a 18 anos. A amostra consistiu de 34 componentes, todos do gênero masculino, sem nenhum tipo de tratamento realizado. As medidas lineares auferidas foram: NENA, N-A, N-B, N-Gn, Go-Gn e S $\mathrm{N}$; e as angulares foram: SN.ENA, SNA, SNB, SNPog, SNGn, NSGn, SN.GoGn, NAGn e FH.SN. Os achados médios revelaram que a grande mudança na forma do 
perfil, em direção ântero-posterior, ocorreu após os sete anos de idade, principalmente no ponto gnátio. O intervalo de 12 a 18 anos de idade mostrou movimento em direção anterior significante de $1 \mathrm{~mm}$ para o ponto $A, 2,2 \mathrm{~mm}$ para o $B$ e $3.7 \mathrm{~mm}$ para o $\mathrm{Gn}$.

STRANG, em $1952^{85}$, estudando os fatores associados ao sucesso da terapêutica ortodôntica, verificou que a inclinação axial de cada unidade dentária, normal ou propositalmente modificada, deve ser estabelecida resistindo a qualquer força de estresse que favoreça a recidiva da má oclusão.

STEINER, em $1953^{79}$, estabeleceu um método de análise cefalométrica de acordo com as posições e inclinações axiais dos incisivos. Quando as bases apicais, maxila e mandíbula, se encontravam bem orientadas, os incisivos centrais superiores deveriam angular-se com a linha NA (uni-se os pontos $N$ - násio ao $\mathrm{A}$ subespinhal) em $22^{\circ}$, e o ponto mais anterior da coroa clínica destes dentes deveriam distanciar em $4 \mathrm{~mm}$ da mesma linha, definindo seu grau de protrusão. Empregou-se o mesmo raciocínio para os incisivos centrais inferiores, inclinando-se em $25^{\circ}$ e posicionando-se em $4 \mathrm{~mm}$ da linha de referência NB (B - supramental).

Tendo em mente que o crescimento e o desenvolvimento trazem consigo mudanças apreciáveis na oclusão dos dentes, BJÖRK; PALLING, em $1954^{10}$, analisaram medidas cefalométricas de 243 garotos suecos, nas idades de 12 e 20 anos. Verificaram que existe um mecanismo compensatório de natureza alveolar e dentária, com o evoluir da idade, como resultado proveniente da pressão exercida pelos lábios e língua (mantendo uma forma aceitável de mordida) e do 
crescimento e desenvolvimento dos ossos maxilar e mandibular (minimizando a discrepância entre as bases apicais no sentido sagital).

GRABER, em $1954^{30}$, revisou criticamente os métodos cefalométricos existentes até então, dando ênfase às posições e às inclinações dentárias do segmento anterior. Observou que a relação dos incisivos superiores com os inferiores (leitura angular da intersecção dos longos eixos destes dentes) mostrava a maior variabilidade de todos os critérios e era o menos confiável do ponto de vista de diagnóstico. Entretanto, devido à possibilidade de grande controle sobre os incisivos, alterações ocasionadas pelo tratamento ortodôntico são refletidas em grande magnitude nesta grandeza.

TWEED, em $1954^{90}$, e na década de $60^{91,92}$, descreveu sobre o seu método de análise, o triângulo de TWEED ${ }^{90,91,92}$. Os ângulos que compõem o triângulo são: IMPA (o ângulo formado pelo longo eixo do incisivo inferior com o plano mandibular); FMA (o ângulo formado pelo plano mandibular com o plano horizontal de Francfort) e FMIA (o ângulo formado pelo longo eixo do incisivo inferior com o plano horizontal de Francfort) (Figura 2.1). Ele preconizou para a obtenção da estética facial e estabilidade de tratamento ortodôntico os seguintes valores: FMA = $25^{\circ}, \mathrm{FMIA}=65^{\circ}$ e IMPA $=90^{\circ}$. 




FIGURA 2.1 - Ângulos que compõem o triângulo de TWEED ${ }^{90,91,92}$

Em 1955, WYLIE ${ }^{101}$ discordou com alguns preceitos de TWEED ${ }^{90,91,92}$ dizendo que as mudanças faciais que ocorriam não deveriam ser atribuídas inteiramente aos movimentos dentários induzidos, pois existiam outros fatores relacionados, como por exemplo o crescimento mandibular. Além disso, enfatizou a importância da individualização dos casos, contestando a aplicação de valores médios nos planejamentos ortodônticos como objetivos rígidos.

Em 1956, HIXON ${ }^{36}$ reafirmou, baseado em dados científicos, a notificação de WYLIE ${ }^{101}$. Concretizourse de que, devido à existência da variabilidade na aferição de medidas, não se justificava pensar em média como uma meta no planejamento do tratamento. Além do mais, a maioria das normas disponíveis na ortodontia eram e ainda são construídas de amostras pequenas, que indubitavelmente necessitam de cautela em seu uso. Não se substitui o julgamento profissional. 
HOLDAWAY, em $1956^{37}$, traçou 37 telerradiografias de pessoas apresentando excelente harmonia facial, atendo-se aos ângulos ANB (relação ântero-posterior dos maxilares entre si), ao relacionamento dentário com os diversos planos e com as bases de suporte. O significado dos resultados foi de que, concordando com o trabalho de BJÖRK e PALLING ${ }^{10}$, a natureza faz um excelente trabalho de compensação dentária, dependendo do relacionamento existente entre a maxila e a mandíbula. O maior número de faces bem harmonizadas apresentou o ângulo ANB próximo a $2^{\circ}$. Casos em que a relação apical se encontrou deficiente, HOLDAWAY ${ }^{37}$ preconizou uma tabela como guia para, com o auxílio da mecânica ortodôntica, orientar o posicionamento e a inclinação dentária (Tabela 2.2). Isto se deu devido à incapacidade e dificuldade do autor em manter, ou até atingir os valores considerados por STEINER ${ }^{79}$ como normais $\left(\underline{1} . \mathrm{NA}=22^{\circ} ; \underline{1}-\mathrm{NA}=4 \mathrm{~mm} ; \overline{1} . \mathrm{NB}\right.$ $\left.=25^{\circ} ; \overline{1}-\mathrm{NB}=4 \mathrm{~mm}\right)$.

TABELA 2.2 - Tabela de valores preconizada por HOLDAWAY ${ }^{37}$ para orientar o posicionamento e a inclinação dentária quando a relação entre as bases apicais se encontra deficiente

\begin{tabular}{l|ll|ll}
$\begin{array}{c}\text { Ângulo ANB } \\
\text { (graus) }\end{array}$ & \multicolumn{2}{|c|}{$\begin{array}{c}1-N B \\
\text { (mm) }\end{array}$} & $\begin{array}{c}\text { 1.NA } \\
\text { (graus) }\end{array}$ \\
\hline Acima de 4 & 3.0 & & 22 & \\
5 & 3.5 & & 21 & \\
6 & 4.0 & & 20 & \\
7 & 4.5 & & 18 & \\
8 & 5.0 & & 17 & \\
9 & 5.5 & & 15 & \\
10 & 6.0 & & 13 & \\
11 & 7.0 & & 11 & \\
12 & 8.0 & 8 & \\
\hline
\end{tabular}


STEVENS, em $1956^{84}$, realizou um estudo eletromiográfico em 25 pacientes para medir a pressão exercida sobre os dentes oriunda dos músculos da língua e dos lábios. Todos os participantes apresentavam má oclusão Classe II, $1^{\text {ạ }}$ divisão de Angle, sendo 16 do gênero feminino e 9 do masculino. Os locais intrabucais específicos do trabalho foram: superfícies vestibulares dos incisivos centrais superiores, superfícies vestibulares dos incisivos centrais inferiores e superfícies linguais dos incisivos centrais em nível do plano oclusal. Os dados obtidos revelaram não haver qualquer relacionamento significante entre as pressões musculares vestibular e lingual. Entretanto, durante o ato de deglutição, a pressão lingual excedeu a vestibular em todos os casos.

Em 1957, RICKETTS ${ }^{61}$ contesta as análises de DOWNS ${ }^{24}$ e STEINER $^{79}$ por não considerarem os tecidos moles. Restringiu-se a uma análise estática da condição imediata, a aplicação clínica de ambos os métodos. Não incluíram também os fatores de crescimento que deveriam interferir no planejamento ortodôntico.

Em 1957, RIEDEL ${ }^{67}$ estudou os traçados cefalométricos de um grupo de 30 princesas de Seattle (EUA), da feira do mar. As medidas auferidas foram: ANB, FMIA, IMPA, $\underline{1} \overline{1}$ (ângulo interincisivos), $\underline{1}$.NA, $\overline{1} . \mathrm{NB}, \underline{1}-\mathrm{NA}$ e $\overline{1}-\mathrm{NB} . \mathrm{A}$ idade média era de 18 anos e 10 meses. Vinte e um componentes apresentavam má oclusão Classe I de Angle; 4, Classe II, 1aㅡ divisão; 2, Classe II, $1^{\text {a }}$ divisão, subdivisão; 3, Classe II, $2^{a}$ divisão. Apenas quatro garotas receberam o tratamento ortodôntico. Comparou-se este grupo com um outro de oclusão normal já existente para averiguar as possíveis diferenças. No grupo de princes as, verificou-se uma 
maior verticalização dos incisivos superiores devido a maior protrusão maxilar que apresentavam. Conseqüentemente, para a manutenção do ângulo interincisivos próximo ao padrão normal, os incisivos inferiores apresentaram-se mais vestibularizados, caracterizando as chamadas compensações dentárias.

STEINER, em $1959^{80,81}$, e na década de $60^{82,83}$, explicou e exemplificou, com a ilustração de casos, a importância da utilização da análise cefalométrica designada Análise de STEINER ${ }^{80,81,82,83}$. Para ele, o relacionamento da maxila com a mandíbula (ângulo ANB) se faz necessário. Portanto, no planejamento ortodôntico, estima-se este ângulo considerando vários aspectos como, a idade do paciente, o potencial de crescimento, o tipo de má oclusão, o tipo de tratamento e a habilidade profissional. A partir do momento que este ângulo é estimado (por exemplo: de $10^{\circ}$ para $6^{\circ}$ ), o seu valor irá ditar as posições e as inclinações dos incisivos superiores e inferiores. Para isso, deve-se olhar o diagrama, proposto por ele, chamado de compromissos aceitáveis, baseado em pessoas com oclusão normal (Figura 2.3).



FIGURA 2.3 - Diagrama proposto por STEINER ${ }^{80,81,82,83}$, chamado de compromissos aceitáveis 
Conforme o ângulo ANB aumenta em $1^{\circ}$,

o ângulo 1.NA diminui em $1^{\circ}$,

o ângulo $\overline{1}$.NB aumenta em $1^{\circ}$,

a medida linear 1 -NA diminui em $1 \mathrm{~mm}$, e

a medida linear $\overline{1}-\mathrm{NB}$ aumenta em $0,25 \mathrm{~mm}$. Ou seja, as medidas superiores diminuem e as inferiores aumentam, e vice-versa. Este raciocínio, por ele esquematizado, mostra as compensações dentárias necessárias para o disfarce das discrepâncias basais deficientes. Utilizam-se todas estas estimativas como guias, porém elas devem ser modificadas para cada indivíduo.

Cinqüenta faces apresentando um bom equilíbrio facial, não tratadas ortodonticamente, relação molar Classe I, idade média de 23 anos, foram avaliadas por GOLDSMAN, em $1959^{29}$, com o objetivo de averiguar a hipótese de TWEED ${ }^{90}$ em relação à medida FMIA (ângulo do incisivo inferior com o plano horizontal de Francfort). Encontraram um valor aproximado ao de TWEED $^{90}$ (amostra $-65.4^{\circ}$, Tweed $-65.0^{\circ}$ ), porém notou-se uma grande variabilidade nos valores, com um desvio padrão de $\pm 5.79^{\circ}$.

RICKETTS, em $1960^{62}$, estudou longitudinalmente casos tratados e não tratados ortodonticamente de más oclusões Classe II, $1^{\text {a }}$ e $2^{\underline{a}}$ divisão de Angle, com a idade média de 8.1 anos no início das documentações radiográficas. Concluiu que o comportamento do ponto A (subespinhal) relaciona-se em certo grau com a mudança posicional dos incisivos superiores ao erupcionarem e com as forças de torque aplicadas durante o tratamento. Em geral, preconizou-se que a cada $3 \mathrm{~mm}$ de 
movimento de corpo em sentido posterior dos incisivos superiores, ocorre uma redução de $2 \mathrm{~mm}$ do ponto $\mathrm{A}$ e $1 \mathrm{~mm}$ da espinha nasal anterior.

Em 1960, SCHWARTZ ${ }^{73}$ fez uma observação interessante quanto ao tempo necessário de acompanhamento dos casos ortodonticamente tratados. Alegou que não se pode basear as conclusões em modelos obtidos imediatamente após a remoção do aparelho, enganando nosso pensamento quanto a estabilidade do caso ortodôntico. Com certeza, após alguns anos de sua remoção, nos depararemos com as recidivas, ao registrar cefalometricamente ou em modelos as posições dentárias.

RICKETTS, em $1961^{63}$, escreveu sobre a importância da estética como parte integral no planejamento ortodôntico. Quando se satisfaz os requerimentos da harmonia facial, os elementos dentários se relacionam funcionalmente bem e viceversa. Portanto, ele não concordou integralmente com o auxílio da cefalometria como guia na avaliação dos relacionamentos dos dentes anteriores.

Realizou-se um estudo radiográfico longitudinal com a técnica de implantação de pinos de tântalo em 1963, por BJÖRK ${ }^{9}$. A amostra compreendeu 110 crianças dinamarquesas de ambos os gêneros e com diferentes tipos de más oclusões. No total 900 pinos foram colocados e a téc nica de análise empregada foi a de sobreposição dos traçados orientados pela localização dos pinos. Avaliaram -se as direções do crescimento condilar, mostrando uma variação interindividual, porém sendo distribuídas simetricamente. Quando a direção se dava em sentido vertical, a curvatura da base mandibular era aumentada e quando se dava sagitalmente, a 
base mandibular se mostrava planificada. Verificou-se também uma diferença quanto ao sentido de erupção dentária em relação ao tipo de crescimento condilar: em crescimentos verticais - todos os dentes erupcionaram em sentido anterior; em crescimentos sagitais - os dentes anteriores erupcionaram em sentido posterior.

Em 1963, SCHUDY ${ }^{70}$ introduziu o ângulo OM (ângulo formado pelo plano mandibular e o plano oclusal) como um meio de diagnóstico preciso na determinação da inclinação axial dos incisivos inferiores. Realizou-se um estudo de 400 más oclusões selecionadas aleatoriamente de pacientes com as idades variando de 9 a 18 anos, de ambos os gêneros. Pacientes que apresentavam o ângulo OM acima de $20^{\circ}$ foram classificados no grupo II (retrognatia), e os que apresentavam abaixo de $11^{\circ}$, no grupo III (prognatia). O grupo I consistia de pacientes que apresentavam o ângulo $\mathrm{OM}$ entre $11^{\circ}$ a $20^{\circ}$ (relação interbases apicais considerada normal). O ângulo médio formado pelo longo eixo do incisivo inferior e o plano mandibular no grupo I, era de $96.1^{\circ}$, no grupo II, $90.6^{\circ}$ e no grupo III, $101.8^{\circ}$. Porém, os ângulos formados pelo incisivo inferior e o plano oclusal no grupo I era de $69.3^{\circ}$, no grupo II, $66.2^{\circ}$ e no grupo III, $68.7^{\circ}$. De acordo com estes dados, os incisivos inferiores se relacionaram mais eficazmente com o ângulo OM, do que com o plano mandibular.

Em 1963, WEINSTEIN; HAACK; MORRIS; SNYDER; ATTAWAY97, estudando o crescimento e o desenvolvimento das dentições, bem como a ortodontia em geral, verificaram a importância dos efeitos dos tecidos musculares sobre a conformação dos arcos dentários. Concluíram que as forças exercidas pelos tecidos moles sobre as coroas clínicas dentárias podem ser suficientes para 
movimentá-las, do mesmo modo como as forças produzidas pelos aparelhos ortodônticos; ou seja, mesmo sendo menores em magnitude, quando aplicadas prolongadamente, produzem deslocamentos facilmente mensuráveis.

MILLS, em $1966^{53}$, no afã de avaliar os resultados a longo prazo da vestibularização dos incisivos inferiores como parte da mecânica ortodôntica, estudou 56 casos tratados em que todos os incisivos inferiores foram inclinados para vestibular pelo menos em $5^{\circ}$ durante a terapia. As telerradiografias foram obtidas no início do tratamento, durante e no final (após um ano pelo menos sem contenção). A idade dos pacientes variaram de 11 a 17 anos. Levando em consideração as mudanças que poderiam ocorrer na ausência de qualquer tratamento, comparou-se a amostra com um grupo controle - compatíveis em raça e idade. Como método de avaliação, o grau de inclinação se deu pelo ângulo formado entre o longo eixo do incisivo inferior e o plano mandibular. Perante os resultados encontrados, ocorreu um suave aumento dos ângulos SNA e SNB durante a infância e a adolescência. Os incisivos vestibularizados mecanicamente de modo severo, em média $14.4^{\circ}$, recidivaram para uma posição média de $8.6^{\circ}$. Aqueles vestibularizados de modo suave, em média $7.23^{\circ}$, recidivaram para uma posição média de $4.8^{\circ}$.

Já em 1967, MILLS ${ }^{54}$ avaliou o movimento de lingualização dos mesmos dentes. Selecionou uma amostra de 22 casos, em que os incisivos inferiores foram lingualizados em pelo menos $7^{\circ}$ e que a extração dos primeiros prémolares inferiores foi efetuada. O método de avaliação era similar ao anterior. Concluiu-se que a longo prazo, os dentes ântero-inferiores recidivaram metade a 2/3 da distância alcançada. O autor enfatizou que o sucesso do tratamento não se 
relaciona com a inclinação original dos incisivos inferiores, nem com o período de tempo sem o uso de contenção.

Em 1968, SCHUDY ${ }^{71}$ relacionou o ângulo interincisivos ao fenômeno da sobremordida, classificando-o como um fator causal local. Quando uma sobremordida profunda se desenvolve, acompanhada por um grande ângulo interincisivos, tende-se a forçar as coroas dos incisivos inferiores lingualmente e os ápices dos incisivos superiores vestibularmente. Isto, por sua vez, aumenta o ângulo interincisivos que causa ainda mais sobremordida. $O$ autor define este relacionamento como um simbiótico que desenvolve entre o tamanho deste ângulo e a profundidade da sobremordida. Ele aconselha durante o tratamento ortodôntico, correlacionar, corretamente, os longos eixos dos incisivos superiores e inferiores em $\pm 135^{\circ}$ (valor preconizado para o ângulo interincisivos), promover oclusão de topo a topo dos incisivos e uso de contenção $3 \times 3$ no arco inferior na prevenção deste fenômeno indesejável.

HASUND; ULSTEIN, em $1970^{34}$, realizaram um estudo com os seguintes propósitos: conferir os valores oferecidos por STEINER ${ }^{80}$, em sua tabela de compromissos aceitáveis, verificar se o ângulo ANB está realmente compensado no modelo cefalométrico construído; e observar se as inclinações axiais, pertencentes a este modelo, podem ser transferidas individualmente para 0 paciente, não considerando o grau de prognatismo dos maxilares. $O$ material constituiu-se de 165 adultos noruegueses (72 mulheres e 93 homens), com as idades variando dos 18 aos 50 anos, cujas oclusões se apresentavam ideais ou não. Concluíram que ambas as posições dos incisivos inferiores e superiores 
correlacionam-se com o ângulo ANB. Os resultados mostraram-se similares àqueles do modelo cefalométrico proposto por STEINER $^{80}$, onde as inclinações axiais realmente variam de acordo com a discrepância entre as bases apicais. A grandeza angular 1.NA, bem como a linear 1 -NA podem ser transferidas do modelo padrão de STEINER ${ }^{80}$ para o paciente individual, não considerando necessariamente o grau de prognatismo. Finalizando, a distância $\overline{1}-\mathrm{NB}$ mostrou uma íntima correlação com a inclinação mandibular (verificada pelo ângulo formado entre as linhas mandibular e násio-sela tracejadas) de tal modo que quando aumentada a inclinação mandibular (maior que $32^{\circ}$ ) a distância $\overline{1}-\mathrm{NB}$ se torna maior do que os valores padrão de STEINER ${ }^{80}$, e vice-versa.

Procurando quantificar os erros decorrentes do processo de identificação de 16 pontos cefalométricos freqüentem ente utilizados nas análises como os pontos Sela, Násio, Gônio e Mentoniano, entre outros, em 1971, BAUMRIND; FRANTZ̋ afirmaram que mesmo quando a identificação dos pontos é repetida, a magnitude dos erros foi muito grande para ser desprezada e extremamente variável entre os diferentes pontos considerados. Verificaram, ainda, que a distribuição dos erros para a maior parte dos pontos não foi aleatória, mas sim sistemática, visto que a variação dos erros de cada ponto apresentou limites característicos e freqüentemente não circulares (envelopes de erro). Essa última consideração se refere ao fato de alguns pontos cefalométricos apresentarem variações de erros, predominantemente, no sentido vertical, como os pontos Násio, Orbitário e outros no horizontal, como no caso do Mentoniano. 
Em outra publicação, BAUMRIND; FRANTZ ,em 19714, consideraram ser três os fatores que determinavam o grau de influência que os erros de identificação dos pontos cefalométricos exercem sobre as mensurações lineares ou angulares que envolvam esses pontos. O primeiro consiste na magnitude do erro envolvido na identificação do ponto. O segundo corresponde à distância linear entre os pontos a serem unidos para a determinação de uma linha ou plano de referência, sendo que quanto menor a distância entre os pontos, maior a porcentagem do erro introduzida na avaliação. Nesse sentido, um determinado erro de identificação da ponta de cúspide mesiovestibular do primeiro molar inferior exerce maior influência no plano oclusal cujo ponto de referência anterior é a cúspide do primeiro molar inferior, que naquele em que o ponto anterior é a borda incisal do incisivo inferior. Por fim, a influência dos erros pode se relacionar à direção na qual a linha ou plano de referência determinados por dois pontos atinge o envelope de erros de cada um dos pontos envolvidos, sendo maior quando a direção da referência for perpendicular ao eixo de maior variação dos erros, e menor quando paralela a esse eixo.

Quarenta adolescentes não tratados ortodonticamente, todos caucasianos entre as idades de 12 a 15 anos, foram examinados por HOPKINS; MURPHY, em $1971^{38}$, com o propósito de averiguar a similaridade ou não das medidas cefalométricas com os dados provenientes das análises anteriores como a de DOWNS $^{24}$, STEINER $^{80}$ e TWEED ${ }^{90}$. Direcionou a seleção da amostra principalmente para perfis harmônicos, com belos sorrisos. Conclusivamente as comparações revelaram somente que estes jovens apresentaram um perfil mais protrusivo do que nos estudos anteriores. Observou-se também que os meninos 
apresentaram um perfil mais cheio que as meninas, o ângulo FMIA se mostrou maior nas meninas, os incisivos inferiores mais verticalizados nos jovens de 14 anos de idade em comparação com os de 13 anos e o ângulo FMA como o menos variável dos três ângulos de TWEED ${ }^{90}$.

ANDREWS, em $1972^{1}$, avaliou 120 modelos de pacientes não ortodônticos, agradáveis esteticamente com oclusões consideradas corretas, e que não se beneficiariam de qualquer mecânica empregada. Ele estabeleceu, diante as característic as encontradas, as "6 chaves de oclusão normal" vistas como essenciais para o sucesso do tratamento ortodôntico. A $3^{\text {a }}$ chave diz respeito à inclinação coronária em sentido vestibulolingual do longo eixo da coroa. Os dentes anteriores, quando inclinados propriamente, resistiriam à sobreerupção dos mesmos e seriam eficientes na promoção de boa oclusão posterior.

Seguindo seus métodos de análise com a implantação de pinos de tântalo em ambos os maxilares, BJÖRK; SKIELLER, em $1972^{11}$, avaliaram 9 meninas e 12 meninos pela sobreposição de traçados cefalométricos. Observaram que durante o crescimento, quando existe a rotação mandibular em sentido anterior, ocorre uma adaptação compensatória de vestibularização dos incisivos e molares inferiores; porém quando a rotação ocorre em sentido posterior, os incisivos inferiores são lingualizados, havendo uma redução simultânea no prognatismo alveolar. Os autores destacaram também a importância das ações dos músculos dos lábios e da língua na manutenção do relacionamento funcional dos incisivos, apesar da rotação mandibular. 
BRADER, em $1972^{12}$, sugeriu que as posições dentárias poderiam ser expressas dentro da equação $P R=C$ \{onde $P=$ pressão $\left(\mathrm{g} / \mathrm{cm}^{2}\right) ; R=$ raio de curvatura $(\mathrm{mm}) ; \mathrm{C}=$ constante matemática\}, pois em seu conceito faz-se necessário obter as medidas das pressões intrabucais $(\mathrm{P})$ como critério de diagnóstico na avaliação ortodôntica dos pacientes individuais. Desde que a pressão e o raio de curvatura são inversamente proporcionais, $P R=C$ explica o porquê que os incisivos inferiores mostram-se apinhados e apresentam a menor estabilidade após as mudanças posicionais produzidas pelos movimentos ortodônticos. No segmento anterior do arco dentário inferior, onde o raio de curvatura se apresenta menor, as pressões são maiores e entretanto exercem a mais crítica influência sobre as posições dos dentes. Concluiu-se que perante as duas opções de tratamento de más oclusões caracterizadas pela discrepância negativa de modelo, expansão dentária ou constrição do arco em conjunção com a extração de dentes, ambas violam a relação pressão-raio que as constantes musculares permitem, requerendose, portanto, mais investigações sobre qual procedimento conduziria a dentaduras mais estáveis.

Em 1975, PROFFIT ${ }^{58}$, seguindo a mesma linha de raciocínio de BRADER $^{12}$, estudou 18 jovens aborígenes, em que as pressões vestibular e lingual referentes aos elementos dentários foram gravadas. Alegou que os fatores etiológicos que causam uma má oclusão, permanecem ativos após a finalização do tratamento ortodôntico, conduzindo, conseqüentemente, à recidiva. Quando se colocam os dentes em posições mais estáveis, considera-se que sejam posições que a musculatura melhor aceite. Estes foram e são raciocínios que refletem a 
importância dos fatores ambientais, devendo ser considerados no diagnóstico e planejamento dos casos ortodônticos.

Com o propósito de averiguar os tipos de mudanças ocorridas nas posições dos incisivos inferiores durante a terapia ortodôntica, em 1975, KUFTINEC $^{44}$ estudou 50 más oclusões Classe I de Angle, com vários graus de protrusão bimaxilar, tratados ortodonticamente com a técnica Edgewise. A amostra incluiu 26 do gênero feminino e 24 do masculino, sendo que 30 componentes do total necessitaram extrair os quatro primeiros pré-molares. Os modelos ortodônticos, bem como as telerradiografias compunham as documentações utilizadas, obtidas anteriormente ao tratamento ativo, após a remoção dos aparelhos fixos e com no mínimo quatro meses sem a contenção. Os valores das medidas cefalométricas, entre elas o ângulo interincisivos e o IMPA, foram medidos e anotados. Os parâmetros investigados se comportaram de modo similar tanto nos grupos com, quanto nos grupos sem extração dentária, porém a magnitude das mudanças foi significantemente maior no grupo com extração, indubitavelmente pela disponibilidade de mais espaços nos arcos dentários destes casos. Observou-se também que o apinhamento ântero-inferior recidivou mais nos pacientes sem extração dos pré -molares.

CORELIUS; LINDER-ARONSON, em $1976^{21}$, objetivaram verificar o relacionamento entre as inclinações dos incisivos inferiores e as diferentes linhas e planos de referência craniana. Selecionaram crianças com idades entre 7 e 12 anos, nas quais realizaram-se dois registros cefalométricos: um inicialmente e outro 3 a 4 anos após, com o intuito de verificar as mudanças oriundas do crescimento. 
Analisaram-se as seguintes grandezas: $\overline{1}-\mathrm{NB}, \overline{1}$.NB, $\overline{1}$.GoMe (ângulo formado pelo longo eixo do incisivo inferior com o plano mandibular), ANB e ENP-ENA.GoMe (ângulo formado entre os planos mandibular e palatino). Os resultados encontrados evidenciaram que o ângulo ANB está fortemente relacionado com as inclinações dos incisivos inferiores, dando crédito para a análise de STEINER ${ }^{80,81,82,83}$, a respeito da compensação dentária de acordo com a discrepância óssea basal encontrada e que as variáveis linear $\overline{1}-\mathrm{NB}$ e angular $\overline{1}$.NB relacionam-se entre si e ambas com a variável $\overline{1}$.GoMe durante o período de crescimento.

WILLIAMS, HOSILA, em $1976^{99}$, analisaram os efeitos de diversos locais de extração sobre a quantidade de retração dos incisivos. Para isto, examinaram 260 casos tratados ortodonticamente com a técnica de Begg no início do tratamento, no final e 1 a 10 anos após a finalização. Não se extraíram dentes em 40 pacientes, extraíram -se os primeiros pré-molares superiores e inferiores em 101, em 24 foram extraídos os primeiros pré-molares superiores e os segundos inferiores, em 79 foram extraídos os primeiros molares superiores e inferiores e em 16 foram realizadas as extrações dos primeiros pré-molares superiores e inferiores, mais os primeiros molares. Os resultados indicaram que a extração de dentes aumenta potencialmente a retração dos incisivos. Nos casos em que se realizou a extração dos primeiros pré-molares superiores e inferiores, $66.5 \%$ do espaço disponível foi ocupado pelo segmento anterior, devido ao fato de que o movimento molar ocorre de corpo, e nos incisivos há uma combinação de ambos os movimentos de corpo e de inclinação. Os grupos que apresentaram a menor quantidade de retração anterior, exibiram a menor quantidade de recidiva anterior, e vice-versa. Os autores 
propuseram a sobrecorreção em alguns casos já corrigidos, como um auxílio na obtenção de resultados mais satisfatórios.

CHRISTIE, em $1977^{18}$, discorreu sobre a importância da consideração do padrão de crescimento facial do paciente no planejamento ortodôntico. Selecionou 82 adultos apresentando oclusões consideradas próximas do ideal, 43 do gênero feminino e 39 do masculino sem terem sido submetidos a qualquer tipo de mecânica empregada. A amostra foi subdividida em 39 pacientes braquifaciais, 39 mesofaciais e 4 dolicofaciais. A observação mais evidente deste estudo foi a maior incidência de oclusões normais em pessoas que apresentavam um padrão de crescimento no sentido horizontal. Quanto mais severo era o padrão de crescimento no sentido vertical, menor era a chance de obtenção de oclusões satisfatórias. Explicou-se isto pelo fato de que os pacientes braquifaciais possuem mais espaço para os seus elementos dentários. Nos indivíduos braquifaciais, o ângulo interincisivos se apresentou menor, com os incisivos mais vestibularizados. A dentadura no gênero feminino se mostrou mais verticalizada e menos protrusiva.

\section{Realizaram-se análises cefalométricas em 120 estudantes} dinamarqueses do gênero masculino com as idades entre 22 e 30 anos, em 1977, por SOLOW; TALLGREN ${ }^{76}$, com o objetivo de desvendar qualquer associação entre a morfologia dentoalveolar e a postura craniocervical. Os resultados indicaram que as correlações encontradas foram consideradas reflexo das adaptações compensatórias dentoalveolares. Quando o mecanismo compensatório é operado satisfatoriamente (nas dimensões dos arcos dentários, nas inclinações dentárias e nos contatos oclusais), discrepâncias nos relacionamentos sagital, vertical e 
transversal das bases apicais são compensadas por mudanças correspondentes nos relacionamentos dentobasais. Portanto, mantém-se uma oclusão normal dos arcos dentários.

Em 1977, SCHULHOF; ALLEN; WALTERS; DRESKIN ${ }^{72}$ verificaram a credibilidade em posicionar os incisivos inferiores em relação às diversas linhas de referência cefalométricas. Utilizaram -se duas amostras para este propósito: uma contendo 78 pacientes com documentações ortodônticas, apresentando um período de pós-contenção de pelo menos quatro anos e a outra amostra composta por 82 pessoas com oclusões normais. Observaram que a posição da maxila deveria ser considerada no posicionamento dos incisivos inferiores. Para isto, o plano APog (linha traçada do ponto A - subespinhal - ao ponto Pog - pogônio) serviria adequadamente como guia, onde outros planos de referência como o mandibular e o facial não o fariam. A avaliação dos indivíduos com oclusão normal demonstraram que o plano APog explica adequadamente a convexidade do perfil ósseo. Verificaram também que não houve diferença significante na recidiva do apinhamento ântero-inferior entre os casos onde os incisivos foram lingualizados, vestibularizados ou mantidos em posição durante o tratamento. Finalmente, no último resultado observou-se a ausência de uma correlação entre a recidiva do apinhamento inferior e as linhas de referência APog, NB e o plano mandibular. Portanto, outros guias clínicos de melhores resultados deveriam ser de eleição na determinação da estabilidade.

Os fatores relacionados ao equilíbrio dentário foram discorridos por PROFFIT, em $1978^{59}$. Identificou quatro fatores primários: 1- forças intrínsecas pela 
língua e lábios; 2- forças extrínsecas como hábitos deletérios e aparelhos ortodônticos; 3 forças provenientes da oclusão dentária e 4 forças do ligamento periodontal. Além destes, identificou os fatores secundários no equilíbrio como a posição postural da cabeça, da mandíbula e da língua.

EL-MANGOURY, em $1979^{26}$, selecionou 50 casos ortodônticos com os seguintes critérios: 1- origem caucasiana; 2- tratamento com a técnica Edgewise; 3 modelos dentários pré-tratamento apresentando displasia ântero-posterior e/ou vertical; 4- modelos dentários pós-tratamento revelando resultados ortodônticos bem sucedidos em relação à correção da sobremordida, sobressaliência e das relações canino e molar; 5- modelos dentários pós-contenção obtidos com um mínimo de dois anos sem contenção e 6- telerradiografias do pré-tratamento, pós-tratamento e póscontenção, correspondentes às datas dos três períodos dos modelos dentários. A partir da avaliação entre os modelos ortodônticos pós-tratamento e pós-contenção, classificaram -se 25 casos como o grupo estável e 25 como o grupo da recidiva. Para o estudo cefalométrico 35 medidas angulares e lineares foram obtidas. Objetivando relacionar fatores como grande displasia ântero-posterior e/ou vertical, classificação de Angle, realização de extração ou não no tratamento ortodôntico, à predição do fenômeno da recidiva, chegaram às seguintes conclusões: 1 - não houve uma relação significante entre a recidiva e os casos de Classe I e II de Angle; 2 - o ângulo ANB não pareceu ser de valor em predizer a recidiva e 3 - não houve também uma inter -relação entre o tratamento realizado com e o tratamento realizado sem extração e a recidiva. 
Em 1980, SOLOW ${ }^{75}$ escreveu criteriosamente sobre o mecanismo compensatório dentoalveolar, relatando sua formação e as implicações clínicas, em que os dentes e os arcos alveolares se adaptam aos variados relacionamentos dos maxilares, mantendo uma relação normal entre os arcos dentários. Considerando os fatores responsáveis pela adaptação dentoalveolar, como um primeiro requisito, requere-se um sistema eruptivo normal; como um segundo, a aplicação das forças provenientes da língua, lábios e bochechas; e terceiro, a influência da posição dentária exercida pelos dentes vizinhos durante a erupção e pelo o efeito planoinclinado dos dentes opostos durante a oclusão e mastigação. Por outro lado, se este mecanismo falhar não ocorrerá a manutenção de uma intercuspidação normal ou ótima dos arcos dentários. O autor narrou os vários sistemas de análises cefalométricas, onde se incorporou o mecanismo compensatório dentoalveolar, entre eles, a de STEINER ${ }^{79}$ estabelecendo os "compromissos aceitáveis" e a de RICKETTS ${ }^{61}$, que nada mais vem a ser do que métodos empíricos baseados no entendimento do mecanismo. Enfatizou-se muito a individualização de cada caso, sem ter um "compromisso" e sem um "ideal" no planejamento ortodôntico.

RICKETTS, em 198164, discorreu sobre o ângulo interincisivos alegando que a maioria dos indivíduos caucasianos adultos apresenta ângulos médios próximos a $130^{\circ}$, contrastando com o valor preconizado por $\mathrm{DOWNS}^{24} \mathrm{em}$ sua análise original, de 135․ Entretanto, o ângulo interincisivos muda com o passar dos anos. Como os maxilares crescem em altura, os dentes verticalizam-se suavemente. A cada cinco anos, com o desenvolvimento vertical, ocorre uma verticalização de $2^{\circ}$ ( 3 anos de idade $-122^{\circ}$; 8 anos de idade $-124^{\circ}$; 13 anos de




CRUZ, em $1982^{23}$, teve como objetivo avaliar, com o auxílio da telerradiografia, a posição dos incisivos inferiores em pacientes portugueses que necessitaram de tratamento ortodôntico. Todos eram caucasianos, entre as idades de 7 a 18 anos, pertencendo aos dois gêneros. Verificou-se que quando se realiza o planejamento do tratamento ortodôntico, tem-se que considerar a posição dos incisivos inferiores. Numa oclusão anatomicamente normal os incisivos podem apresentar inclinações diversas. Obrigatoriamente deve-se analisar as variáveis influenciadas pelo crescimento e as suas correlações com a posição destes dentes. O ângulo ANB exemplifica uma destas variáveis, sendo que ele também é influenciado fortemente pela ação direta do torque sobre os dentes ânterosuperiores.

Setenta e dois casos tratados ortodonticamente com a técnica Edgewise foram estudados por UHDE; SADOWSKY; BEGOLE, em $1983^{93}$, com o intuito de verificar as alterações ocorridas a longo prazo. As más oclusões pertenciam às Classes I e II de Angle. De acordo com as variáveis estudadas (relacionamento molar, sobressaliência, sobremordida, apinhamentos superior e inferior e distâncias intercaninos e intermolares), os relacionamentos dentários tenderam a retornar para os seus valores pré-tratamento com o passar dos anos, porém a maior parte da correção manteve-se contida. Observourse que houve uma tendência em aumentar a sobressaliência no período pós-tratamento em quase todos os componentes, com um aumento mais acentuado no grupo de más oclusões classe II. 
SHIELDS; LITTLE; CHAPKO, em $1985^{74}$, analisaram uma amostra de 54 casos de extração dos primeiros pré-molares submetidos à mecanoterapia ortodôntica com a técnica Edgewise, seguidos pela utilização de aparelhos de contenção. Obtiveram -se documentações completas anterior ao tratamento $\left(\mathrm{T}_{1}\right)$, no final $\left(T_{2}\right)$, e após um mínimo de dez anos sem contenção $\left(T_{3}\right) .46 .3 \%$ dos pacientes apresentavam má oclusão Classe I de Angle, 44.4\% Classe II, 1a divisão e 9.3\% Classe II, 2a divisão. Utilizou-se como método de avaliação cefalométrica, a sobreposição de traçados e um programa de computador que determinou 76 variáveis angulares e lineares. Com base nos resultados, os autores concluíram que não dá para prever irregularidades do período pós-contenção (por ex.: o apinhamento ântero-inferior) tendo por base as inclinações axiais e o posicionamento dos incisivos inferiores em qualquer período estudado (pré ou póstratamento). As mudanças pós-contenção, avaliadas cefalometricamente como medidas do comprimento mandibular e do deslocamento do mento ósseo, também fracassaram em explicar o apinhamento pós-contenção.

O ângulo ANB é utilizado como o mais comum indicador na determinação da discrepância óssea basal. JÄRVINEN, em $1985^{42}$, conferiu a segurança em usá-lo nas análises cefalométricas. O material foi constituído de 138 telerradiografias de crianças não tratadas ortodonticamente de 7 a 15 anos de idade. As crianças foram clinicamente classificadas em grupos de más oclusões Classes I, II e III de Angle. Os resultados, referentes ao ANB, entre os grupos, mostraram uma diferença estatisticamente significante. Entretanto, pelo fato do ângulo ANB poder variar sem quaisquer anormalidades no relacionamento sagital, não se justifica o emprego de normas para este ângulo. O autor sugere, contudo, uma substituição 
deste método por um outro melhor na determinação da diferença entre as bases ósseas apicais.

WILLIAMS, em $1985^{98}$, sugeriu vários passos que podem ser seguidos durante a mecânica com aparelho fixo, objetivando a não necessidade de contenção no arco inferior. Seis chaves são citadas: $1^{\text {a }}$ - a borda incisal do incisivo inferior deve ser colocada a frente da linha APog $1 \mathrm{~mm} ; 2^{\underline{a}}$ - o ápice do incisivo central inferior deve estar por distal em relação à coroa, e o ápice do lateral mais que do central; 3ạ- o ápice radicular do canino inferior deve estar posicionado por distal da coroa; 4ㄹ todos os ápices radiculares dos quatro incisivos inferiores devem estar no mesmo plano vestibulolingual; 5 $5^{\mathrm{a}}$ - o ápice radicular, do canino inferior deve ser posicionado suavemente por vestibular em relação à coroa e 6 a $^{\mathrm{a}}$ - os incisivos inferiores devem ser desgastados o necessário após a finalização do tratamento.

O tratamento da protrusão bimaxilar envolve a verticalização dos incisivos superiores e inferiores (aumento do ângulo interincisivos) e conseqüentemente a redução da proeminência do perfil facial. KEATING, em $1986^{43}$, examinou a questão da estabilidade e as mudanças associadas a este tipo de tratamento. Escolheram -se dois grupos, o de protrusão bimaxilar e o controle, cujas características presentes eram: caucasianos, extração dos primeiros pré-molares, sobremordida e sobressaliência dentro dos limites normais, radiografias em norma lateral obtidas antes do tratamento $\left(T_{1}\right)$, no final $\left(T_{2}\right)$ e após um ano sem contenção $\left(\mathrm{T}_{3}\right)$. Além disso o grupo de protrusão bimaxilar apresentava o ângulo interincisivos (1. 1 ) menor que $125^{\circ}$, o longo eixo do incisivo superior ao plano palatino (1.ENP ENA) maior que $115^{\circ}$ e o longo eixo do incisivo inferior ao plano mandibular 
(1.GoMe) excedendo 99. O grupo controle, por sua vez, apresentava má oclusão classe I de Angle, $1 . \overline{1} \geq 131^{\circ}, \underline{1}$.ENP-ENA $\leq 109^{\circ}$ e $\overline{1}$.GoMe $\leq 93^{\circ}$. Analisando os efeitos do tratamento executado, um aumento significante e permanente pode ser realizado no ângulo interincisivos em casos de protrusão bimaxilar com as extrações dentárias. Houve um aumento de $20.7^{\circ}$ nesse ângulo, em média e apenas $4^{\circ}$ recidivou (20\%), totalizando no período pós-contenção $16.3^{\circ}$. Diferente do grupo controle, em que houve um aumento total de $9.10^{\circ}$. A protrusão do tecido mole foi reduzida significantemente em ambos os grupos.

RICHARDSON, em $1986^{60}$, triou um grupo de 51 adolescentes, 22 do gênero masculino e 29 do feminino, com a idade média de 13 anos, objetivando verificar supostas variáveis relacionadas ao desenvolvimento do apinhamento tardio do arco dentário inferior. Realizou-se um estudo longitudinal destes jovens, sendo que todos apresentavam os arcos inferiores intactos, com os terceiros molares presentes em ambos os lados. Restringiu-se o tratamento ao arco superior, mas que poderia afetar algumas variáveis sob consideração, entre elas o ângulo interincisivos. Cinco anos após a primeira avaliação, verificou-se que o ângulo interincisivos aumentou significantemente. $\mathrm{O}$ autor concluiu, perante os resultados, que nenhuma variável sozinha apresenta uma conexão forte com a mudança na condição de espaço no arco inferior.

Em 1989, ISIEKWE ${ }^{40}$ propositou o estabelecimento de normas padrão para as inclinações axiais dos incisivos numa população nigeriana. A amostra foi composta de 110 pessoas, melanodermas, com idades entre 11 e 26 anos, sem algum tipo de tratamento ortodôntico. O método de análise foi o cefalograma. Os 
valores médios do ângulo formado pelo incisivo inferior e o plano mandibular estavam entre $96^{\circ}$ e $104^{\circ}$. Logo, ângulos maiores que $104^{\circ}$, foram considerados vestibularizados e menores que $96^{\circ}$, lingualizados. Já, para os incisivos superiores, com o plano Francfort, os valores médios se encontraram entre $118.6^{\circ}$ e $127^{\circ}$. Acima de $127^{\circ}$, classificou-se como vestibularizados, e abaixo de $119^{\circ}$, lingualizados. Em relação ao ângulo interincisivos, os valores considerados biologicamente normais se enquadraram entre $108^{\circ}$ e $116^{\circ}$. Estes dados confirmaram a protrusão da raça negra, garantindo suas utilizações no diagnóstico e no planejamento ortodôntico da população nigeriana.

ARTUN; KROGSTAD; LITTLE, em $1990^{3}$, conduziram um estudo no afã de verificar se os incisivos inferiores poderiam ser vestibularizados sem aumentar o potencial de recidiva do apinhamento, em casos de correção combinada ortodôntico/cirúrgico do prognatismo mandibular. Selecionaram modelos de estudo e telerradiografias anterior ao tratamento ortodôntico, imediatamente antes e após a intervenção cirúrgica, no momento da remoção do aparelho e no período pósoperatório de seis meses, um, dois e três anos. A medida do ângulo 1.GoMe foi obtida antes do tratamento ortodôntico e antes do procedimento cirúrgico. Diagnosticou-se a vestibularização excessiva durante a fase ortodôntica précirúrgica por um aumento maior que $10^{\circ}$ do ângulo 1 .GoMe em 29 pacientes e mínima mudança, ou seja, menor que $2^{\circ}$ em 33 pacientes. Os resultados indicaram que os incisivos inferiores podem ser vestibularizados em grande extensão durante a fase de nivelamento e alinhamento, nestes tipos de casos, sem aumentar o risco do apinhamento pós-tratamento. Alguns dos pré -requisitos são a correção cirúrgica da discrepância esquelética e que as posições e inclinações destes dentes estejam 
dentro das normas estabelecidas. Contudo, os autores enfatizaram a inevitabilidade do desenvolvimento do apinhamento secundário nos casos tratados ortodonticamente, por ser um processo lento e contínuo em adultos.

NANDA; NANDA, em 1992 ${ }^{56}$, escreveram com perspicácia e inteligência sobre a estabilidade a longo prazo. Apesar das mudanças esqueléticas com o crescimento serem considerações importantes no diagnóstico e durante o tratamento ortodôntico, pouc a ou nenhuma consideração é dada às mudanças esqueléticas pós-tratamento. Emprega-se o foco maior durante a contenção na manutenção das posições dentárias corrigidas, sendo que não se realizam compensações para o futuro crescimento dentoalveolar e esquelét ico dos maxilares em sentido vertical e/ou horizontal. Sugeriu-se, conseqüentemente, a individualização dos aparelhos de contenção baseados na morfologia dentofacial e na magnitude e direção do crescimento. O diagnóstico pós-tratamento diferencial é tão im portante quanto as projeções do crescimento pré-tratamento.

Em 1993, foram avaliadas por ROSSOUW; PRESTON; LOMBARD; $\operatorname{TRUTER}^{68}$, as mudanças a longo prazo concentradas na região anterior dos arcos dentários e possíveis relacionamentos ao apinhamento ântero-inferior. Oitenta e oito pacientes leucodermas, tratados pela técnica Edgewise convencional, foram estudados longitudinalmente em três fases $\left(T_{1}\right.$ - pré-tratamento, $T_{2}$ - póstratamento, $\bar{B}- \pm 7$ anos pós-tratamento). Selecionaram-se modelos ortodônticos, bem como telerradiografias nas três fases correspondentes. Entre os vários dados obtidos das análises, o incisivo inferior verticalizou-se $1.72^{\circ}$ durante o período de $\mathrm{T}_{2}$ para $T_{3}$. Embora pouco significante, sua contribuição ao apinhamento sugere que 
durante a fase de $T_{1}$ para $T_{2}$ ocorreu uma vestibularização além dos limites estáveis, ou ainda, devido ao componente anterior de forças musculares sobre estes dentes não permitindo uma posição mais vestibularizada.

A proposta desta pesquisa, em 1995, de FIDLER; ARTUN; JOONDEPH; LITTLE ${ }^{28}$, foi examinar os modelos de estudo e cefalogramas de um grupo de casos que apresentavam más oclusões Classe II, $1^{\text {a }}$ divisão de Angle, tratados com sucesso, avaliando o mecanismo de correção empregado, a estabilidade a longo prazo e qualquer associação entre as mudanças pré e póscontenção. As fases de avaliação foram: $T_{1}$ - anterior ao tratamento, $T_{2}$ - após e $T_{3}$ - a longo prazo. Incluíram-se 33 adolescentes do gênero masculino e 45 do feminino. Realizaram-se as extrações dos quatro primeiros pré-molares em 37 pacientes e nos demais não foi realizado nenhum tipo de extração. Calculou-se para cada paciente as alterações nas medidas obtidas dos modelos e dos cefalogramas de $T_{1}$ para $T_{2}$ e de $T_{2}$ para $T_{3}$. Obtiveram-se os seguintes resultados: os incisivos superiores foram lingualizados de $T_{1}$ para $T_{2}$, as inclinações dos incisivos inferiores permaneceram inalteradas e as mudanças pós-tratamento foram uma suave vestibularização dos incisivos superiores e inalteração dos inferiores. Portanto, observou-se uma associação positiva entre o aumento da sobressaliência de $T_{2}$ para $T_{3}$ e a vestibularização dos incisivos superiores de $T_{2}$ para $T_{3}$. Durante a terapia não se alteraram as inclinações dos incisivos inferiores, refletindo uma filosofia de tratamento em evitar a vestibularização destes elementos. Na opinião dos autores, os fatores mais importantes para a estabilidade a longo prazo são os relacionamentos obtidos pós-tratamento e a função. 
WILLIAMS; ANDERSEN, em 1995 ${ }^{100}$, avaliaram a estabilidade do movimento de vestibularização dos incisivos inferiores em pacientes com crescimento rotacional mandibular em sentido anterior. Todos os 42 pacientes selecionados apresentavam más oclusões Classe I ou II de Angle e que foram realizadas as vestibularizações dos incisivos inferiores durante a mecânica com a técnica Edgewise. As documentações ortodônticas foram obtidas em três estádios: $\mathrm{T}_{1}$ - antes do tratamento ativo ortodôntico (idade média 12 anos e 5 meses); $T_{2}-$ após o tratamento ativo (idade média 14 anos e 8 meses); T3- pós-contenção (idade média 22 anos e 1 mês). Cefalometricamente, mediu-se a inclinação incisiva pelo ângulo formado entre o longo eixo do incisivo central inferior e o plano mandibular. Antes da execução do tratamento, os incisivos inferiores se apresentavam inclinados em média $94.5^{\circ}$ e o ângulo ANB (que relata a discrepância entre as bases apicais) em média $4.8^{\circ}$. Após o tratamento ativo, os incisivos inferiores formaram um ângulo em média de $104.3^{\circ}$ com o plano mandibular e o ângulo ANB foi em média de $3.6^{\circ}$. No período pós-contenção, a inclinação incisiva diminuiu para $100.9^{\circ}$ e o ângulo entre as bases apicais permaneceu praticamente o mesmo, $3.8^{\circ}$. Embora suave recidiva tenha acontecido, a vestibularização nestes casos pode conduzir a bons resultados. Uma possível explicação deste fenômeno é a rotação contínua em sentido anterior da mandíbula (plano de referência) distanciando-se dos incisivos, que permanecem estáveis em relação aos seus antagonistas.

Em 1996, ARTUN; GAROL; LITTLE² explanaram sobre a recidiva do alinhamento ântero-inferior. Fato segundo os autores inevitável apesar da realização de um excelente diagnóstico e da execução adequada da mecânica ortodôntica. Consideraram-na um problema multifatorial. 
Ao executar um estudo das radiografias cefalométricas de perfil, de uma amostra de 30 indivíduos que foram submetidos a tratamento ortodôntico técnica Edgewise - e que ficaram no mínimo cinco anos sem contenção, VILELLA; MUCHA, em $1996^{95}$, objetivaram avaliar as modificações nas angulações e posições dos incisivos inferiores. Os 30 pacientes componentes da amostra apresentavam as seguintes características: todos eram leucodermas brasileiros, sendo 15 do gênero masculino e 15 do feminino. A idade média no início do tratamento era de 11 anos e 4 meses, no final do tratamento era de 15 anos e 4 meses e 26 anos e 5 meses na fase de pós-contenção. No início do tratamento, 18 adolescentes apresentavam más oclusões Classe I de Angle, e os demais Classe II, 1a divisão. Realizaram-se extrações dentárias em 17 casos apenas. As grandezas angulares (IMPA, ī.NB, $\overline{1}$.Plano Oclusal, $\overline{1}$.APog) e lineares $(\overline{1}-\mathrm{NB}, \overline{1}$-APog) foram obtidas por via dos traçados cefalométricos nas fases inicial, final e pós-contenção. Apesar da pouca significância estatística, a ocorrência de correlações negativas sugeriu que existe uma leve tendência dos incisivos inferiores em retornarem às angulações e posições que ocupavam antes do início do tratamento, durante o período de póscontenção. Verificou-se, também, uma grande variação individual no comportamento destes dentes.

BISHARA; CUMMINS; ZAHER, em $1997^{8}$, confirmaram o aumento do ângulo interincisivos em pacientes que apresentavam más oclusões Classe II, 1aㅡ divisão de Angle, tratados ortodonticamente com a técnica Edgewise, como resultado da grande retração dos incisivos superiores e inferiores durante o período ativo. 


\section{Em 1998, BISHARA ${ }^{7}$ avaliou as alterações provenientes do} crescimento e do tratamento ortodôntico numa amostra composta por três grupos: $1^{\circ}$ - más oclusões Classe II, $1^{1 \mathfrak{a}}$ divisão de Angle não tratadas ortodonticamente; $2^{\circ}$ más oclusões Classe II, $1^{\text {a }}$ divisão tratadas ortodonticamente e $3^{\circ}$ - um grupo normal com relacionamentos molar e canino Classe I. Os resultados encontrados foram: 1em ambos os gêneros, a magnitude das curvas para os ângulos ANB e NAPog e para a sobressaliência eram maiores nos indivíduos de más oclusões Classe II, 1a divisão de Angle não tratados do que nos indivíduos normais; 2- na fase prétratamento, comparados com os indivíduos normais, os pacientes de Classe II, $1^{\text {a }}$ divisão de Angle apresentaram significantemente maior ângulo ANB, maior sobressaliência e maior sobremordida; 2.1- nos indivíduos do gênero masculino ocorreu uma redução significante nos ângulos ANB e NAPog em ambos os grupos, mas esta redução foi significantemente maior nos pacientes com extração do que nos pacientes correspondentes sem extração; 2.2- a sobressaliência e a sobremordida foram significantemente diminuídas no grupo Classe II tratados ortodonticamente durante o período de observação, sendo que os pacientes normais demonstraram pouca ou nenhuma mudança nestes parâmetros. Perante os resultados, ocorreu uma normalização dos relacionamentos esqueléticos e dentários nos indivíduos que apresentavam má oclusão Classe II, 1a divisão, tratados ortodonticamente com e sem extração, comparados ao grupo normal. Contudo, as mudanças foram mais pronunciadas no grupo com extrações dentárias.

Em 1998, MARTINS; JANSON; ALMEIDA; PINZAN; HENRIQUES; FREITAS ${ }^{52}$ tornaram realidade um estudo de aproximadamente 30 anos. Selecionaram-se 75 jovens brasileiros leucodermas, 37 do gênero masculino e 38 do 
feminino, filhos ou netos de brasileiros descendentes de mediterrâneos: portugueses, espanhóis ou italianos, sem mutilações nos arcos dentários, que nunca foram submetidos a tratamento ortodôntico. A partir das telerradiografias tomadas anualmente, dos 6 aos 18 anos de idade, grandezas angulares e lineares foram obtidas, dispondo-as em tabelas e gráficos de acordo com a idade, número de componentes, gênero, valor da medida e desvio padrão (Tabela 2.4).

TABELA 2.4 - Alguns exemplos de medidas auferidas no trabalho de MARTINS et al. ${ }^{52}$, dispostas em tabela

\begin{tabular}{|c|c|c|c|c|c|c|c|}
\hline & Idade & No & $\begin{array}{c}\text { Gênero } \\
\text { masculino } \\
\text { Média } \\
\text { (graus) }\end{array}$ & $\begin{array}{c}\text { D.P. } \\
\text { (graus) }\end{array}$ & No & $\begin{array}{c}\text { Gênero } \\
\text { feminino } \\
\text { Média } \\
\text { (graus) }\end{array}$ & $\begin{array}{c}\text { D.P. } \\
\text { (graus) }\end{array}$ \\
\hline SNA & 13 & 21 & 82,0 & 2,9 & 15 & 80,6 & 3,7 \\
\hline SNB & 18 & 13 & 82,8 & 3,9 & 15 & 81,4 & 3,3 \\
\hline & 13 & 21 & 78,5 & 2,9 & 15 & 77,9 & 3,4 \\
\hline ANB & 18 & 13 & 80,6 & 3,2 & 15 & 78,5 & 3,4 \\
\hline & 13 & 21 & 3,4 & 2,1 & 15 & 2,6 & 1,6 \\
\hline 1.NA & 18 & 13 & 2,2 & 2,6 & 15 & 2,9 & 1,8 \\
\hline & 13 & 21 & 22,3 & 6,4 & 15 & 22,3 & 6,8 \\
\hline 1-NA & 13 & 13 & 22,0 & 6,8 & 15 & 19,5 & 5,8 \\
\hline & 18 & 13 & 4,3 & 2,6 & 15 & 3,5 & 2,4 \\
\hline 1.NB & 13 & 21 & 24,2 & 4,9 & 15 & 26,1 & 4,1 \\
\hline & 18 & 13 & 23,4 & 6,7 & 15 & 25,4 & 5,2 \\
\hline 1-NB & 13 & 21 & 4,6 & 2,2 & 15 & 4,6 & 1,3 \\
\hline & 18 & 13 & 4,7 & 2,4 & 15 & 5,0 & 2,2 \\
\hline IMPA & 13 & 21 & 88,6 & 3,4 & 15 & 90,3 & 5,1 \\
\hline & 18 & 13 & 89,9 & 6,0 & 15 & 90,2 & 6,2 \\
\hline 1.ENP-ENA & 13 & 21 & 112,2 & 5,4 & 15 & 114,1 & 7,2 \\
\hline & 18 & 13 & 116,6 & 6,8 & 15 & 112,1 & 6,0 \\
\hline 1.1 & 13 & 21 & 129,9 & 8,3 & 15 & 128,8 & 7,6 \\
& 18 & 13 & 132,3 & 7,9 & 15 & 132,0 & 7,5 \\
\hline
\end{tabular}


CHANG; MOON, em $1999^{17}$, examinaram os resultados do tratamento das más oclusões com a técnica MEAW (multiloop edgewise arch wire) e verificaram que as mudanças ocorreram principalmente na região dentoalveolar, mostrando uma considerável similaridade com o mecanismo compensatório dentoalveolar. Em outras palavras, a técnica "MEAW" permite aos ortodontistas produzir a compensação dentoalveolar natural ortodonticamente.

LENZ; WOODS, em $1999^{47}$, avaliaram telerradiografias e modelos de estudo de 55 pacientes para determinar se existia algum relacionamento entre as mudanças nas posições e angulações dentárias e a estabilidade oclusal a longo prazo. Todos foram tratados pela técnica Edgewise pré-angulados nos arcos superior e inferior, sendo que 16 sofreram extrações dos primeiros pré-molares superiores e inferiores. As três fases de estudo foram: $T_{1}-$ pré-tratamento; $T_{2}-$ póstratamento; e $\mathrm{T}_{3}$ - aproximadamente 6.5 anos após a remoção de todas as contenções. A idade média em $\mathrm{T}_{1}$ era de 13 anos e 5 meses, sendo que 41 eram do gênero feminino e 14 do masculino. Em geral, as mudanças que ocorreram durante o tratamento ativo foram maiores que as do período seguinte. Houve uma suave tendência das posições e angulações dos incisivos em recidivarem para os valores pré-tratamento, mesmo tendo sido observado uma grande variação individual. Verificaram-se que estas mudanças (em retornarem próximas aos valores anteriores) não estão diretamente relacionadas às posições e angulações dentárias em $T_{2}$ ou mesmo às mudanças ocorridas de $T_{1}$ para $T_{2}$. Os autores sugeriram a individualização dos casos, ao invés de seguir a risca os valores estabelecidos por várias análises. Estas normas deveriam ser utilizadas mais como guias estéticos e funcionais. 
3 - PROPOSIÇÃO 


\section{PROPOSIÇÃO}

Este trabalho propõe-se a:

- $\quad$ Avaliar as mudanças ocorridas entre as fases de estudo inicial e final das medidas cefalométricas envolvidas;

- $\quad$ Avaliar as mudanças ocorridas entre as fases de estudo final e cinco anos após a finalização do tratamento ortodôntico das medidas cefalométricas envolvidas;

- Avaliar se ocorreram as compensações dentárias na mecânica ortodôntica e se estas foram preservadas a longo prazo. 


\section{4 - MATERIAL E MÉTODOS}




\section{MATERIAL E MÉTODOS}

\section{Material}

Realizou-se a seleção do material desta pesquisa no acervo de documentações da Disciplina de Ortodontia do Departamento de Odontopediatria, Ortodontia e Saúde Coletiva da Faculdade de Odontologia de Bauru - USP. Para compor a amostra, vários requisitos foram observados: 1-tratamento ortodôntico com aparelhos fixos, utilizando-se a técnica Edgewise; 2 extrações dentárias dos primeiros pré-molares superiores e inferiores; 3- ângulo ANB maior que 4ํ; 4- más oclusões Classes I ou II de Angle; 5 radiografias cefalométricas de norma lateral obtidas nas fases inicial, final, e cinco anos após a finalização terapêutica.

Vinte e sete indivíduos foram selecionados apresentando as seguintes características obtidas das fichas clínicas e de trabalhos das pastas de documentação: todos jovens brasileiros leucodermas, 14 do gênero masculino e 13 do gênero feminino, filhos ou netos de brasileiros descendentes de mediterrâneos: portugueses, espanhóis ou italianos. A média das idades no início do tratamento foi 13 anos e 5 meses, no final do tratamento 14 anos e 5 meses e na fase póstratamento 19 anos e 4 meses. A média dos tempos de tratamento foi 1 ano 5 meses e 9 dias, com o mínimo de 1 ano 1 mês e 17 dias e o máximo de 5 anos e 8 meses. No início do tratamento, 14 componentes apresentavam más oclusões Classe II, $1^{\text {ạ }}$ divisão de Angle, 12 componentes apresentavam más oclusões Classe I e 1, má oclusão Classe II, $2^{\text {a }}$ divisão. Da amostra completa, 20 mostravam o padrão de 
crescimento facial no sentido vertical, 3 no sentido horizontal e 4 padrão de crescimento equilibrado, verificado pel as medidas angulares FMA e SN.GoGn.

\section{Métodos}

As telerradiografias utilizadas foram padronizadas na época, o que possibilitou uma uniformidade entre elas e uma boa qualidade. Designou-se como $\mathrm{T}_{1}$ a radiografia inicial - obtida antes da colocação do aparelho ortodôntico; $T_{2}$ a radiografia final - obtida imediatamente após a remoção do aparelho ortodôntico; $T_{3}$ a radiografia pós-tratamento - obtida cinco anos após a remoção do aparelho ortodôntico.

Realizaram-se os 81 cefalogramas manualmente, seguindo as orientações fornecidas por VION, em 199496, para uma melhor localização e demarcação das estruturas anatômicas, e conseqüentemente a obtenção de uma maior exatidão dos pontos, linhas e planos cefalométricos. Requereram -se os seguintes materiais: folha de papel acetato transparente "Ultraphan", de tamanho $17,5 \times 17,5 \mathrm{~cm}$ e espessura de $0,07 \mathrm{~mm}$, adaptada com fita adesiva sobre a telerradiografia; lapiseira com grafite preto $0,5 \mathrm{~mm}$; compasso; régua milimetrada; transferidor; template (para a padronização dos desenhos dos incisivos superiores e inferiores) e negatoscópio. O local de trabalho estabelecido foi a sala de arquivos da Disciplina, permanecendo escurecida durante a execução dos traçados cefalométricos. O critério para o arredondamento dos valores obtidos das medidas cefalométricas se deu pela preferência do número maior quando a mensuração se 
localizava entre dois valores equidistantemente; caso não se apresentasse desta forma, dava-se preferência ao número mais próximo.

Seqüência das etapas necessárias para a obtenção dos cefalogramas:

1. Delimitação do Desenho Anatômico

2. Pontos Cefalométricos

3. Linhas e Planos Cefalométricos

4. Medidas Cefalométricas Angulares

5. Medidas Cefalométricas Lineares

\section{A Delimitação do Desenho Anatômico (Figura 4.1):}

o contorno anterior do osso frontal e dos ossos nasais $\rightarrow$ contorno exterior do osso frontal (glabela) e o limite anterior dos ossos nasais unidos entre si pela sutura frontonasal

a sela túrcica $\rightarrow$ contorno anterior, inferior e posterior da sela, estendendo-se anterior e posteriormente, abrangendo os processos clinóides anterior e posterior

- $\quad$ o meato auditivo externo $\rightarrow$ contorno da imagem radiolúcida do meato acústico externo 
a fissura pterigomaxilar $\rightarrow$ limites posterior da tuberosidade maxilar e anterior do processo pterigóide do osso esfenóide

órbita $\rightarrow$ contorno póstero-inferior das cavidades orbitárias

maxila $\rightarrow$ contorno da concavidade anterior, desde a espinha nasal anterior até próximo à região cervical das coroas dos incisivos, estendendo-se posteriormente da espinha nasal anterior até a posterior, por sobre a cortical do assoalho das fossas nasais, completando-se o desenho com uma linha correspondente ao limite inferior da região anterior do palato duro

mandíbula $\rightarrow$ contorno das corticais vestibular e lingual da sínfise mandibular e média das bordas inferior do corpo, posterior do ramo e dos côndilos

os incisivos centrais superiores e inferiores mais vestibularizados $\rightarrow$ contorno das coroas e raízes dentárias (utilizou-se o template)

os primeiros molares superiores e inferiores $\rightarrow$ contorno das coroas e raízes dentárias (utilizou-se o template)

o perfil tegumentar $\rightarrow$ a partir da metade inferior da fronte até completar o contorno do mento, e interrompido na altura dos lábios, quando entreabertos 


\section{DESENHO ANATÔMICO}

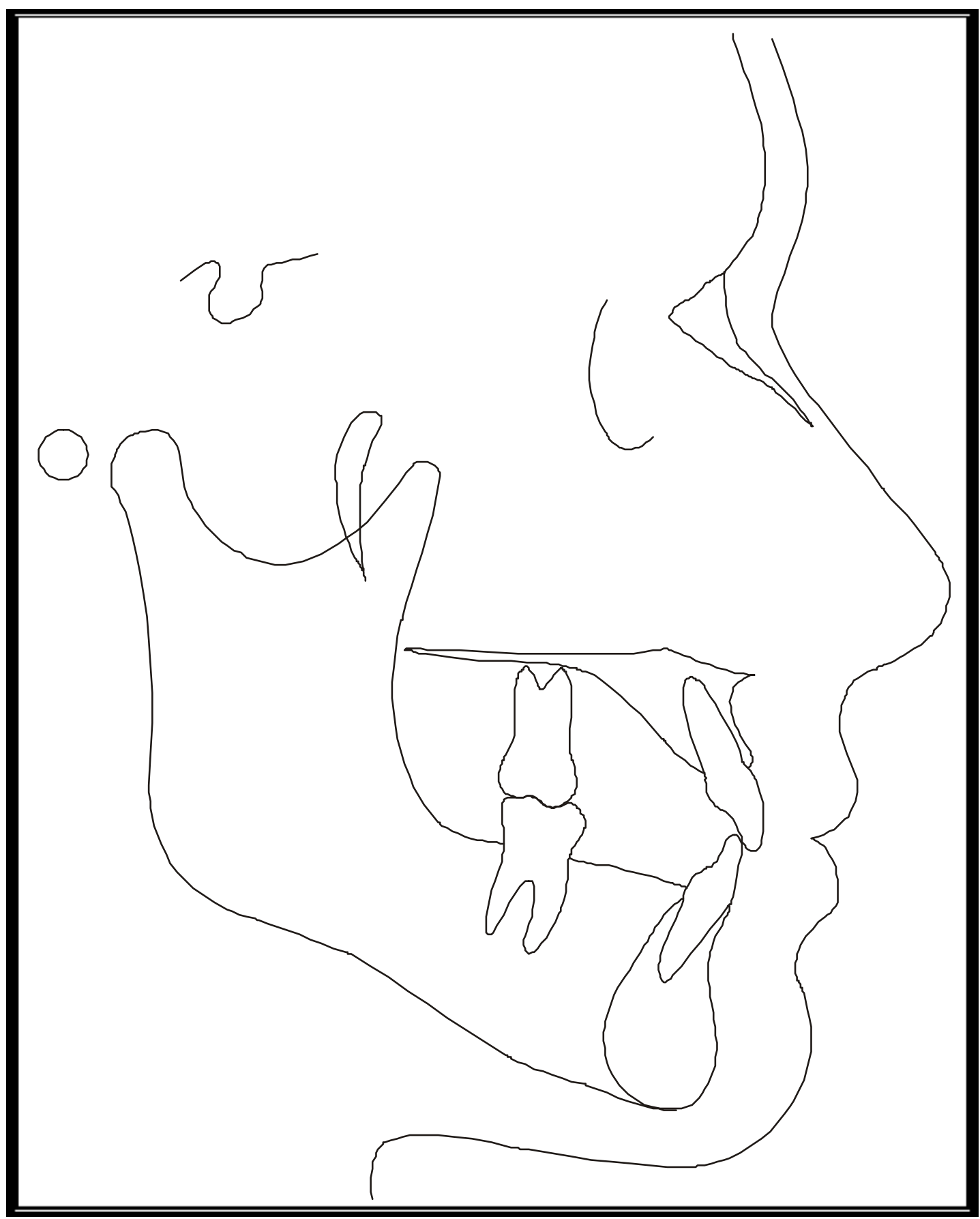

FIGURA 4.1 - Composição do desenho anatômico adotado 


\section{Os Pontos Cefalométricos utilizados (Figura 4.2):}

\begin{tabular}{|c|c|c|}
\hline Número & Abreviação & Definição \\
\hline 1 & $\mathrm{~N}$ & $\begin{array}{l}\text { NÁSIO - intersecção da sutura internasal com a } \\
\text { sutura frontonasal }\end{array}$ \\
\hline 2 & ENP & $\begin{array}{l}\text { ESPINHA NASAL POSTERIOR - ponto mais } \\
\text { posterior do palato duro }\end{array}$ \\
\hline 3 & ENA & $\begin{array}{l}\text { ESPINHA NASAL ANTERIOR - ponto mais } \\
\text { anterior da maxila }\end{array}$ \\
\hline 4 & A & $\begin{array}{l}\text { PONTO A - ponto mais profundo da concavidade } \\
\text { anterior da maxila }\end{array}$ \\
\hline 5 & AIS & $\begin{array}{l}\text { ÁPICE DO INCISIVO SUPERIOR - ponto mais } \\
\text { superior da raiz do incisivo central superior }\end{array}$ \\
\hline 6 & IIS & $\begin{array}{l}\text { INCISAL DO INCISIVO SUPERIOR - ponto mais } \\
\text { inferior da coroa do incisivo superior }\end{array}$ \\
\hline 7 & III & $\begin{array}{l}\text { INCISAL DO INCISIVO INFERIOR - ponto mais } \\
\text { superior da coroa do incisivo inferior }\end{array}$ \\
\hline 8 & All & $\begin{array}{l}\text { ÁPICE DO INCISIVO INFERIOR - ponto mais } \\
\text { inferior da raiz do incisivo central inferior }\end{array}$ \\
\hline 9 & B & $\begin{array}{l}\text { PONTO B - ponto mais profundo da concavidade } \\
\text { anterior da mandíbula }\end{array}$ \\
\hline 10 & $\mathrm{Me}$ & $\begin{array}{l}\text { MENTONIANO - ponto mais inferior do contorno } \\
\text { da sínfise mentoniana }\end{array}$ \\
\hline 11 & Go & $\begin{array}{l}\text { GÔNIO - ponto mais póstero-inferior do contorno } \\
\text { do ângulo goníaco }\end{array}$ \\
\hline 12 & $S$ & $\begin{array}{l}\text { SELA TÚRCICA - centro da concavidade óssea } \\
\text { da sela túrcica }\end{array}$ \\
\hline
\end{tabular}




\section{PONTOS CEFALOMÉTRICOS}

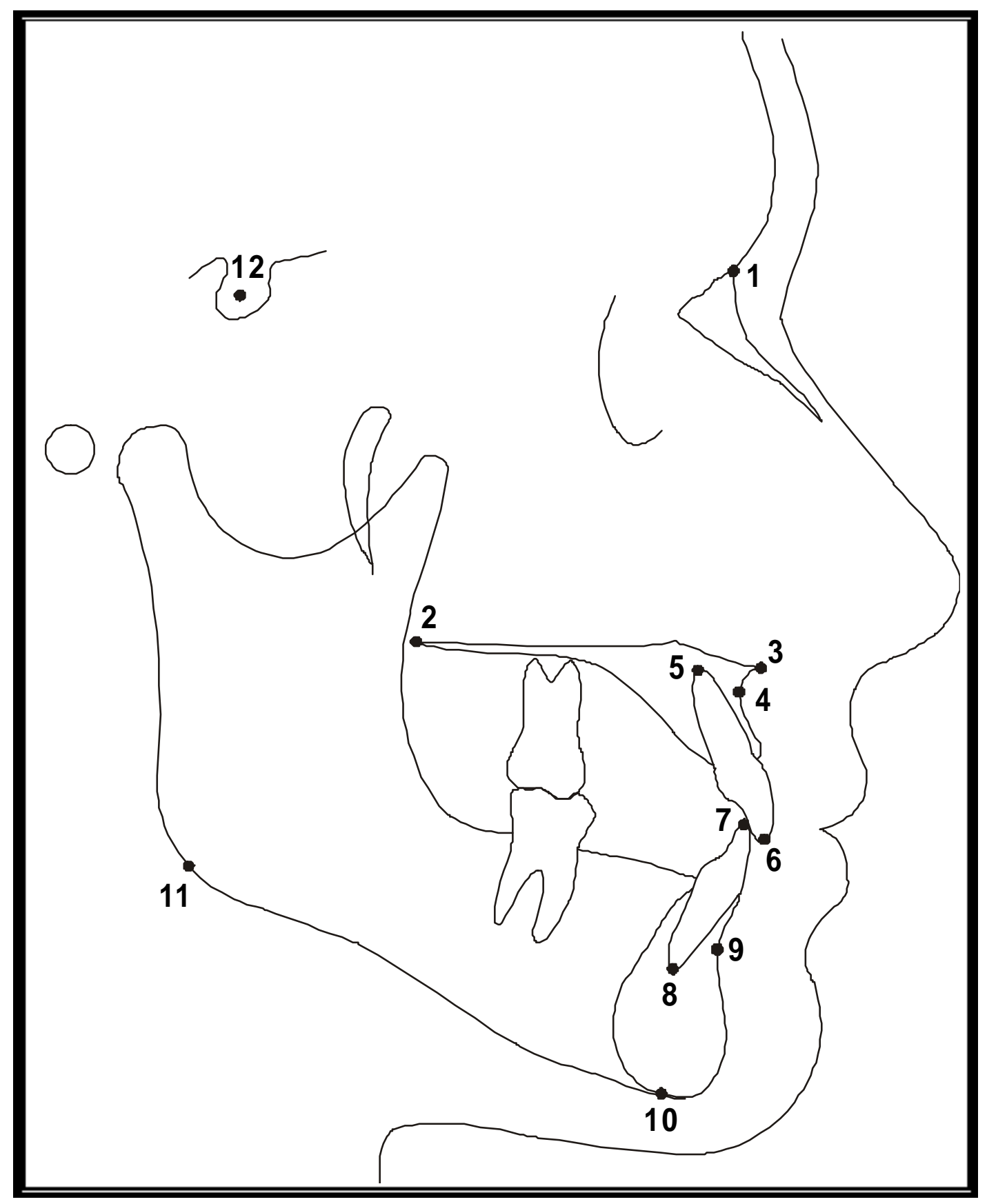

FIGURA 4.2 - Pontos cefalométricos utilizados e suas localizações no desenho anatômico 


\section{As Linhas e os Planos Cefalométricos utilizados (Figura 4.3):}

\section{Linha Sela Násio}

Linha traçada desde a margem direita à margem esquerda do papel, passando pelos pontos $\mathrm{S}$ e $\mathrm{N}$.

\section{Plano Palatino}

Linha traçada do ponto ENA ao ponto ENP, não estendendo-a muito.

\section{Plano Mandibular de Tweed}

Traçado da margem direita à margem esquerda do papel, passando pelos pontos Me e Go.

\section{Linha Násio-Ponto A}

Traçado iniciando-se cinco milímetros abaixo de $\mathrm{N}$ passando pelo ponto $\mathrm{A} e$ terminando a cinco milímetros abaixo da face incisal do incisivo superior.

\section{Linha Násio-Ponto B}

Traçado iniciando-se três milímetros abaixo de $\mathrm{N}$ passando pelo ponto $\mathrm{B} e$ terminando no plano mandibular.

6. Linha do Longo Eixo do Incisivo Superior mais vestibularizado

Linha traçada passando pelos pontos do ápice e da incisal do incisivo superior, se estendendo desde a linha SN até cinco milímetros abaixo da coroa do incisivo superior.

7. Linha do Longo Eixo do Incisivo Inferior mais vestibularizado

Linha traçada passando pelos pontos do ápice e da incisal do incisivo inferior, desde o plano mandibular, não estendendo-a muito acima da coroa do incisivo inferior.

\section{Sela - Násio \\ S-N}

Espinha Nasal Posterior - Espinha

Nasal Anterior

ENP-ENA

Gônio - Mentoniano

Go-Me

Násio - Ponto A

$\mathrm{N}-\mathrm{A}$

Násio - Ponto B

$\mathrm{N}-\mathrm{B}$

Ápice do Incisivo Superior - Incisal do Incisivo Superior

AIS-IIS

Ápice do Incisivo Inferior - Incisal do Incisivo Inferior All-III 


\section{LINHAS E PLANOS CEFALOMÉTRICOS}
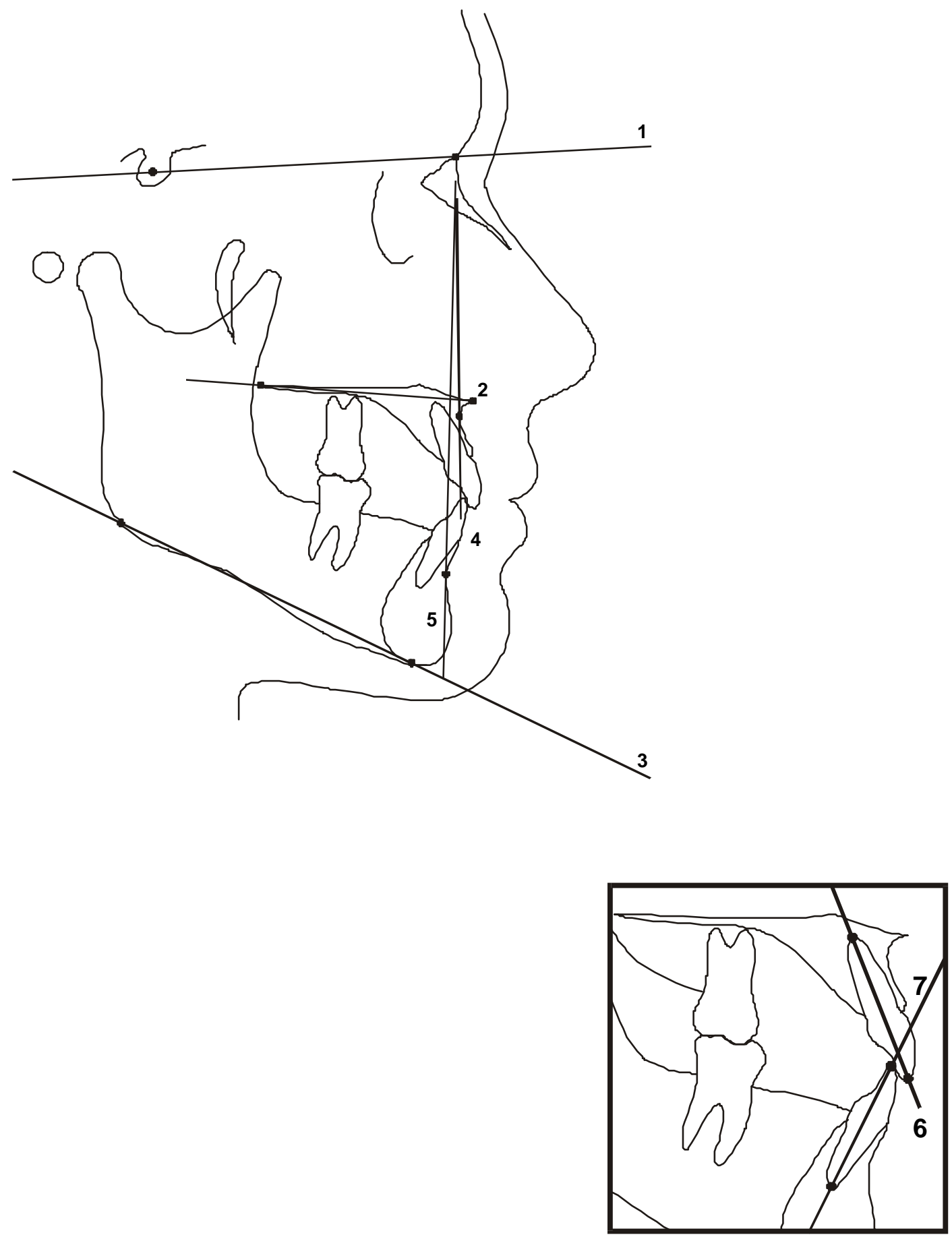

FIGURA 4.3 - Planos e linhas de referência que constituíram o traçado de orientação dos cefalogramas 
O conjunto dos planos e linhas de referência adotados possibilitou a interpretação de dez grandezas cefalométricas, sendo oito angulares e duas lineares.

As Medidas Cefalométricas Angulares (Figuras 4.4, 4.5, 4.6, 4.7, 4.8, 4.9, 4.10, 4.11):

1. Sela.Násio.Ponto A

S.N.A

Intersecção das linhas SN e NA. Determina uma medida angular que mostra o posicionamento ântero-posterior da maxila em relação à base do crânio.

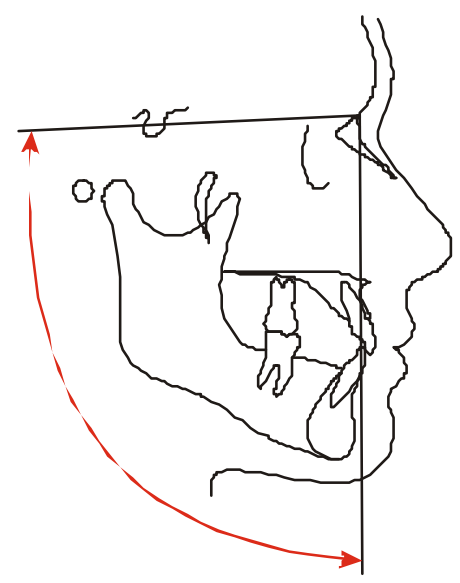

FIGURA 4.4 - Medida Angular SNA 


\section{Sela.Násio.Ponto B}

S.N.B

Intersecção das linhas SN e NB. A medida angular mostra se a mandíbula está protruída, retruída ou bem posicionada em relação à base do crânio.

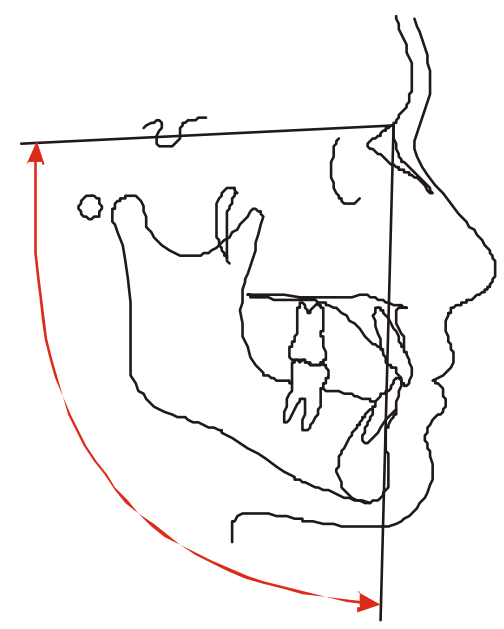

FIGURA 4.5 - Medida Angular SNB

\section{Ponto A.Násio.Ponto B}

A.N.B

Indica o relacionamento entre a maxila e a mandíbula. $\mathrm{O}$ valor angular é dado pela diferença entre os ângulos SNA e SNB. 




FIGURA 4.6 - Medida Angular ANB

4. Incisivo Superior.Násio-Ponto A

AIS-IIS.N-A ( 1.NA)

Revela a inclinação do incisivo superior em relação à linha NA, mostrando se este está inclinado para vestibular ou para palatina. O ângulo é formado pelo cruzamento das linhas NA e o longo eixo do incisivo superior.

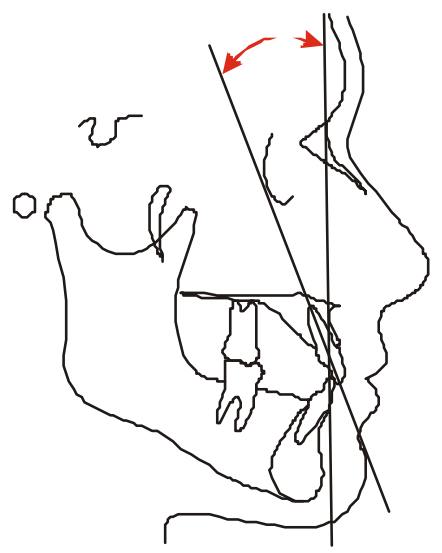

FIGURA 4.7 - Medida Angular 1.NA 
5. Incisivo Superior.Incisivo Inferior

AIS-IIS.AIHIII ( $1 . \overline{1})$

Esta medida angular mostra a inclinação dos incisivos superior e inferior entre si. Obtém-se esta medida do ângulo formado pelo cruzamento das linhas dos longos eixos destes dentes.

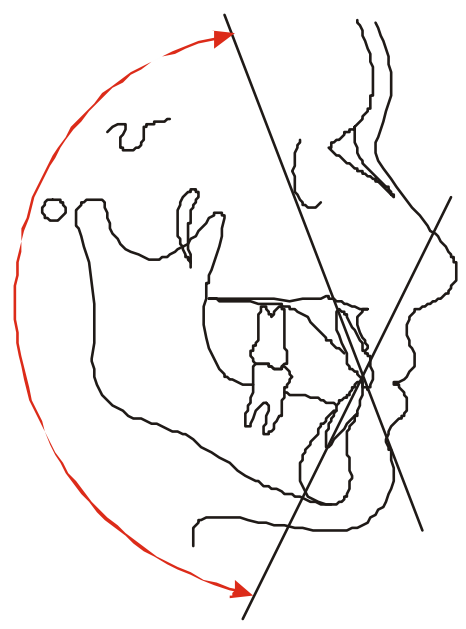

FIGURA 4.8 - Medida Angular $\underline{1} \cdot \overline{1}$

6. Incisivo Inferior.Plano Mandibular (IMPA)

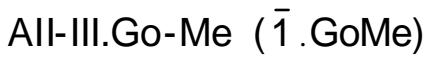

Ângulo formado pela linha do longo eixo do incisivo inferior e o plano Mandibular. Esta medida revela a inclinação dentária em relação ao plano utilizado, dizendo se o dente está verticalizado sobre o osso basal, vestibularizado ou lingualizado. 


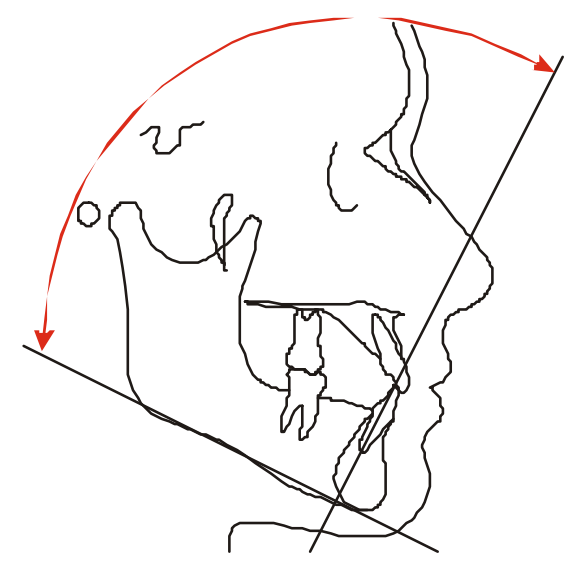

FIGURA 4.9 - Medida Angular $\overline{1}$.GoMe

7. Incisivo Inferior.Násio-Ponto B

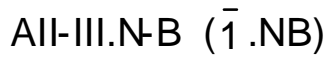

Revela a inclinação do incisivo inferior em relação à linha NB, mostrando se este está inclinado para vestibular ou para lingual. $O$ ângulo é formado pelo cruzamento das linhas NB e o longo eixo do incisivo inferior.

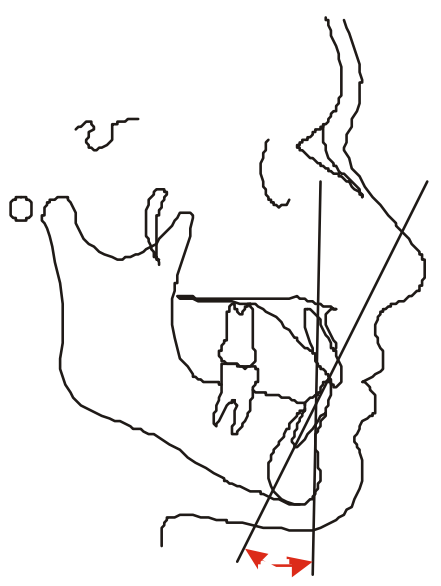

FIGURA 4.10 - Medida Angular $\overline{1}$.NB 
8. Incisivo Superior.Plano Palatino

AIS-IIS.ENP-ENA (1.ENP-ENA)

Ângulo formado pela linha do longo eixo do incisivo superior e o plano Palatino. Esta medida mostra o grau de inclinação dentária em relação ao plano utilizado.

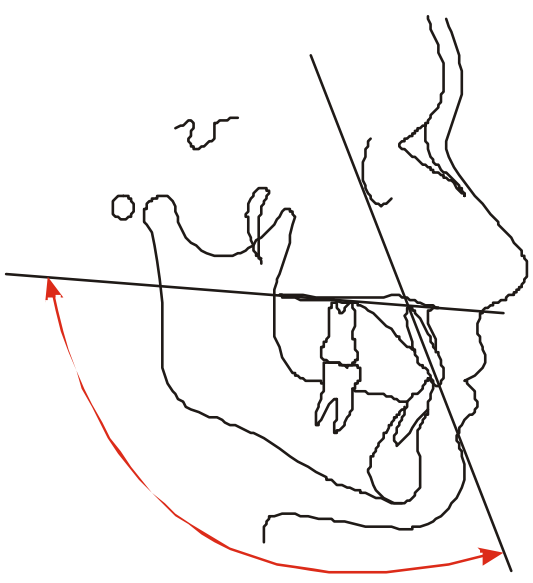

FIGURA 4.11 - Medida Angular 1.ENP-ENA

\section{As Medidas Cefalométricas Lineares (Figuras 4.12, 4.13):}

1. Incisal do Incisivo Superior Perpendicular - Linha Násio-Ponto A $\mathrm{IIS} \perp \mathrm{N}-\mathrm{A}(\underline{1-\mathrm{NA}})$

É a distância linear entre o incisivo superior e a linha NA, mostrando se o dente está bem posicionado, protruído ou retruído em relação à sua base 
apical. Mede-se do ponto mais anterior da face vestibular da coroa do incisivo até a linha NA.



FIGURA 4.12 - Medida Linear 1-NA

2. Incisal do Incisivo Inferior Perpendicular - Linha Násio-Ponto B

III $\perp \mathrm{N}-\mathrm{B}(\overline{1}-\mathrm{NB})$

É a distância linear entre o incisivo inferior e a linha NB, mostrando se o dente está bem posicionado, protruído ou retruído em relação à sua base apical. Mede-se do ponto mais anterior da face vestibular da coroa do incisivo até a linha NB. 


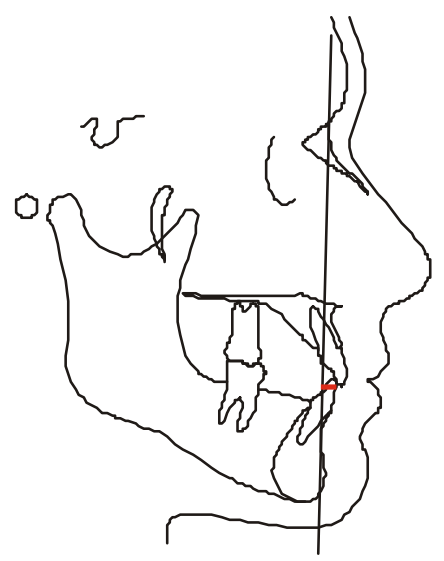

FIGURA 4.13 - Medida Linear $\overline{1}-\mathrm{NB}$

Obtiveram-se estas medidas cefalométricas dos 27 pacientes para todas as fases estabelecidas $\left(T_{1}, T_{2}\right.$ e $\left.T_{3}\right)$.

\section{Análise Estatística}

A estatística descritiva envolveu o cálculo da média e do desvio padrão de cada variável cefalométrica, nas distintas fases do estudo $\left(T_{1}, T_{2}, T_{3}\right)$, assim como de suas alterações nos intervalos interfases. Após a obtenção destes dados, para a realização da estatística indutiva, aplicou-se a análise de variância a um critério, com vistas a identificar as alterações interfases no valor de cada variável estudada. $\mathrm{Na}$ observação de um resultado estatisticamente significante, utilizou-se o teste de Tukey para indicar, especificamente, entre quais fases de estudo estariam ocorrendo diferenças significantes. Finalmente, empregou-se o coeficiente de correlação de 
Pearson para relacionar o ângulo interincisivos com as demais medidas nas diferentes fases de estudo.

A estatística descritiva também foi realizada para verificar as diferenças quanto aos gêneros, envolvendo o cálculo da média, desvio padrão, valores de t e p nas diferentes fases de estudo.

\section{Avaliação do erro metodológico}

Uma semana após a obtenção das medidas cefalométricas, procedeu-se à efetuação do erro metodológico para avaliação dos erros casuais e sistemáticos de cada uma das grandezas cefalométricas estudadas. As medidas foram refeitas pelo mesmo examinador de dez pacientes selecionados aleatoriamente.

\section{ERRO SISTEMÁTICO}

O erro sistemático foi obtido de acordo com o teste "t" de Student, em nível de significância de 5\% para o método.

\section{ERRO CASUAL}

Obteve-se o erro casual de acordo com a fórmula proposta por DAHLBERG

$$
E^{2}=\frac{\sum d^{2}}{2 n}
$$


na qual: "d" indica a diferença entre os valores medidos na $1^{\underline{a}}$ e $2^{\text {a }}$ mensuração e "n" indica o número de casos em que as medidas foram repetidas. 


\section{5 - RESULTADOS}




\section{RESULTADOS}

TABELA 5.1 - Médias e desvios padrão calculados para cada variável cefalométrica nas diferentes fases do estudo

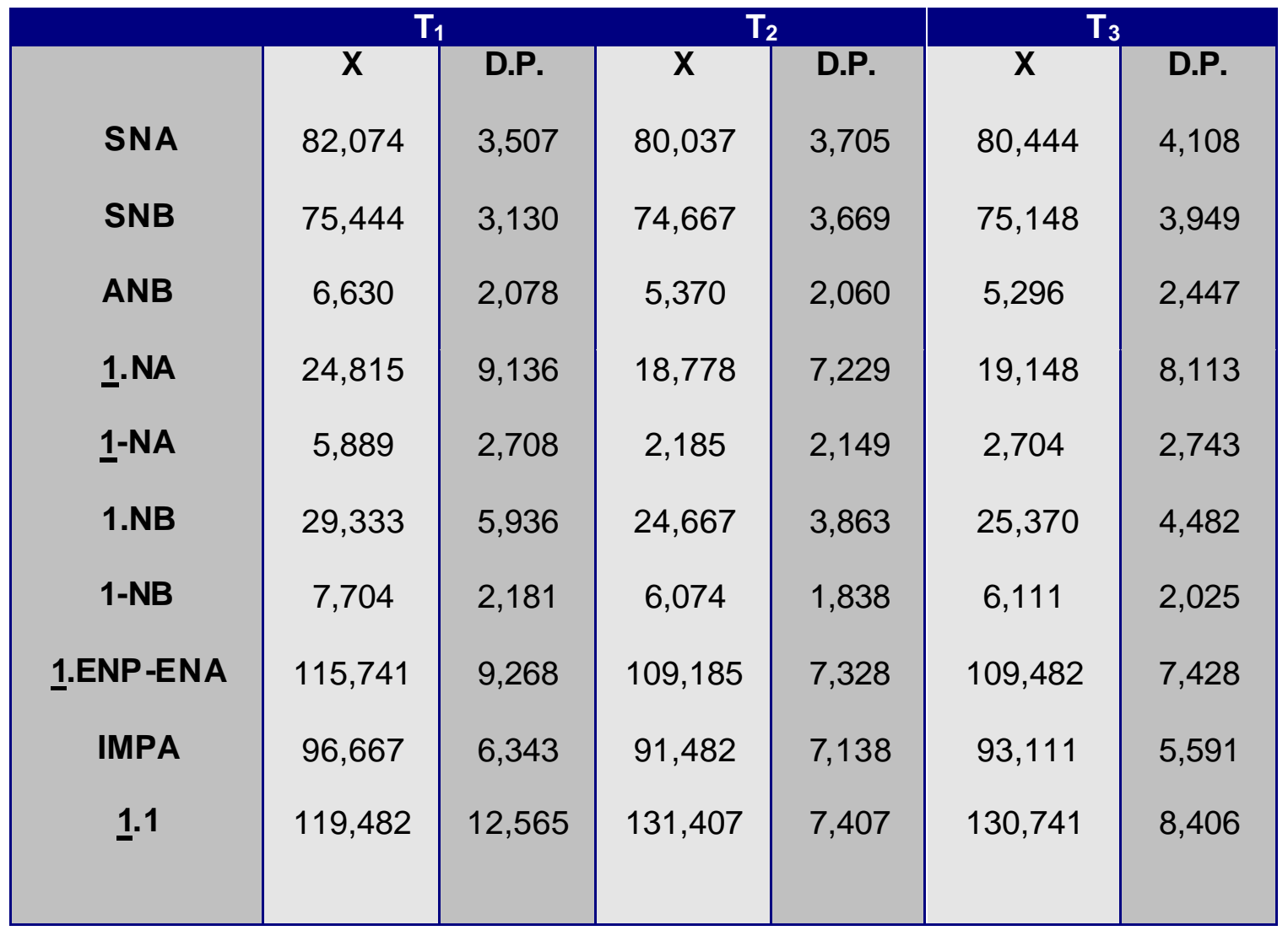


TABELA 5.2 - Médias e desvios padrão calculados das alterações ocorridas para cada variável cefalométrica nos intervalos interfases

\begin{tabular}{|c|c|c|c|c|c|c|}
\hline & \multicolumn{2}{|c}{$\mathbf{T}_{2}-\mathbf{T}_{1}$} & \multicolumn{2}{c|}{$\mathbf{T}_{3}-\mathbf{T}_{2}$} & \multicolumn{2}{c|}{$\mathbf{T}_{3}-\mathbf{T}_{1}$} \\
SNA & $-2,037$ & 1,931 & 0,407 & 1,500 & $-1,630$ & 1,904 \\
SNB & $-0,778$ & 1,251 & 0,482 & 1,014 & $-0,296$ & 1,613 \\
ANB & $-1,259$ & 2,030 & $-0,074$ & 0,958 & $-1,333$ & 1,961 \\
1.NA & $-6,037$ & 13,198 & 0,370 & 4,626 & $-5,667$ & 12,140 \\
1-NA & $-3,704$ & 3,326 & 0,519 & 1,503 & $-3,185$ & 3,763 \\
1.NB & $-4,667$ & 6,239 & 0,704 & 3,473 & $-3,963$ & 5,557 \\
1-NB & $-1,630$ & 1,548 & 0,037 & 0,808 & $-1,593$ & 1,600 \\
1.ENP-ENA & $-6,556$ & 13,072 & 0,296 & 5,312 & $-6,259$ & 11,850 \\
IMPA & $-5,185$ & 7,484 & 1,630 & 3,295 & $-3,556$ & 5,989 \\
1.1 & 11,926 & 15,928 & $-0,667$ & 6,945 & 11,259 & 13,786 \\
& & & & & & \\
\hline
\end{tabular}


Os dados obtidos serão visualizados e interpretados, em seguida, na seguinte ordem:

\section{1ㅇ- Análise de Variância a um critério}

Se a medida cefalométrica apresenta um valor de "p" significante representado pelo asterisco $\left({ }^{*}\right)$, indica-se que ocorreu uma mudança significativa entre as fases de estudo.

\section{2-- Teste de Tukey}

Os valores com asterisco $\left(^{*}\right)$ indicam entre quais fases de estudo especificamente ocorreram as mudanças.

O esquema abaixo ilustra o método de análise deste teste:

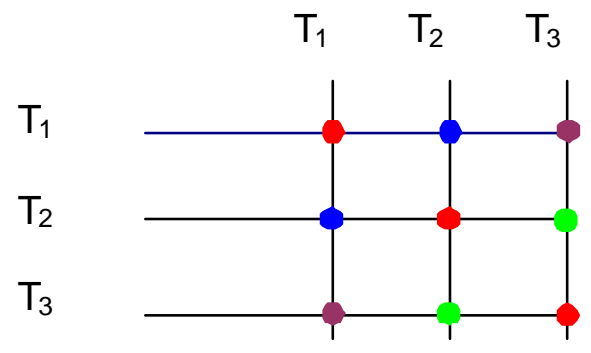

3-- Representação Gráfica

As mudanças ocorridas nas medidas cefalométricas são mostradas graficamente

\section{4-- Descrição sucinta dos resultados}


TABELA 5.3 - Análise de Variância a um critério - SNA

\begin{tabular}{ccccccc}
\hline & \multicolumn{7}{c}{ SNA } \\
Efeito & $\begin{array}{c}\text { G.L. } \\
\text { Efeito }\end{array}$ & $\begin{array}{c}\text { Q.M. } \\
\text { Efeito }\end{array}$ & $\begin{array}{c}\text { G.L. } \\
\text { Erro }\end{array}$ & $\begin{array}{c}\text { Q.M. } \\
\text { Erro }\end{array}$ & F & p \\
Fases & $2^{*}$ & $31,370^{*}$ & $52^{*}$ & $1,601^{*}$ & $19,593^{*}$ & $0,000^{*}$ \\
& & & & & & \\
\hline
\end{tabular}

TABELA 5.4 - Teste de Tukey - SNA

\begin{tabular}{|cccc|}
\hline & \multicolumn{3}{c|}{ SNA } \\
\hline SNA & $\mathrm{T}_{1}$ & $\mathrm{~T}_{2}$ & $\mathrm{~T}_{3}$ \\
& $\mathbf{8 2 , 0 7 4}$ & $\mathbf{8 0 , 0 3 7}$ & $\mathbf{8 0 , 4 4 4}$ \\
$\mathrm{T}_{1}$ & & $0,000^{*}$ & $0,000^{*}$ \\
$\mathrm{~T}_{2}$ & $0,000^{*}$ & & 0,469 \\
$\mathrm{~T}_{3}$ & $0,000^{*}$ & 0,469 & \\
\hline
\end{tabular}

* diferença estatisticamente significante $(p<0,05)$



FIGURA 5.5 - Representação Gráfica - SNA

Medida angular SNA:

de $T_{1}$ para $T_{2} \rightarrow$ diminuição significante

de $T_{2}$ para $T_{3} \rightarrow$ suave incremento não significante 
TABELA 5.6 - Análise de Variância a um critério - SNB

\begin{tabular}{ccccccc}
\hline & \multicolumn{7}{c}{ SNB } \\
Efeito & $\begin{array}{c}\text { G.L. } \\
\text { Efeito }\end{array}$ & $\begin{array}{c}\text { Q.M. } \\
\text { Efeito }\end{array}$ & $\begin{array}{c}\text { G.L. } \\
\text { Erro }\end{array}$ & $\begin{array}{c}\text { Q.M. } \\
\text { Erro }\end{array}$ & F & p \\
& $2^{*}$ & $4,160^{*}$ & $52^{*}$ & $0,866^{*}$ & $4,806^{*}$ & $0,012^{*}$ \\
\hline
\end{tabular}

TABELA 5.7 - Teste de Tukey - SNB

\begin{tabular}{|cccc|}
\hline & & SNB & \\
\hline SNB & $\mathrm{T}_{1}$ & $\mathrm{~T}_{2}$ & $\mathrm{~T}_{3}$ \\
& 75,444 & 74,667 & 75,148 \\
$\mathrm{~T}_{1}$ & & $0,009^{*}$ & 0,476 \\
$\mathrm{~T}_{2}$ & $0,009^{*}$ & & 0,149 \\
$\mathrm{~T}_{3}$ & 0,476 & 0,149 & \\
\hline
\end{tabular}

${ }^{\star}$ diferença estatisticamente significante $(p<0,05)$

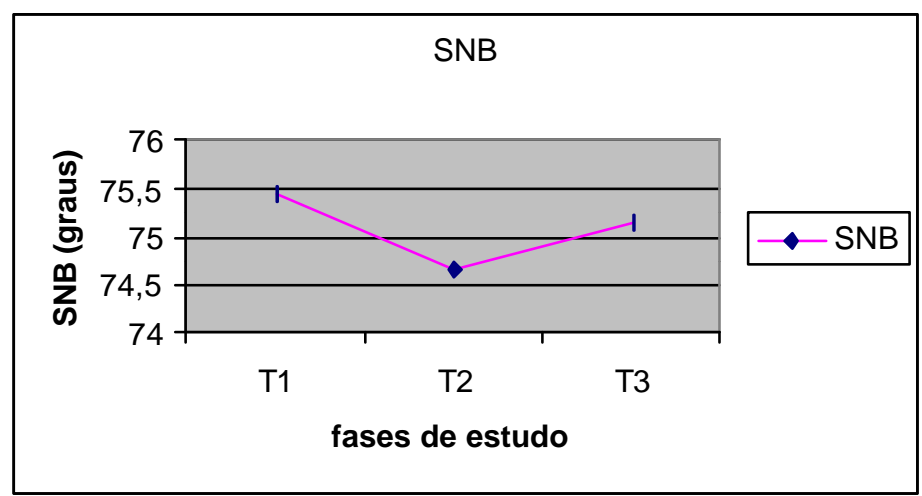

FIGURA 5.8 - Representação Gráfica - SNB

Medida angular SNB:

de $T_{1}$ para $T_{2} \rightarrow$ diminuição significante

de $T_{2}$ para $T_{3} \rightarrow$ incremento não significante 
TABELA 5.9 - Análise de Variância a um critério - ANB

\begin{tabular}{ccccccc}
\hline & \multicolumn{6}{c}{ ANB } \\
\hline \multirow{2}{*}{ Efeito } & $\begin{array}{c}\text { G.L. } \\
\text { Efeito }\end{array}$ & $\begin{array}{c}\text { Q.M. } \\
\text { Efeito }\end{array}$ & $\begin{array}{c}\text { G.L. } \\
\text { Erro }\end{array}$ & $\begin{array}{c}\text { Q.M. } \\
\text { Erro }\end{array}$ & F & p \\
& $2^{*}$ & $15,160^{*}$ & $52^{*}$ & $1,481^{*}$ & $10,237^{*}$ & $0,000^{*}$ \\
\hline
\end{tabular}

TABELA 5.10 - Teste de Tukey - ANB

\begin{tabular}{|cccc|}
\hline & \multicolumn{3}{c|}{ ANB } \\
\hline & $\mathrm{T}_{1}$ & $\mathrm{~T}_{2}$ & $\mathrm{~T}_{3}$ \\
$\mathrm{~T}_{1}$ & 6,630 & 5,370 & 5,296 \\
$\mathrm{~T}_{2}$ & $0,001^{*}$ & $0,001^{*}$ & $0,001^{*}$ \\
$\mathrm{~T}_{3}$ & $0,001^{*}$ & 0,973 & 0,973 \\
\hline
\end{tabular}

* diferença estatisticamente significante $(p<0,05)$

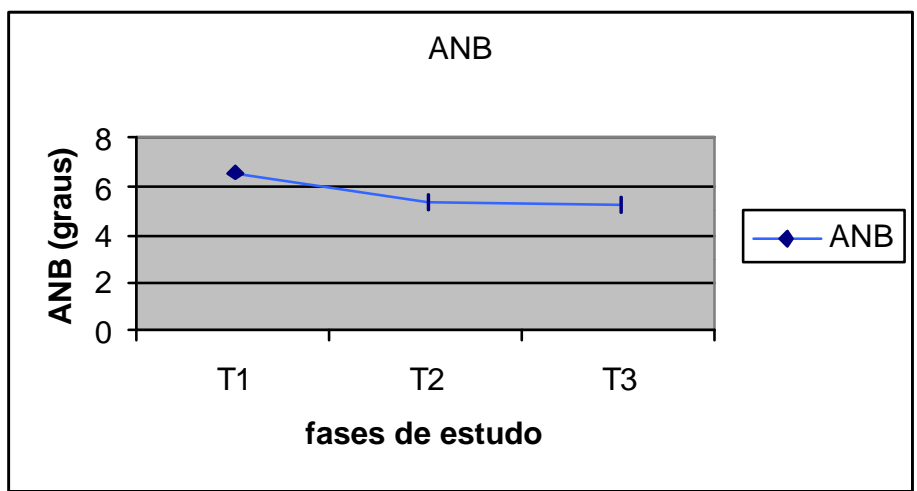

FIGURA 5.11 - Representação Gráfica - ANB

Medida angular ANB:

de $T_{1}$ para $T_{2} \rightarrow$ diminuição significante

de $T_{2}$ para $T_{3} \rightarrow$ praticamente constante 
TABELA 5.12 - Análise de Variância a um critério - 1.NA

\begin{tabular}{|c|c|c|c|c|c|c|}
\hline & \multicolumn{6}{|c|}{ 1.NA } \\
\hline Efeito & $\begin{array}{c}\text { G.L. } \\
\text { Efeito }\end{array}$ & $\begin{array}{l}\text { Q.M. } \\
\text { Efeito }\end{array}$ & $\begin{array}{l}\text { G.L. } \\
\text { Erro }\end{array}$ & $\begin{array}{l}\text { Q.M. } \\
\text { Erro }\end{array}$ & $F$ & p \\
\hline fases & $2^{*}$ & $309,123^{*}$ & $52^{*}$ & $57,162^{*}$ & $5,408^{*}$ & $0,007^{\star}$ \\
\hline
\end{tabular}

TABELA 5.13 - Teste de Tukey - 1.NA

\begin{tabular}{|cccc|}
\hline & & 1.NA & \\
\hline 1.NA & $\mathrm{T}_{1}$ & $\mathrm{~T}_{2}$ & $\mathrm{~T}_{3}$ \\
& $\mathbf{2 4 , 8 1 5}$ & 18,778 & 19,148 \\
$\mathrm{~T}_{1}$ & & $0,014^{*}$ & $0,022^{*}$ \\
$\mathrm{~T}_{2}$ & $0,014^{*}$ & & 0,982 \\
$\mathrm{~T}_{3}$ & $0,022^{*}$ & 0,982 & \\
\hline
\end{tabular}

* diferença estatisticamente significante $(p<0,05)$

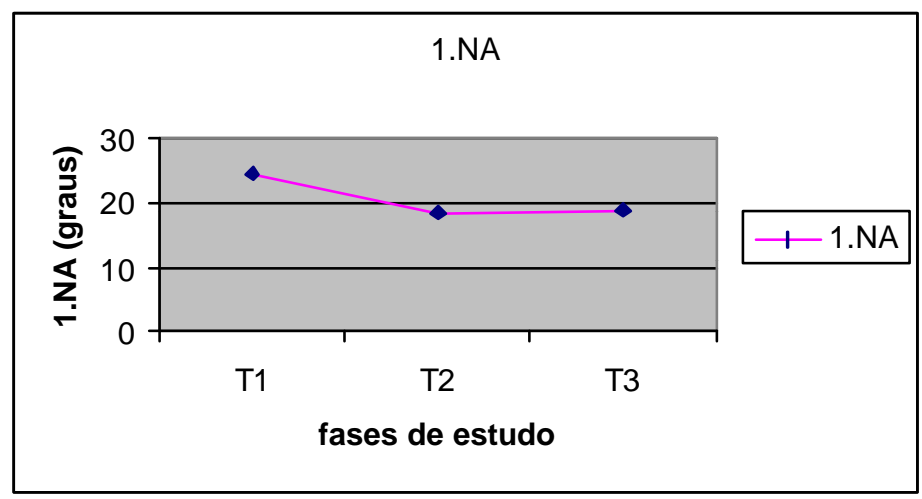

FIGURA 5.14 - Representação Gráfica - 1.NA

Medida angular 1.NA:

de $T_{1}$ para $T_{2} \rightarrow$ diminuição significante

de $T_{2}$ para $T_{3} \rightarrow$ suave incremento não significante 
TABELA 5.15 - Análise de Variância a um critério - I-NA

\begin{tabular}{ccccccc}
\hline & \multicolumn{7}{c}{ 1-NA } \\
Efeito & $\begin{array}{c}\text { G.L. } \\
\text { Efeito }\end{array}$ & $\begin{array}{c}\text { Q.M. } \\
\text { Efeito }\end{array}$ & $\begin{array}{c}\text { G.L. } \\
\text { Erro }\end{array}$ & $\begin{array}{c}\text { Q.M. } \\
\text { Erro }\end{array}$ & F & p \\
& $2^{*}$ & $108,593^{*}$ & $52^{*}$ & $4,580^{*}$ & $23,711^{*}$ & $0,000^{*}$ \\
& & & & & & \\
\hline
\end{tabular}

TABELA 5.16 - Teste de Tukey - 1-NA

\begin{tabular}{|cccc|}
\hline & & \multicolumn{3}{c|}{ 1-NA } \\
\hline 1-NA & $\mathrm{T}_{1}$ & $\mathrm{~T}_{2}$ & $\mathrm{~T}_{3}$ \\
& $\mathbf{5 , 8 8 9}$ & $\mathbf{2 , 1 8 5}$ & $\mathbf{2 , 7 0 4}$ \\
$\mathrm{T}_{1}$ & & $0,000^{*}$ & $0,000^{*}$ \\
$\mathrm{~T}_{2}$ & $0,000^{*}$ & & 0,649 \\
$\mathrm{~T}_{3}$ & $0,000^{*}$ & 0,649 & \\
\hline
\end{tabular}

* diferença estatisticamente significante $(p<0,05)$



FIGURA 5.17 - Representação Gráfica - 1-NA

Medida linear 1-NA:

de $T_{1}$ para $T_{2} \rightarrow$ diminuição significante

de $T_{2}$ para $T_{3} \rightarrow$ suave incremento não significante 
TABELA 5.18 - Análise de Variância a um critério - 1.NB

\begin{tabular}{ccccccc}
\hline & \multicolumn{7}{c}{ 1.NB } \\
Efeito & $\begin{array}{c}\text { G.L. } \\
\text { Efeito }\end{array}$ & $\begin{array}{c}\text { Q.M. } \\
\text { Efeito }\end{array}$ & $\begin{array}{c}\text { G.L. } \\
\text { Erro }\end{array}$ & $\begin{array}{c}\text { Q.M. } \\
\text { Erro }\end{array}$ & F & p \\
fases & $2^{*}$ & $170,901^{*}$ & $52^{*}$ & $13,645^{\star}$ & $12,525^{\star}$ & $0,000^{*}$ \\
& & & & & & \\
\hline
\end{tabular}

TABELA 5.19 - Teste de Tukey - I.NB

\begin{tabular}{|cccc|}
\hline & \multicolumn{3}{c|}{$\mathbf{1 . N B}$} \\
\hline & $\mathrm{T}_{1}$ & $\mathrm{~T}_{2}$ & $\mathrm{~T}_{3}$ \\
$\mathrm{~T}_{1}$ & 29,333 & 24,667 & $\mathbf{2 5 , 3 7 0}$ \\
$\mathrm{T}_{2}$ & $0,000^{*}$ & $0,000^{*}$ & $0,001^{*}$ \\
$\mathrm{~T}_{3}$ & $0,001^{*}$ & 0,765 & 0,765 \\
\hline
\end{tabular}

* diferença estatisticamente significante $(p<0,05)$

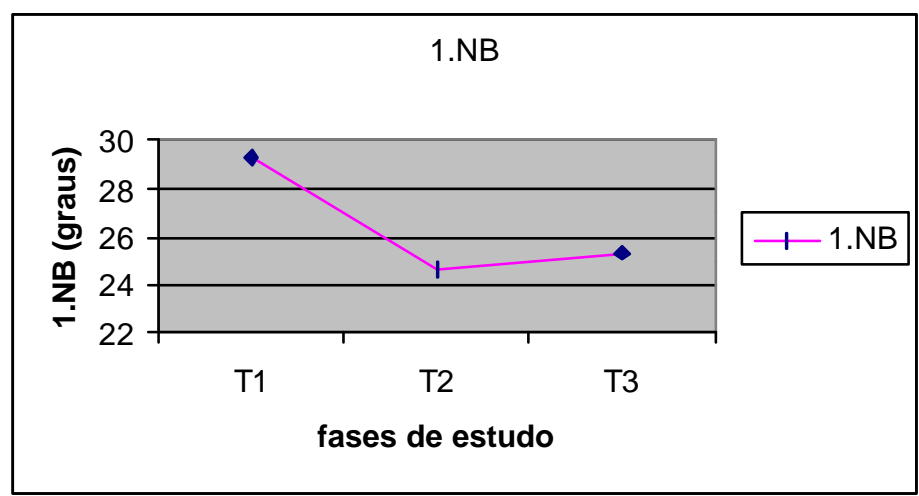

FIGURA 5.20 - Representação Gráfica - 1.NB

Medida angular 1.NB:

de $T_{1}$ para $T_{2} \rightarrow$ diminuição significante

de $T_{2}$ para $T_{3} \rightarrow$ suave incremento não significante 
TABELA 5.21 - Análise de Variância a um critério - 1-NB

\begin{tabular}{ccccccc}
\hline & \multicolumn{7}{c}{ 1-NB } \\
\hline Efeito & G.L. & Q.M. & G.L. & Q.M. & F & p \\
& Efeito & Efeito & Erro & Erro & & \\
1 1fases & $2^{*}$ & $23,370^{*}$ & $52^{*}$ & $0,934^{*}$ & $25,009^{*}$ & $0,000^{*}$ \\
& & & & & \\
\hline
\end{tabular}

TABELA 5.22 - Teste de Tukey - 1-NB

\begin{tabular}{|cccc|}
\hline & & $1-\mathrm{NB}$ & \\
\hline 1-NB & $\mathrm{T}_{1}$ & $\mathrm{~T}_{2}$ & $\mathrm{~T}_{3}$ \\
& 7,704 & 6,074 & 6,111 \\
$\mathrm{~T}_{1}$ & & $0,000^{*}$ & $0,000^{*}$ \\
$\mathrm{~T}_{2}$ & $0,000^{*}$ & & 0,989 \\
$\mathrm{~T}_{3}$ & $0,000^{*}$ & 0,989 & \\
\hline
\end{tabular}

* diferença estatisticamente significante $(p<0,05)$



FIGURA 5.23 - Representação Gráfica - 1-NB

Medida linear 1-NB:

de $T_{1}$ para $T_{2} \rightarrow$ diminuição significante

de $T_{2}$ para $T_{3} \rightarrow$ praticamente constante 
TABELA 5.24 - Análise de Variância a um critério - 1.ENP-ENA

\begin{tabular}{ccccccc}
\hline & \multicolumn{7}{c}{ 1.ENP-ENA } \\
Efeito & $\begin{array}{c}\text { G.L. } \\
\text { Efeito }\end{array}$ & $\begin{array}{c}\text { Q.M. } \\
\text { Efeito }\end{array}$ & $\begin{array}{c}\text { G.L. } \\
\text { Erro }\end{array}$ & $\begin{array}{c}\text { Q.M. } \\
\text { Erro }\end{array}$ & F & p \\
& $2^{*}$ & $370,086^{*}$ & $52^{*}$ & $56,586^{*}$ & $6,540^{*}$ & $0,003^{*}$ \\
& & & & & & \\
\hline
\end{tabular}

TABELA 5.25 - Teste de Tukey - 1.ENP-ENA

\begin{tabular}{|cccc|}
\hline & \multicolumn{3}{c|}{ 1.ENP-ENA } \\
\hline 1.ENP-ENA & $\mathrm{T}_{1}$ & $\mathrm{~T}_{2}$ & $\mathrm{~T}_{3}$ \\
& 115,741 & 109,185 & 109,482 \\
$\mathrm{~T}_{1}$ & & $0,007^{*}$ & $0,010^{*}$ \\
$\mathrm{~T}_{2}$ & $0,007^{*}$ & & 0,989 \\
$\mathrm{~T}_{3}$ & $0,010^{*}$ & 0,989 & \\
\hline
\end{tabular}

* diferença estatisticamente significante $(p<0,05)$

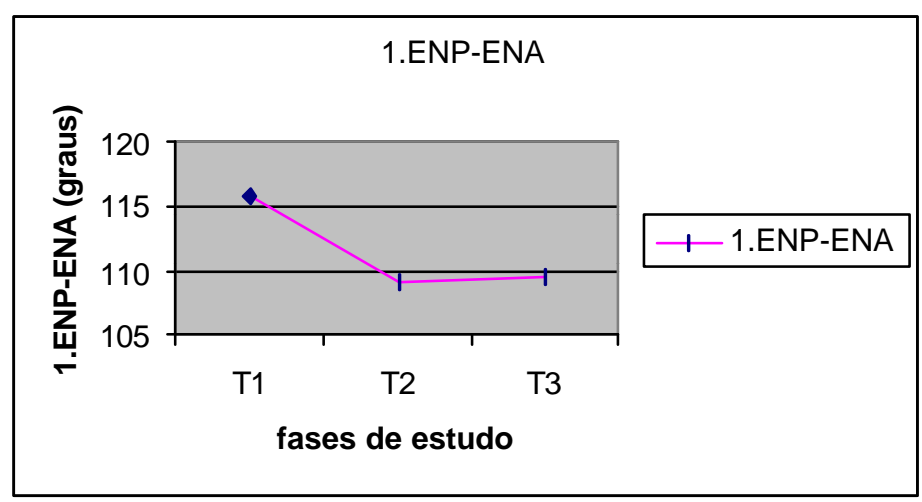

FIGURA 5.26 - Representação Gráfica - 1.ENP-ENA

Medida angular 1.ENP-ENA:

de $T_{1}$ para $T_{2} \rightarrow$ diminuição significante

de $T_{2}$ para $T_{3} \rightarrow$ suave incremento não significante 
TABELA 5.27 - Análise de Variância a um critério - IMPA

\begin{tabular}{ccccccc}
\hline \multicolumn{7}{c}{ IMPA } \\
Efeito & $\begin{array}{c}\text { G.L. } \\
\text { Efeito }\end{array}$ & $\begin{array}{c}\text { Q.M. } \\
\text { Efeito }\end{array}$ & $\begin{array}{c}\text { G.L. } \\
\text { Erro }\end{array}$ & $\begin{array}{c}\text { Q.M. } \\
\text { Erro }\end{array}$ & F & p \\
& $2^{*}$ & $189,827^{*}$ & $52^{*}$ & $17,122^{*}$ & $11,087^{*}$ & $0,000^{*}$ \\
\hline
\end{tabular}

TABELA 5.28 - Teste de Tukey - IMPA

\begin{tabular}{|cccc|}
\hline & \multicolumn{3}{c|}{ IMPA } \\
\hline IMPA & $\mathrm{T}_{1}$ & $\mathrm{~T}_{2}$ & $\mathrm{~T}_{3}$ \\
& 96,667 & 91,481 & 93,111 \\
$\mathrm{~T}_{1}$ & & $0,000^{*}$ & $0,007^{*}$ \\
$\mathrm{~T}_{2}$ & $0,000^{*}$ & & 0,325 \\
$\mathrm{~T}_{3}$ & $0,007^{*}$ & 0,325 & \\
\hline
\end{tabular}

* diferença estatisticamente significante



FIGURA 5.29 - Representação Gráfica - IMPA

Medida angular 1.Go-Me:

de $T_{1}$ para $T_{2} \rightarrow$ diminuição significante

de $T_{2}$ para $T_{3} \rightarrow$ incremento não significante 
TABELA 5.30 - Análise de Variância a um critério - 1.1

\begin{tabular}{ccccccc}
\hline & \multicolumn{7}{c}{1.1} \\
Efeito & $\begin{array}{c}\text { G.L. } \\
\text { Efeito }\end{array}$ & $\begin{array}{c}\text { Q.M. } \\
\text { Efeito }\end{array}$ & $\begin{array}{c}\text { G.L. } \\
\text { Erro }\end{array}$ & $\begin{array}{c}\text { Q.M. } \\
\text { Erro }\end{array}$ & F & p \\
& $2^{*}$ & $1212,494^{*}$ & $52^{*}$ & $81,994^{*}$ & $14,788^{*}$ & $0,000^{*}$ \\
& & & & & & \\
\hline
\end{tabular}

TABELA 5.31 - Teste de Tukey - 1.1

\begin{tabular}{|c|c|c|c|}
\hline & \multicolumn{3}{|c|}{1.1} \\
\hline 1.1 & $\begin{array}{c}\mathrm{T}_{1} \\
119,482\end{array}$ & $\begin{array}{c}\overline{\mathbf{T}}_{2} \\
131,407\end{array}$ & $\begin{array}{c}T_{3} \\
130,741\end{array}$ \\
\hline $\mathbf{T}_{1}$ & & $0,000^{*}$ & $0,000^{*}$ \\
\hline $\mathrm{T}_{2}$ & $0,000^{*}$ & & 0,961 \\
\hline $\mathbf{T}_{3}$ & $0,000^{*}$ & 0,961 & \\
\hline
\end{tabular}

* diferença estatisticamente significante $(p<0,05)$

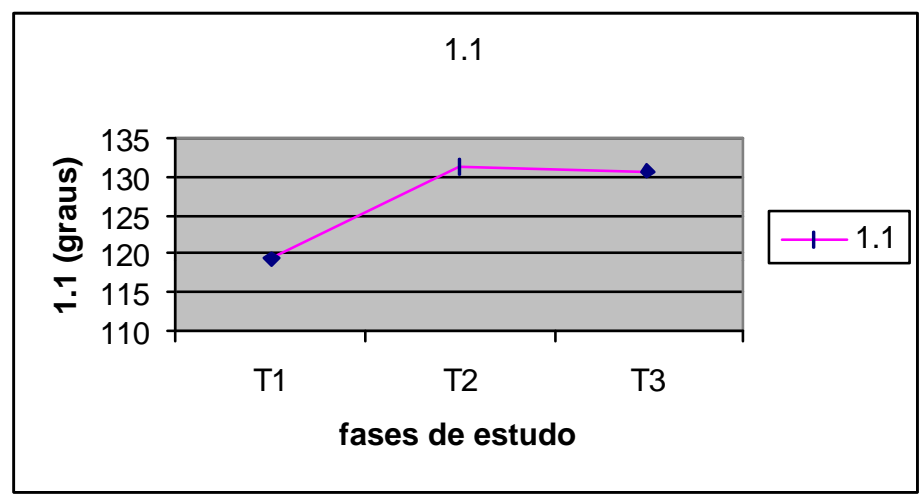

FIGURA 5.32 - Representação Gráfica - 1.1

Medida angular 1.1:

de $T_{1}$ para $T_{2} \rightarrow$ incremento significante

de $T_{2}$ para $T_{3} \rightarrow$ suave diminuição não significante 
TABELA 5.33 - Coeficiente de correlação de Pearson

\begin{tabular}{|c|c|c|c|}
\hline & $1.1-T_{1}$ & $1.1-T_{2}$ & $1.1-\mathrm{T}_{3}$ \\
\hline SNA $-\mathrm{T}_{1}$ & 0,005 & & \\
\hline SNA $-T_{2}$ & & $-0,233$ & \\
\hline SNA $-T_{3}$ & & & $-0,022$ \\
\hline SNB $-\mathrm{T}_{1}$ & 0,199 & & \\
\hline SNB $-T_{2}$ & & $-0,412^{*}$ & \\
\hline SNB $-T_{3}$ & & & $-0,053$ \\
\hline ANB $-T_{1}$ & $-0,290$ & & \\
\hline ANB $-T_{2}$ & & 0,315 & \\
\hline ANB $-T_{3}$ & & & 0,049 \\
\hline 1.NA $-\mathrm{T}_{1}$ & $-0,850^{\star}$ & & \\
\hline 1.NA $-\mathrm{T}_{2}$ & & $-0,776^{*}$ & \\
\hline 1.NA $-\mathrm{T}_{3}$ & & & $-0,730^{*}$ \\
\hline 1-NA - $\mathrm{T}_{1}$ & $-0,748^{\star}$ & & \\
\hline 1-NA - $\mathrm{T}_{2}$ & & $-0,657^{*}$ & \\
\hline 1-NA $-\mathrm{T}_{3}$ & & & $-0,602^{*}$ \\
\hline 1.NB $-\mathrm{T}_{1}$ & $-0,708^{\star}$ & & \\
\hline 1.NB $-\mathrm{T}_{2}$ & & $-0,552^{*}$ & \\
\hline 1.NB $-\mathrm{T}_{3}$ & & & $-0,596^{*}$ \\
\hline $1-N B-T_{1}$ & $-0,716^{*}$ & & \\
\hline $1-N B-T_{2}$ & & $-0,124$ & \\
\hline $1-N B-T_{3}$ & & & $-0,520$ * \\
\hline 1.ENP-ENA - ${ }_{1}$ & $-0,860^{\star}$ & & \\
\hline 1.ENP-ENA - $T_{2}$ & & $-0,695^{*}$ & \\
\hline 1.ENP-ENA $-\mathrm{T}_{3}$ & & & $-0,652^{*}$ \\
\hline IMPA - $T_{1}$ & $-0,278$ & & \\
\hline IMPA $-\mathrm{T}_{2}$ & & $-0,419^{*}$ & \\
\hline IMPA $-T_{3}$ & & & 0,016 \\
\hline
\end{tabular}

* diferença estatisticamente significante $(p<0,05)$ 


\section{Análise estatística para a diferença entre os gêneros}

As tabelas irão apresentar os valores numéricos do grupo feminino e do masculino para cada variável cefalométrica nas diferentes fases de estudo na seguinte ordem: médias do grupo feminino; médias do grupo masculino; valores de t; valores de $\mathrm{p}$; desvios padrão do grupo feminino e desvios padrão do grupo masculino (Tabela 5.34).

TABELA 5.34 - Médias, desvios padrão, valores de t e p para os gêneros nas diferentes fases de estudo

\begin{tabular}{|c|c|c|c|c|c|c|}
\hline & $\begin{array}{c}\text { X } \\
\text { Fem. }\end{array}$ & $\begin{array}{c}\text { X } \\
\text { Mas. }\end{array}$ & $t$ & $p$ & $\begin{array}{l}\text { D.P. } \\
\text { Fem. }\end{array}$ & $\begin{array}{l}\text { D.P. } \\
\text { Mas. }\end{array}$ \\
\hline SNA $-T_{1}$ & 81,846 & 82,286 & $-0,320$ & 0,752 & 3,387 & 3,730 \\
\hline $\mathrm{SNA}-\mathrm{T}_{2}$ & 80,000 & 80,071 & $-0,049$ & 0,961 & 4,416 & 3,075 \\
\hline $\mathrm{SNA}-\mathrm{T}_{3}$ & 80,539 & 80,357 & 0,112 & 0,911 & 4,807 & 3,522 \\
\hline SNB $-T_{1}$ & 75,077 & 75,786 & $-0,580$ & 0,567 & 3,353 & 2,992 \\
\hline $\mathrm{SNB}-\mathrm{T}_{2}$ & 73,923 & 75,357 & $-1,015$ & 0,320 & 4,153 & 3,153 \\
\hline $\mathrm{SNB}-\mathrm{T}_{3}$ & 74,154 & 76,071 & $-1,276$ & 0,214 & 4,562 & 3,174 \\
\hline ANB $-T_{1}$ & 6,769 & 6,500 & 0,331 & 0,744 & 1,301 & 2,653 \\
\hline ANB - $T_{2}$ & 6,077 & 4,714 & 1,789 & 0,086 & 1,754 & 2,164 \\
\hline ANB $-T_{3}$ & $6,385^{*}$ & $4,286^{*}$ & $2,428^{*}$ & $0,023^{*}$ & $1,805^{\star}$ & $2,585^{\star}$ \\
\hline 1.NA $-\mathrm{T}_{1}$ & 25,692 & 24,000 & 0,474 & 0,640 & 7,341 & 10,756 \\
\hline 1.NA - $\mathrm{T}_{2}$ & 17,539 & 19,929 & $-0,854$ & 0,401 & 6,385 & 7,995 \\
\hline 1. $\mathrm{NA}-\mathrm{T}_{3}$ & 18,539 & 19,714 & $-0,370$ & 0,715 & 5,782 & 10,003 \\
\hline$\overline{1}-\mathrm{NA}-\mathrm{T}_{1}$ & 6,154 & 5,643 & 0,483 & 0,634 & 2,076 & 3,249 \\
\hline 1-NA - ${ }_{2}$ & 2,154 & 2,214 & $-0,072$ & 0,943 & 1,772 & 2,517 \\
\hline $1-\mathrm{NA}-\mathrm{T}_{3}$ & 2,615 & 2,786 & $-0,158$ & 0,876 & 1,938 & 3,401 \\
\hline$\overline{1} . \mathrm{NB}-\mathrm{T}_{1}$ & 30,154 & 28,571 & 0,685 & 0,500 & 5,178 & 6,665 \\
\hline 1. $\mathrm{NB}-\mathrm{T}_{2}$ & 25,923 & 23,500 & 1,685 & 0,104 & 2,900 & 4,363 \\
\hline 1. $\mathrm{NB}-\mathrm{T}_{3}$ & $27,769^{*}$ & $23,143^{*}$ & $3,089^{*}$ & $0,005^{*}$ & $3,086^{*}$ & $4,504^{*}$ \\
\hline $1-N B-T_{1}$ & 7,692 & 7,714 & $-0,026$ & 0,980 & 1,888 & 2,494 \\
\hline $1-\mathrm{NB}-\mathrm{T}_{2}$ & 6,462 & 5,714 & 1,058 & 0,300 & 1,898 & 1,773 \\
\hline $1-\mathrm{NB}-\mathrm{T}_{3}$ & 6,846 & 5,429 & 1,907 & 0,068 & 1,864 & 1,989 \\
\hline 1.ENP -ENA - $T_{1}$ & 116,539 & 115,000 & 0,424 & 0,675 & 6,293 & 11,576 \\
\hline 1.ENP -ENA - T 2 & 107,615 & 110,643 & $-1,076$ & 0,292 & 7,101 & 7,490 \\
\hline 1.ENP -ENA - T 3 & 108,615 & 110,286 & $-0,576$ & 0,570 & 5,485 & 9,008 \\
\hline IMPA $-T_{1}$ & 95,077 & 98,143 & $-1,270$ & 0,216 & 5,057 & 7,210 \\
\hline IMPA $-T_{2}$ & 90,846 & 92,071 & $-0,439$ & 0,665 & 5,535 & 8,535 \\
\hline IMPA $-T_{3}$ & 92,769 & 93,429 & $-0,301$ & 0,766 & 3,166 & 7,282 \\
\hline $1.1-\mathrm{T}_{1}$ & 118,000 & 120,857 & $-0,583$ & 0,565 & 8,784 & 15,501 \\
\hline$\overline{1} .1-T_{2}$ & 130,846 & 131,929 & $-0,373$ & 0,712 & 7,883 & 7,195 \\
\hline$\overline{1.1}-\mathrm{T}_{3}$ & 128,231 & 133,071 & $-1,533$ & 0,138 & 7,259 & 8,974 \\
\hline
\end{tabular}

* diferença estatisticamente significante $(p<0,05)$ 
No período pós-tratamento $\left(T_{3}\right)$, os valores médios de ANB e $\overline{1}$.NB mostram -se diferentes estatisticamente significantes entre os gêneros, com valores maiores para o grupo feminino (Figuras 5.35, 5.36).

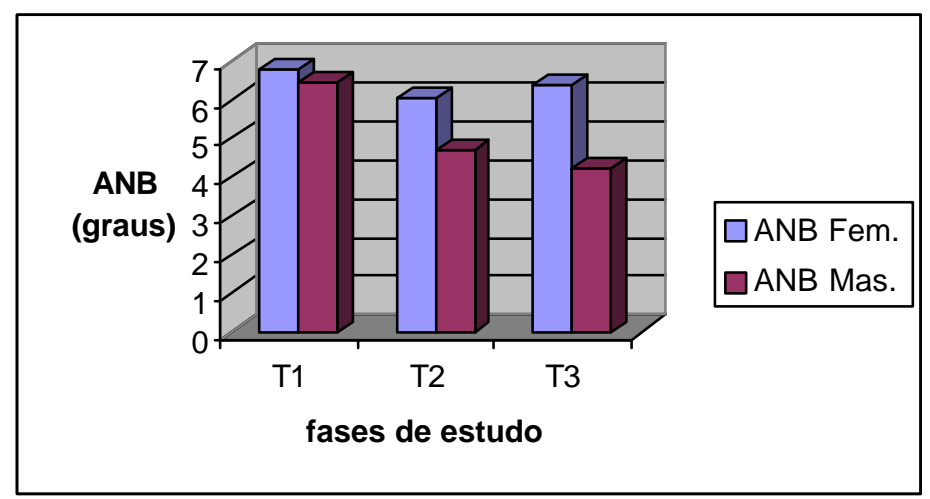

FIGURA 5.35 - Representação gráfica do ângulo ANB, na fase $T_{3}$, para os gêneros masculino e feminino

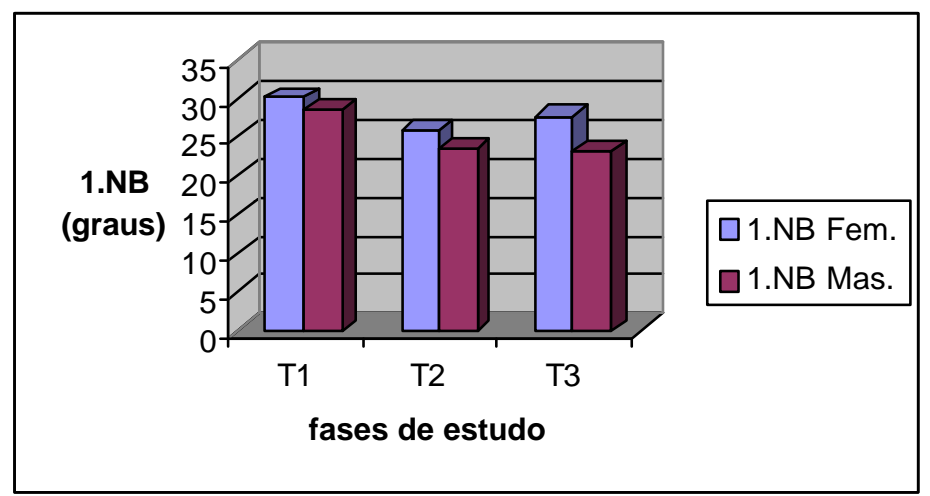

FIGURA 5.36 - Representação gráfica do ângulo $\overline{1}$.NB, na fase $T_{3}$, para os gêneros masculino e feminino

Apresentam-se maiores as magnitudes das colunas para o gênero feminino em ambos os gráficos. 


\section{ERRO SISTEMÁTICO}

TABELA 5.37 - Erros sistemáticos das grandezas cefalométricas

\begin{tabular}{|c|c|c|c|c|}
\hline Variável & $\begin{array}{c}\text { Diferença média entre a } 1^{\circ} \mathrm{e} \\
2^{\circ} \text { análise }\end{array}$ & $t$ & $p$ & \\
\hline SNA $-\mathrm{T}_{1}$ & 0,000 & 0,000 & 1,000 & ns \\
\hline SNA $-T_{2}$ & $-0,000$ & $-0,000$ & 1,000 & ns \\
\hline $\mathrm{SNA}-\mathrm{T}_{3}$ & 0,200 & 0,802 & 0,443 & ns \\
\hline $\mathrm{SNB}-\mathrm{T}_{1}$ & $-0,100$ & $-0,429$ & 0,678 & ns \\
\hline $\mathrm{SNB}-\mathrm{T}_{2}$ & $-0,500$ & $-2,236$ & 0,052 & ns \\
\hline $\mathrm{SNB}-\mathrm{T}_{3}$ & 0,100 & 0,429 & 0,678 & ns \\
\hline ANB $-T_{1}$ & 0,100 & 0,318 & 0,758 & ns \\
\hline ANB $-T_{2}$ & 0,500 & 2,236 & 0,052 & ns \\
\hline ANB $-T_{3}$ & 0,100 & 0,429 & 0,678 & ns \\
\hline 1. $\mathrm{NA}-\mathrm{T}_{1}$ & $-1,900$ & $-2,141$ & 0,061 & ns \\
\hline 1.NA - ${ }_{2}$ & $-1,100$ & $-2,704$ & 0,025 & * \\
\hline 1. $\mathrm{NA}-\mathrm{T}_{3}$ & $-1,200$ & $-2,571$ & 0,030 & * \\
\hline$\overline{1}-\mathrm{NA}-\mathrm{T}_{1}$ & $-0,000$ & $-0,000$ & 1,000 & ns \\
\hline$\overline{1}-\mathrm{NA}-\mathrm{T}_{2}$ & $-0,700$ & $-2,689$ & 0,024 & * \\
\hline $1-N A-T_{3}$ & $-0,400$ & $-1,500$ & 0,168 & ns \\
\hline 1.NB $-T_{1}$ & $-0,500$ & $-0,668$ & 0,521 & ns \\
\hline 1. $\mathrm{NB}-\mathrm{T}_{2}$ & $-0,200$ & $-0,318$ & 0,758 & ns \\
\hline 1. $\mathrm{NB}-\mathrm{T}_{3}$ & $-0,500$ & $-0,711$ & 0,495 & ns \\
\hline $1-N B-T_{1}$ & 0,000 & 0,000 & 1,000 & ns \\
\hline $1-\mathrm{NB}-\mathrm{T}_{2}$ & 0,200 & 0,802 & 0,443 & ns \\
\hline $1-\mathrm{NB}-\mathrm{T}_{3}$ & 0,100 & 1,000 & 0,343 & ns \\
\hline 1.ENP-ENA - $T_{1}$ & $-1,900$ & $-2,237$ & 0,052 & ns \\
\hline 1.ENP-ENA - T 2 & $-0,500$ & $-0,832$ & 0,427 & ns \\
\hline 1.ENP-ENA - $T_{3}$ & $-1,400$ & $-1,801$ & 0,105 & ns \\
\hline IMPA $-T_{1}$ & $-0,300$ & $-0,276$ & 0,789 & ns \\
\hline IMPA $-T_{2}$ & $-0,400$ & $-0,629$ & 0,545 & ns \\
\hline${\text { IMPA }-T_{3}}$ & $-0,300$ & $-0,367$ & 0,722 & ns \\
\hline $1.1-T_{1}$ & 2,600 & 2,230 & 0,053 & ns \\
\hline$\underline{1} .1-T_{2}$ & 0,600 & 0,919 & 0,382 & ns \\
\hline$\overline{1} .1-T_{3}$ & 2,200 & 1,153 & 0,279 & ns \\
\hline
\end{tabular}


Os dados mostram uma diferença estatisticamente significante entre os valores obtidos da $1^{\underline{a}}$ com a $2^{\underline{a}}$ análise nas fases $T_{2}$ (radiografia final) $\mathrm{e}_{3}$ (radiografia pós-tratamento) para a medida cefalométrica angular 1.NA e na fase $\mathrm{T}_{2}$ (radiografia final) para a medida cefalométrica linear 1-NA (TABELA 5.37).

Mesmo sendo o erro sistemático com média de $-1,1^{\circ}$ para 1.NA na fase $T_{2}$, isto não influencia o resultado final obtido com um decréscimo de $6,037^{\circ}$ de $T_{1}$ para $T_{2}\left(T_{1}=24,815 ; T_{2}=18,778\right)$. Já na fase $T_{3}$, o erro sistemático com média de $1,2^{\circ}$ pode ou não interferir no resultado final de suave incremento de $T_{2}$ para $T_{3}\left(T_{2}=\right.$ 18,$\left.778 ; T_{3}=19,148\right)$. Contudo, mesmo que se altere, o julgamento final não muda, podendo ocorrer no máximo uma constância do ângulo 1.NA de $T_{2}$ para $T_{3}$.

Na fase $T_{2}$, o erro sistemático foi considerado significante de $-0,7 \mathrm{~mm}$ para 1-NA. Como ocorreu um decréscimo desta medida de $3,704 \mathrm{~mm}$ de $T_{1}$ para $T_{2}\left(T_{1}=\right.$ $\left.5,889 \mathrm{~mm} ; \mathrm{T}_{2}=2,185 \mathrm{~mm}\right)$, novamente o erro não influencia o julgamento final. 


\section{ERRO CASUAL}

TABELA 5.38 - Erros casuais das grandezas cefalométricas

\begin{tabular}{|c|c|}
\hline \multicolumn{1}{|c|}{ SNA } & 0,632 \\
SNB & 0,532 \\
ANB & 0,592 \\
1.NA & 1,673 \\
1-NA & 0,695 \\
1.NB & 1,506 \\
1-NB & 0,465 \\
1.ENP-ENA & 1,871 \\
IMPA & 1,853 \\
1.1 & 3,183 \\
\hline
\end{tabular}

Os valores numéricos evidenciam o quanto cada medida cefalométrica pode variar durante a mensuração. Denota-se que as medidas angulares que envolvem o longo eixo dos incisivos apresentam os maiores erros casuais (TABELA 5.38). 


\section{6 - DISCUSSÃO}




\section{DISCUSSÃO}

Alguns dos desafios da ortodontia estão centralizados no alcance do equilíbrio facial e da estabilidade dentária, sendo mais difícil em saná-los em casos onde exista uma pobre orientação entre as bases apicais superior e inferior ${ }^{37}$. Realizam-se as chamadas compensações dentárias, com o auxílio da mecânica ortodôntica, justamente no afã de mascarar esta discrepância esquelética no sentido ântero-posterior, quando se decide em aceitá-la durante o planejamento minucioso ortodôntico. Estas compensações artificiais ${ }^{2,8,17,20,26,28,47,49,68,74,93,95}$ seguem o mesmo raciocínio do mecanismo compensatório dentoalveolar que a própria natureza realiza para se manter uma oclusão considerada satisfatória ${ }^{6,9,10,11,57,67,75,76,94}$.

A quantidade de compensação, porém, não influencia somente a correção oclusal como também a estabilidade pós-tratamento ${ }^{55}$. A inclinação axial dos dentes ântero-superiores e principalmente dos dentes ântero-inferiores merecem atenção ímpar no diagnóstico e planejamento dos casos, pois sabe-se que não se pode movimentá-los arbitrariamente durante a terapia desrespeitando as características ambientais $^{12,16,58,59,84,85,86,97}$.

A efetuação desta pesquisa foi designada para verificar as mudanças esqueléticas e a quantidade de movimento de corpo e de inclinação no sentido vestibulolingual dos incisivos ocorrida entre as fases inicial e final do tratamento e relacioná-las às possíveis mudanças pós-tratamento que pudessem interferir no sucesso ortodôntico a longo prazo. O ângulo avaliado principalmente, entre outros, 
foi o ângulo interincisivos por indicar a inclinação axial dos dentes em questão e a relação existente entre os arcos dentoalveolares superior e inferior.

A discussão seguinte apresentar-se-á da seguinte forma: com referência à metodologia empregada, aos resultados obtidos e uma discussão geral.

\section{1 - DISCUSSÃO DO MATERIAL E MÉTODOS}

Os requisitos propostos para a seleção da amostra desta pesquisa (tratamento ortodôntico fixo com a técnica Edgewise, extrações dos primeiros prémolares superiores e inferiores, ângulo ANB maior que 4ํㅜ, más oclusões Classes I ou II de Angle e telerradiografias obtidas no início, no final e cinco anos após a finalização terapêutica) foram praticamente similares aos propostos nos trabalhos de COLE ${ }^{20}$, LENZ; WOODS ${ }^{47}$, LITOWITZ49, ROSSOUW; PRESTON; LOMBARD; TRUTER $^{68}$, SHIELDS; LITTLE; $\mathrm{CHAPKO}^{74}$, VILELLA; MUCHA ${ }^{95}$. Avaliaram-se as pastas de documentações ortodônticas pertencentes à Disciplina de Ortodontia da Faculdade de Odontologia de Bauru - USP, sendo que apenas 27 pacientes se enquadraram nestas características. De acordo com $\mathrm{HIXON}^{\beta 6}$, o tamanho da amostra pode ser considerado uma restrição quando da utilização de normas para a população em geral. Com menos de 50 casos avaliados há pouca chance de se obter casos não tão freqüentes. 
O porquê destes requisitos:

1. Técnica Edgewise $\rightarrow$ o braquete desta técnica utiliza o fio retangular que permite todos as movimentos, inclusive o de torque (movimento no sentido vestibulolingual) ${ }^{78}$.

2. Extrações dentárias dos primeiros pré-molares superiores e inferiores $\rightarrow$ favorecem a inclinação axial dos incisivos, bem como contribuem para a estabilidade do resultado final ${ }^{14,33,85,86,99}$.

3. Ângulo ANB maior que $4^{\circ} \rightarrow$ o grau de compensação dentária é maior para o disfarce da discrepância esquelética²1.

4. Más oclusões Classes I ou II de Angle $\rightarrow$ são as más oclusões mais freqüentes na população.

5. Radiografias nas fases inicial, final e cinco anos após $\rightarrow$ avalia-se a quantidade das mudanças ocorridas entre as fases inicial e final e depois relaciona-se com as ocorridas entre as fases final e cinco anos após para prever a recidiva e a estabilidade de um caso ortodôntico ${ }^{26}$. A determinação dos cinco anos de período pós-tratamento, de acordo com SCHWARTZ ${ }^{73}$, possibilita verificar as possíveis tendências de recidiva a longo prazo. 
O método manual de análise cefalométrica foi de preferência do examinador. Realizou-se o erro metodológico justam ente para proporcionar maior confiabilidade dos resultados obtidos, pois sabe-se da existência de variáveis que podem interferir na realização dos cefalogramas ${ }^{4,5}$.

As medidas cefalométricas utilizadas:

- $\quad$ SNA $\rightarrow$ medida angular da posição relativa no sentido ânteroposterior da maxila em relação à base craniana ${ }^{66}$.

- $\quad$ SNB $\rightarrow$ medida angular da posição relativa no sentido ânteroposterior da mandíbula em relação à base craniana ${ }^{66}$.

- $\quad$ ANB $\rightarrow$ relação angular no sentido ântero-posterior entre os pontos $A$ (na maxila) e B (na mandíbula) ${ }^{66}$.

- $\quad$ 1.NA $\rightarrow$ medida angular da inclinação do incisivo superior em relação à linha $N A^{79}$.

- $\quad$ 1-NA $\rightarrow$ medida linear do grau de protrusão do incisivo superior em relação à linha $N A^{79}$.

- $\quad \overline{1}$.NB $\rightarrow$ medida angular da inclinação do incisivo inferior em relação à linha $N B^{79}$. 
- $\quad \overline{1}-\mathrm{NB} \rightarrow$ medida linear do grau de protrusão do incisivo inferior em relação à linha $\mathrm{NB}^{79}$.

As linhas NA e NB são utilizadas vastamente nas análises pela facilidade em localizá-las nas telerradiografias, além de oferecerem meios de medir angular e linearmente seus respectivos incisivos ${ }^{37}$. Segundo GRABER $^{30}$, as inclinações axiais dos incisivos variam com o grau de protrusão ou retrusão dos maxilares. A morfologia esquelética afeta consideravelmente as inclinações e as posições dentárias.

Os pontos A e B são passíveis de alterações com o crescimento, bem como, com a utilização dos aparelhos ortodônticos ${ }^{41,45,62,79,80}$; tanto quanto, o ângulo ANB, de acordo com JÄRVINEN ${ }^{42}$ e SCHUDY $^{70}$, não se diz ser um ângulo totalmente confiável pela sua variabilidade entre os casos analisados. Por isso, há necessidade de cautela na interpretação dos dados obtidos provenientes das análises.

Segundo RICKETTS ${ }^{63}$, as medidas 1.NA, 1-NA, $\overline{1}$.NB e $\overline{1}-\mathrm{NB}$ não consideram a configuração facial nem a idade do paciente, questionando seus empregos no diagnóstico e planejamento ortodôntico. A linha APog serviria adequadamente a estes propósitos. 
- 1.ENP-ENA $\rightarrow$ medida angular da inclinação do inc isivo superior em relação ao plano palatino.

Considera-se o plano palatino como um dos planos que, com o crescimento, muito pouco ou nada muda sua angulação em relação aos planos cranianos $^{69}$.

- $\quad \overline{1}$.GoMe (IMPA) $\rightarrow$ medida angular da inclinação do incisivo inferior em relação ao plano mandibular ${ }^{24,39}$.

A relação existente entre a inclinação axial do incisivo inferior e o ângulo formado pelo plano mandibular e o longo eixo do dente em questão, julga-se ser um dos mais acurados guias para o tratamento das más oclusões $31,48,51,87,88,89,90,91,92$. Porém, existem trabalhos ${ }^{25,64,70}$ que relatam certas controvérsias em relação ao uso deste ângulo por haver diferenças quanto ao método de localização do plano mandibular e por este ser passível à remodel ação pelo crescimento.

- $1 . \overline{1} \rightarrow$ medida do ângulo formado pelas inclinações dos incisivos superiores e inferiores.

Esta medida representa o grau de inclinação dos incisivos ${ }^{24}$, relaciona-se intimamente ao fenômeno da sobremordida ${ }^{71}$ e reflete a magnitude das alterações ocorridas nas inclinações axiais dos dentes anteriores provenientes da mecânica ortodôntica ${ }^{30}$. 


\section{2 - DISCUSSÃO DOS RESULTADOS}

\section{Medida Angular SNA}

Na Análise de Variância, verificase que o ângulo SNA se altera estatisticamente de modo significante entre as fases de estudo. Pelo Teste de Tukey, denota-se que as diferenças são de $T_{1}$ para $T_{2}$ e de $T_{1}$ para $T_{3}$. Os valores médios ( $\left.T_{1}=82,074^{\circ} ; T_{2}=80,037^{\circ} ; T_{3}=80,444^{\circ}\right)$ mostram uma diminuição especificamente de $T_{1}$ para $T_{2}$.

A maxila apresenta uma tendência em tornar-se mais protruída com o crescimento, como observado nos trabalhos de LANDE ${ }^{45}$, MARTINS; JANSON; ALMEIDA; PINZAN; HENRIQUES; FREITAS ${ }^{52}$, MILLS $^{53}$ e de RIEDEL ${ }^{66}$. Porém, com

a intervenção ortodôntica no tempo certo ${ }^{41,62,80}$, as diferenças entre as bases apicais podem ser reduzidas ao normal, ou próximas do normal, na maioria dos casos. Para a execução deste objetivo, deve-se assegurar ou uma redução do ângulo SNA ou um aumento no ângulo SNB em quantidades suficientes durante o período de tratamento, e na supervisão durante o período pós-tratamento, influenciando deste modo, o padrão original de crescimento. Para HOLDAWAY ${ }^{37}$, a maior mudança angular na reorientação das bases apicais concentra-se no ângulo SNA onde ocorre uma combinação da inibição do crescimento alveolar maxilar e uma mudança verdadeira no ponto A pela retração dos incisivos superiores. 


\section{Medida Angular SNB}

$\mathrm{Na}$ Análise de Variância, verificase que o ângulo SNB se altera estatisticamente de modo significante entre as fases de estudo. Pelo Teste de Tukey, denota-se que a diferença é de $T_{1}$ para $T_{2}$ ocorrendo uma diminuição dos valores médios $\left(T_{1}=75,444^{\circ} ; T_{2}=74,667^{\circ} ; T_{3}=75,148^{\circ}\right)$. De $T_{1}$ para $T_{3}$, e de $T_{2}$ para $T_{3}$ não houve diferenças significantes.

A mandíbula se torna menos retruída com o crescimento, como observado nos trabalhos de BJÖRK; PALLING ${ }^{10}$, LANDE ${ }^{45}$, MARTINS; JANSON; ALMEIDA; PINZAN; HENRIQUES; FREITAS ${ }^{52}$, MILLS $^{53}$ e de RIEDEL ${ }^{66}$, em que nos casos de grande discrepância entre as bases apicais isto seria des ejável. Contudo, observou-se que o crescimento mandibular nos pacientes desta amostra, de acordo com os valores médios, não foi o ideal. Além do mais, como a localização do ponto $B$ é passível à remodelação, o emprego do aparelho ortodôntico possibilita, de certa forma, a manutenção, o aumento ou a redução deste ângulo ${ }^{37,80,100}$ de acordo com o tipo de movimento que os incisivos inferiores realizam, seja de lingualização, vestibularização ou permanência da mesma posição $\left(T_{1}=75,444^{\circ}\right.$; $\left.\quad{ }_{2}=74,667^{\circ}\right)$. Os estudos de crescimento invariavelmente também relatam que o crescimento facial tardio está associado com um aumento relativo do prognatismo alveolar ${ }^{28}\left(\mathrm{~T}_{3}=\right.$ $\left.75,148^{\circ}\right)$. 


\section{Medida Angular ANB}

$\mathrm{Na}$ Análise de Variância, verificase que o ângulo ANB se altera estatisticamente de modo significante entre as fases de estudo. Pelo Teste de Tukey, denota-se que as diferenças são de $T_{1}$ para $T_{2}$ e de $T_{1}$ para $T_{3}$. Os valores médios $\left(T_{1}=6,630^{\circ} ; T_{2}=5,370^{\circ} ; T_{3}=5,296^{\circ}\right)$ mostram uma diminuição especificamente de $T_{1}$ para $T_{2}$.

Pela ação direta do movimento de torque sobre os incisivos superiores e pelo crescimento ativo presente no osso mandibular, boas reduções poderiam ocorrer, em quase todos os casos, do ângulo ANB. Porém, com a falta de crescimento mandibular presente nestes casos, não houve grandes reduções deste ângulo. Adicionalmente, a mecânica ortodôntica aplicada no arco inferior lingualizou e retraiu os incisivos inferiores, influenciando, de certo modo, a localização do ponto B, distalizando- $0^{23,37,52}$.

\section{Medida Angular 1.NA}

$\mathrm{Na}$ Análise de Variância, verifica-se que o ângulo 1.NA se altera estatisticamente de modo significante entre as fases de estudo. Pelo Teste de Tukey, denota-se que as diferenças são de $T_{1}$ para $T_{2}$ e de $T_{1}$ para $T_{3}$. Os valores médios ( $\left.T_{1}=24,815^{\circ} ; T_{2}=18,778^{\circ} ; T_{3}=19,148^{\circ}\right)$ mostram uma diminuição especificamente de $T_{1}$ para $T_{2}$. 
A lingualização dos incisivos superiores de $T_{1}$ para $T_{2}$ em média de 6,037ํㅜ realmente seguiu os parâmetros propostos pela Análise de STEINER ${ }^{34,75,81,82,83}$, que em ângulos ANB de $5^{\circ}\left(T_{2}=5,370^{\circ}\right)$ os dentes ânterosuperiores deveriam estar inclinados em $19^{\circ}\left(T_{2}=18,778^{\circ}\right)$. Isto mostra eficazmente a necessidade de se compensar as inclinações destes dentes nos casos ortodônticos com grandes discrepâncias esqueléticas, devido à falta de crescimento mandibular. Foram os incisivos superiores os mais movimentados durante a terapêutica.

\section{Medida Linear 1-NA}

Na Análise de Variância, verifica-se que a medida 1-NA se altera estatisticamente de modo significante entre as fases de estudo. Pelo Teste de Tukey, denota-se que as diferenças são de $T_{1}$ para $T_{2}$ e de $T_{1}$ para $T_{3}$. Os valores médios ( $\left.T_{1}=5,889 \mathrm{~mm} ; T_{2}=2,185 \mathrm{~mm} ; T_{3}=2,704 \mathrm{~mm}\right)$ mostram uma diminuição especificamente de $T_{1}$ para $T_{2}$.

A grande discrepância entre os ossos maxila e mandíbula, no sentido sagital, é acompanhada por pequena distância linear do ponto mais anterior da face vestibular da coroa do incisivo superior à linha NA. Observa-se realmente uma grande diminuição em média de $T_{1}$ para $T_{2}$ de $3,704 \mathrm{~mm}$, concordando com o raciocínio empregado por STEINER ${ }^{34,75,81,82,83}$ em sua análise, dizendo que quando o ângulo ANB for = 5ํㅗ a distância linear deve ser em média $1 \mathrm{~mm}$. 


\section{Medida Angular 1.NB}

$\mathrm{Na}$ Análise de Variância, verifica-se que o ângulo $\overline{1}$.NB se altera estatisticamente de modo significante entre as fases de estudo. Pelo Teste de Tukey, denota-se que as diferenças são de $T_{1}$ para $T_{2}$ e de $T_{1}$ para $T_{3}$. Os valores médios $\left(T_{1}=29,333^{\circ} ; T_{2}=24,667^{\circ} ; T_{3}=25,370^{\circ}\right)$ mostram uma diminuição especificamente de $\mathrm{T}_{1}$ para $\mathrm{T}_{2}$.

O valor de $\overline{1} . \mathrm{NB}$, em $\mathrm{T}_{2}$, para o ângulo $\mathrm{ANB}$ de 5,370ํㅡ, não concorda, de certa forma, com o valor preconizado da tabela de compromissos aceitáveis da Análise de STEINER ${ }^{21,75,81,82,83}$, pois em ângulos ANB de $5^{\circ}$, o incisivo inferior deveria estar vestibularizado em $28^{\circ}$ em relação à linha NB. Contudo, esta análise não diz respeito exatamente à causa do problema, seja ele na maxila, na mandíbula ou em ambas. Nos casos deste estudo, estabeleceu-se que para a correção destas más oclusões pela falta de crescimento mandibular principalmente, seria apropriado a movimentação para lingual dos incisivos inferiores. De $T_{1}$ para $T_{2}$ ocorreu uma diminuição em média do valor de $\overline{1}$.NB de 4,666으, denotando a lingualização destes dentes.

\section{Medida Linear 1-NB}

Na Análise de Variância, verificase que a medida $\overline{1}-\mathrm{NB}$ se altera estatisticamente de modo significante entre as fases de estudo. Pelo Teste de Tukey, denota-se que as diferenças são de $T_{1}$ para $T_{2}$ e de $T_{1}$ para $T_{3}$. Os valores 
médios ( $\left.T_{1}=7,704 \mathrm{~mm} ; T_{2}=6,074 \mathrm{~mm} ; T_{3}=6,111 \mathrm{~mm}\right)$ mostram uma diminuição especificamente de $T_{1}$ para $T_{2}$.

De $T_{1}$ para $T_{2}$ ocorreu uma diminuição em média desta medida de $1.63 \mathrm{~mm}$. De acordo com os valores da tabela de compromissos de STEINER ${ }^{75,81,82,83}$, para o ângulo ANB de $5^{\circ}, \overline{1}-\mathrm{NB}$ deveria ser $4.75 \mathrm{~mm}$, o que difere do valor de $6.074 \mathrm{~mm}$ evidenciando a protrusão dos incisivos inferiores. Porém, de acordo com o trabalho de HASUND; ULSTEIN ${ }^{34}$ quando se analisa a medida linear $\overline{1}$-NB deve-se levar em consideração o tipo de crescimento facial, de tal modo que quando aumentado, a distância do incisivo inferior à linha NB se torna maior do que os valores padrão de STEINER ${ }^{75,81,82,83}$, e vice-versa. Como o padrão de crescimento no sentido vertical foi predominante nesta amostra, obtida esta informação das pastas de documentações, o valor de $\overline{1}$-NB em $T_{2}$ se torna aceitável.

\section{Medida Angular 1.ENP-ENA}

Na Análise de Variância, verifica-se que o ângulo 1.ENP-ENA se altera estatisticamente de modo significante entre as fases de estudo. Pelo Teste de Tukey, denota-se que as diferenças são de $T_{1}$ para $T_{2}$ e de $T_{1}$ para $T_{3}$. Os valores médios $\left(T_{1}=115,741^{\circ} ; T_{2}=109,185^{\circ} ; T_{3}=109,482^{\circ}\right)$ mostram uma diminuição especificamente de $T_{1}$ para $T_{2}$.

O ângulo 1.ENP-ENA mostra uma correlação com a medida 1 .NA, pois ambas evidenciam a lingualização ortodôntica dos incisivos superiores, necessária 
para compensar o alto ângulo ANB do final do tratamento. Neste caso, ocorreu uma diminuição em média de $T_{1}$ para $T_{2}$ de $6,556^{\circ}$.

\section{Medida Angular IMPA}

Na Análise de Variância, verifica-se que o ângulo IMPA se altera estatisticamente de modo significante entre as fases de estudo. Pelo Teste de Tukey, denota-se que as diferenças são de $T_{1}$ para $T_{2}$ e de $T_{1}$ para $T_{3}$. Os valores médios $\left(T_{1}=96,667^{\circ} ; T_{2}=91,481^{\circ} ; T_{3}=93,111^{\circ}\right)$ mostram uma diminuição especificamente de $T_{1}$ para $T_{2}$.

Observando a lingualização em média dos incisivos inferiores de $\mathrm{T}_{1}$ para $\mathrm{T}_{2}$ de $5,186^{\circ}$, proporcionando a verticalização destes dentes, isto mostra a tendência em seguir os valores preconizados das Análises de TWEED $27,31,48,87,88,89,91,92$ (IMPA $\left.90^{\circ} \pm 5^{\circ}\right)$ e de MARGOLIS 50,51 (IMPA $-90^{\circ} \pm 3^{\circ}$ ) no planejamento dos casos ortodônticos para promover o alcance da estética facial ${ }^{65,90}$. A realização das extrações dentárias, logicamente, permite uma maior magnitude das mudanças de posição e inclinação dentária ${ }^{44}$, permitindo o estabelecimento de posições mais verticais destes dentes.

O incremento de $T_{2}$ para $T_{3}$ do IMPA, porém não estatisticamente significante, sugere uma leve tendência dos incisivos inferiores em retornarem às angulações que ocupavam antes do início do tratamento, durante o período póstratamento, corroborando os achados de COLE $^{20}$, MILLS $^{53,54}$ e VILELLA; MUCHA ${ }^{95}$. 


\section{Medida Angular 1.1}

$\mathrm{Na}$ Análise de Variância, verificase que o ângulo $1 . \overline{1}$ se altera estatisticamente de modo significante entre as fases de estudo. Pelo Teste de Tukey, denota-se que as diferenças são de $T_{1}$ para $T_{2}$ e de $T_{1}$ para $T_{3}$. Os valores médios $\left(T_{1}=119,482^{\circ} ; T_{2}=131,407^{\circ} ; T_{3}=130,741^{\circ}\right)$ mostram um incremento especificamente de $T_{1}$ para $T_{2}$.

O valor preconizado para o ângulo interincisivos, em oclusões normais, varia de $125^{\circ}$ à $135^{\circ 24,46}$. Esta variação reflete a verticalização dos dentes anteriores com o crescimento, aumentando-o com o passar dos anos ${ }^{52,64}$.

O tratamento ortodôntico influencia em grande magnitude esta grandeza angular em casos de Classe I com protrusão bimaxilar e Classe II, com a realização das extrações dentárias, como resultado da grande lingualização dos incisivos superiores e inferiores durante o período ativo, como relatado por BISHARA; CUMMINS; ZAHER ${ }^{8}$, GRABER $^{30}$, KEATING $^{43}$ e RICHARDSON ${ }^{60}$. De $T_{1}$ para $T_{2}$ ocorreu um aumento em média de 11,925을 permanecendo praticamente inalterado de $T_{2}$ para $T_{3}$ com uma diferença média de $0,666^{\circ}$, mostrando a permanência a longo prazo das compensações dentárias realizadas e dentro dos valores preconizados nas oclusões normais. 


\section{Relação da Medida Angular 1.1 com as demais medidas}

A análise estatística do coeficiente de correlação de Pearson mostrou o relacionamento do ângulo interincisivos com as demais medidas cefalométricas nas três fases de estudo. O sinal negativo dos valores indica uma relação inversa das variáveis em questão, ou seja, quanto maior o ângulo 1.NA em $\mathrm{T}_{1}$ por exemplo, menor se mostra o ângulo 1..1. De acordo com os dados obtidos, o ângulo interincisivos se tornou significantemente mais obtuso durante o período ativo de tratamento como resultado da grande lingualização e retração dos incisivos superiores e inferiores, mostrando realmente a realização das compensações dentárias nos segmentos anteriores dos arcos dentários, justamente pela necessidade de mascarar as discrepâncias esqueléticas no sentido sagital devido à falta de crescimento mandibular principalmente, podendo ser evidenciado nesta análise pelos valores não estatisticamente significantes do ângulo ANB nas três fases de estudo. O ângulo interincisivos, de acordo com esta pesquisa é uma excelente medida para se usar nas análises cefalométricas, no afã de se verificar as compensações dentárias realizadas. Os pacientes, componentes desta amostra, foram tratados ortodonticamente com sucesso no que tange a estabilidade destas medidas pós-tratamento, compensando satisfatoriamente as discrepâncias entre os ossos maxila e mandíbula. Este resultado se identifica com os de BISHARA; CUMMINS; ZAHER ${ }^{8}$, GRABER $^{30}, \mathrm{KEATING}^{43}$ e RICHARDSON ${ }^{00}$. 


\section{3 - DISCUSSÃO GERAL}

Nesta pesquisa, em geral, as mudanças que ocorreram durante o tratamento ativo foram maiores que as do período seguinte. Suave tendência das posições e inclinações axiais dos dentes anteriores em recidivarem para os valores pré-tratamento foi unânime em todas as medidas estudadas, embora estatisticamente não significantes. Contudo, observourse uma grande variação individual. Existiram casos, por exemplo, que os incisivos inferiores foram movimentados num determinado sentido durante a mecânica ortodôntica, que ou ocorreu a continuação dos movimentos neste mesmo sentido, ou os dentes permaneceram estáveis durante o período pós-tratamento. Além do mais, cada paciente apresentou uma combinação de tendências diferentes, não seguindo exatamente a mesma condição para todos. Estas observações também foram descritas nos trabalhos de LENZ; WOODS ${ }^{47}$, SCHAEFFER $^{69}$ e VILELLA; MUCHA ${ }^{95}$.

A variação individual é atribuída a diversos fatores como o padrão de crescimento facial $^{18,75}$, o crescimento pós-tratamento ${ }^{56,61,69,73,75,100,101}$, as forças musculares $^{12,16,58,59,61,68,75,84,85,86,97}$ e as oclusais ${ }^{95}$.

Diagnosticada a grande variabilidade entre os componentes da amostra, realizou-se, também, a análise estatística para verificar possíveis diferenças quanto aos gêneros. Perante os resultados, os valores médios do gênero feminino foram maiores para os ângulos ANB e $\overline{1}$.NB na fase $T_{3}$, que de certa forma concorda com o estudo de BISHARA $^{7}$ ao relatar uma diminuição significante nos ângulos ANB e NAPog nos indivíduos do gênero masculino tratados ortodonticamente. 
De acordo com a metodologia empregada, com os resultados obtidos e com diversos trabalhos anteriores ${ }^{14,16,18,29,36,38,47,69,75,77,101}$ não se deve seguir a risca os valores estabelecidos por várias análises no planejamento dos casos ortodônticos e nem considerar os valores médios, obtidos desta pesquisa por exemplo, como valores absolutos. O paciente deve ser tratado de modo particular, pois cada caso é um caso.

Em relação à recidiva do apinhamento ântero-inferior tardio de casos tratados ortodonticamente, não pode ser correlacionada às variáveis estudadas desta pesquisa, nas diferentes fases de estudo. Esta observação também se assimila aos estudos de EL-MANGOURY ${ }^{26}$, RICHARDSON ${ }^{60}$, SCHULHOF; ALLEN; WALTERS; DRESKIN ${ }^{72}$ e SHIELDS; LITTLE; CHAPKO ${ }^{74}$. A recidiva é um fenômeno de processo lento e de causa multifatorial ${ }^{2,3}$. Cabe ao profissional executar, com os aparelhos ortodônticos, movimentos precisos dos elementos dentários ${ }^{1,98}$, supervisar o período pós-tratamento ${ }^{19,32}$ e tentar individualizar os aparelhos de contenção ${ }^{56}$. 
7 - CONCLUSÕES 


\section{CONCLUSÕES}

Os dados obtidos a partir da metodologia empregada indicaram:

- Todas as medidas cefalométricas se alteraram de modo significativo entre as fases de estudo inicial e final refletindo a influência da mecânica ortodôntica sobre os movimentos dentários;

- Entre as fases de estudo final e cinco anos após, todas as medidas cefalométricas mantiveram-se estáveis;

- No final do tratamento ortodôntico, as compensações dentárias foram obtidas e cinco anos após, permaneceram estáveis. 


\section{REFERÊNCIAS BIBLIOGRÁFICAS}




\section{REFERÊNCIAS BIBLIOGRÁFICAS *}

1. ANDREWS, L.F. The six keys to normal occlusion. Amer. J. Orthodont., v.62, n.3, p.296-309, Sept. 1972.

2. ARTUN, B.J.; GAROL, J.D.; LITTLE, R.M. Long-term stability of mandibular incisors following successful treatment of Class II, division 1, malocclusions. Angle Orthodont., v.66, n.3, p.229-38, 1996.

3. ARTUN, B.J.; KROGSTAD, O.; LITTLE, R.M. Stability of mandibular incisors following excessive proclination: a study in adults with surgically treated mandibular prognathism. Angle Orthodont., v.60, n.2, p.99-106, Summer 1990.

4. BAUMRIND, S.; FRANTZ, R.C. The reliability of head film measurements conventional angular and linear measures. Amer. J. Orthodont., v.60, n.5, p.505-15, Nov. 1971.

5. BAUMRIND, S.; FRANTZ, R.C. The reliability of head film measurements landmark identification. Amer. J. Orthodont., v.60, n.2, p.111-27, Aug. 1971.

6. BETZENBERGER, D.; RUF, S.; PANCHERZ, H. The compensatory mechanism in high-angle malocclusions: a comparison of subjects in the mixed and permanent dentition. Angle Orthodont., v.69, n.1, p.27-32, Feb. 1999.

7. BISHARA, S.E. Mandibular changes in persons with untreated and treated Class II division 1 malocclusion. Amer. J. Orthodont., v.113, n.6, p.661 73, June 1998. 
8. BISHARA, S.E.; CUMMINS, D.M.; ZAHER, A.R. Treatment and posttreatment changes in patients with Class $\mathrm{II}$, division 1 malocclusion after extraction and nonextraction treatment. Amer. J. Orthodont, v.11, n.1, p.18-27, Jan. 1997.

9. BJÖRK, A. Variations in the growth pattern of the human mandible: longitudinal radiographic study by the implant method. J. dent. Res., v.42, n.1, p.400-11, 1963.

10. BJÖRK, A.; PALLING, M. Adolescent age changes in sagittal jaw relation, alveolar prognathy, and incisal inclination. Acta. Odont. Scand., v.12, p.201-32, 1954.

11. BJÖRK, A.; SKIELLER, V. Facial development and tooth eruption - an implant study at the age of puberty. Amer. J. Orthodont., v.62, n.4, p.339-83, Oct. 1972.

12. BRADER, A.C. Dental arch form related with intraoral forces: PR=C. Amer. J. Orthodont. Dentofac. Orthop., v.61, n.6, p.541-61, June 1972.

13. BROADBENT, B.H. A new x-ray technique. Angle Orthodont., v.1, n.2, p.45-66, Apr. 1931.

14. BRODIE, A.G. Does scientific investigation support the extraction of teeth in orthodontic therapy? Amer. J. Orthodont, v.30, n.8, p.444-60, Aug.1944.

15. BRODIE, A.G.; DOWNS, W.B.; GOLDSTEIN, A.; MYER, E. Cephalometric appraisal of orthodontic results. Angle Orthodont., v.8, n.4, p.261-5, 1938. 
16. BUCHNER, H.J. Effect of facial growth upon orthodontic treatment. Angle Orthodont., v.37, n.2, p.59-80, Apr. 1967.

17. CHANG, Y.II.; MOON, S.C. Cephalometric evaluation of the anterior open bite treatment. Amer. J. Orthodont. Dentofac. Orthop., v.115, n.1, p.2938, Jan. 1999.

18. CHRISTIE, T.E. Cephalometric patterns of adults with normal occlusion. Angle Orthodont., v.47, n.2, p.128-35, Apr. 1977.

19. COLE, H.J. Bodily retraction of maxillary incisors in extraction cases. Angle Orthodont., v.35, n.2, p.121-5, Apr. 1965.

20. COLE, H.J. Certain results of extraction in the treatment of malocclusion. Angle Orthodont., v.18, n.3-4, p.103-13, July/Oct. 1948.

21. CORELIUS, M.; LINDER-ARONSON, S. The ralationship between lower incisor inclination and various reference lines. Angle Orthodont., v.46, n.2, p.111-7, Apr. 1976.

22. CORLETT, E.L. Mandibular incisor position relative to basal bone. Amer. J. Orthodont., v.33, n.1, p.21-9, Jan.1947.

23. CRUZ, J.P. O incisivo inferior e a sua relação com a morfologia crânio-facial. Rev. bras. Odont., v.39, n.4, p.42-6, jul./ago. 1982.

24. DOWNS, W.B. Variatons in facial relationships: their significance in treatment and prognosis. Amer. J Orthodont. Dentofac. Orthop., v.34, n.10, p.812-40, Oct. 1948.

25. DOWNS, W.B. The role of cephalometrics in orthodontic case analysis and diagnosis. Amer. J. Orthodont. Dentofac. Orthop., v.38, n.3, p.162-82, Mar. 1952. 
26. EL-MANGOURY, N.H. Orthodontic relapse in subjects with varying degrees of anteroposterior and vertical dysplasia. Amer. J. Orthodont., v.75, n.5, p.548-61, May 1979.

27. FERREIRA, F.V. Ortodontia: diagnóstico e planejamento clínico. 2.ed. São Paulo, Artes Médicas, 1998. 503p.

28. FIDLER, B.C.; ARTUN, J.; JOONDEPH, D.R.; LITTLE, R.M. Long-term stability of Angle Class II, division 1 malocclusions with successful occlusal results at end of active treatment. Amer. J. Orthodont. Dentofac. Orthop., v.107, n.3, p.276-85, Mar. 1995.

29. GOLDSMAN, S. The variations in skeletal and denture patterns in excellent adult facial types. Angle Orthodont., v.29, n.2, p.63-92, Apr. 1959.

30. GRABER, T.M. A critical review of clinical cephalometric radiography. Amer. J. Orthodont. Dentofac. Orthop., v.40, n.1, p.1-26, Jan. 1954.

31. GREENYEIN, A.V. The Tweed philosophy. Amer. J. Orthodont., v.29, n.8, p.527-40, Aug. 1943.

32. GRIEVE, G.W. The stability of the treated denture. Amer. J. Orthodont. Oral Surg., v.30, n.4, p.171-91, Apr. 1944.

33. HAHN, G.W. Orthodontics: its objectives, past and present. Amer. J. Orthodont. Oral Surg., v.30, n.8, p.401-4, Aug. 1944.

34. HASUND, A.; ULSTEIN, G. The position of the incisors in relation to the lines NA e NB in different facial types. Amer. J Orthodont., v.57, n.1, p.1-14, Jan. 1970. 
35. HIGLEY, L.B. Application of cephalometric appraisals to orthodontic diagnosis and treatment. Amer. J. Orthodont, v.37, n.4, p.244-52, Apr. 1951.

36. HIXON, E.H. The norm concept and cephalometrics. Amer. J. Orthodont., v.42, n.12, p.898-906, Dec. 1956.

37. HOLDAWAY, R.A. Changes in relationship of points $A$ and $B$ during orthodontic treatment. Amer. J. Orthodont., v.42, n.1, p.176-93, Jan. 1956.

38. HOPKINS, J.B.; MURPHY, J. Variations in good occlusions. Angle Orthodont., v.41, n.1, p.55-65, Jan. 1971.

39. INTERLANDI, S. Projeção USP na relação cefalométrica maxilamandíbula. In: Ortodontia: bases para a iniciação. 3.ed. São Paulo, Artes Médicas, 1994. p. 255.

40. ISIEKWE, M. A cephalometric study of incisor angulations in a Nigerian population. Brit. J. Orthodont., v.16, n.3, p.177-81, Aug. 1989.

41. JAKOBSSON, S.O. Cephalom etric evaluation of treatment effect on Class II, division 1 malocclusions. Amer. J. Orthodont., v.53, n.6, p.446-57, June 1967.

42. JÄRVINEN, S. An analysis of the variation of the ANB angle: a statistical appraisal. Amer. J. Orthodont., v.87, n.2, p.144-6, Feb. 1985.

43. KEATING, P.J. The treatment of bimaxillary protrusion. Brit. J. Orthodont., v.13, n.4, p.209-20, Oct. 1986. 
44. KUFTINEC, M.M. Effect of edgewise treatment and retention on mandibular incisors. Amer. J. Orthodont., v.68, n.3, p.316-22, Sept. 1975.

45. LANDE, M.J. Growth behavior of the human bony facial profile as revealed by serial cephalometric roentgenology. Angle Orthodont., v.22, n.2, p.78-90, Apr. 1952.

46. LANGLADE, M. A análise dinâmica das arcadas dentárias. In: Diagnóstico ortodôntico. São Paulo, Ed. Santos, 1995. p. 564-7.

47. LENZ, G.J.; WOODS, M.G. Incisal changes and orthodontic stability. Angle Orthodont., v.69, n.5, p.424-32, Oct. 1999.

48. LEWIS, S.J. Treatment of Class II, division 1 malocclusion by means of the edgewise arch mechanism. Amer. J. Orthodont, v.28, n.11, p.689-703, Nov. 1942.

49. LITOWITZ, R. A study of the movements of certain teeth during and following orthodontic treatment. Angle Orthodont., v.18, n.3-4, p.113-32, July/Oct. 1948.

50. MARGOLIS, H.I. A basic pattern and its application in clinical orthodontics. Amer. J. Orthodont. Oral Surg., v.33, n.10, p.631-41, Oct. 1947.

51. MARGOLIS, H.I. The axial inclination of the mandibular incisors. Amer. J. Orthodont., v.29, n.10, p.571-94, Oct. 1943.

52. MARTINS, D.R.; JANSON, G.R.P.; ALMEIDA, R.R.; PINZAN, A.; HENRIQUES, J.F.; FREITAS, M.R. Atlas de crescimento craniofacial. São Paulo, Ed. Santos, 1998. 280p.

53. MILLS, J.R.E. The long-term results of the proclination of lower incisors. Brit. dent. J., v.120, n.8, p.355-63, Apr. 1966. 
54. MILLS, J.R.E. A long-term assessment of the mechanical retroclination of lower incisors. Angle Orthodont., v.37, n.3, p.165-74, July 1967.

55. NANDA, R.; BURSTONE. Retention and stability in orthodontics. Philadelphia, Saunders, 1993. p.21,77,117.

56. NANDA, R.S.; NANDA, S.K. Considerations of dentofacial growth in longterm retention and stability: is active retention needed? Amer. J. Orthodont. Dentofac. Orthop., v.101, n.4, p.297-302, Apr. 1992.

57. NOYES, H.J.; RUSHING, C.H.; SIMS, HA. The angle of axial inclination of human central incisor teeth. Angle Orthodont., v.13, n.3/4, p.60-1, July/Oct. 1943.

58. PROFFIT, W.R. Muscle pressures and tooth position: north american whites and australian aborigines. Angle Orthodont., v.45, n.1, p.1-11, Jan. 1975.

59. PROFFIT, W.R. Equilibrium theory revisited: factors influencing position of the teeth. Angle Orthodont., v.48, n.3, p.175-86, July 1978.

60. RICHARDSON, M.E. Late lower arch crowding - the role of facial morphology. Angle Orthodont., p.244-54, July 1986.

61. RICKETTS, R.M. Planning treatment on the basis of the facial pattern and an estimate of its growth. Angle Orthodont., v.27, n.1, p.14-37, Jan. 1957.

62. RICKETTS, R.M. The influence of orthodontic treatment on facial growth and development. Angle Orthodont., v.30, n.3, p.103-33, July 1960.

63. RICKETTS, R.M. Cephalometric analysis and synthesis. Angle Orthodont., v.31, n.3, p.141-56, July 1961. 
64. RICKETTS, R.M. Perspectives in the clinical application of cephalometrics. Angle Orthodont., v.51, n.2, p.115-50, Apr. 1981.

65. RIEDEL. R.A. Esthetics and its relation on orthodontic therapy. Angle Orthodont., v.20, n.3, p.168-78, July 1950.

66. RIEDEL, R.A. The relation of maxillary structures to cranium in malocclusion and in normal occlusion. Angle Orthodont., v.22, n.3, p.142-5, July 1952.

67. RIEDEL, R.A. An analysis of dentofacial relationships. Amer. J. Orthodont., v.43, n.2, p.103-19, Feb. 1957.

68. ROSSOUW, P.E.; PRESTON, C.B.; LOMBARD, C.J.; TRUTER, J.W. A longitudinal evaluation of the anterior border of the dentition. Amer. J. Orthodont. Dentofac. Orthop., v.104, n.2, p.146-52, Aug. 1993.

69. SCHAEFFER, A. Behavior of the axis of human incisor teeth during growth. Angle Orthodont., v.19, n.4, p.254-75, Oct. 1949.

70. SCHUDY, F.F. Cant of the occlusal plane and axial inclinations of teeth. Angle Orthodont., v.33, n.2, p.69-82, Apr. 1963.

71. SCHUDY, F.F. The control of vertical overbite in clinical orthodontics. Angle Orthodont., v.38, n.1, p.19-39, Jan. 1968.

72. SCHULHOF, R.J.; ALLEN, R.W.; WALTERS, R.D.; DRESKIN, M. The mandibular dental arch: part I, lower incisor position. Angle Orthodont., v.47, n.4, p.280-7, Oct. 1977.

73. SCHWARTZ, H. The field concept in orthodontics. Angle Orthodont., v.30, n.3, p.154-61, July 1960. 
74. SHIELDS, T.E.; LITTLE, R.M.; CHAPKO, M.K. Stability and relapse of mandibular anterior alignment: A cephalometric appraisal of firstpremolar-extraction cases treated by traditional edgewise orthodontics. Amer. J. Orthodont. , v.87, n.1, p.27-38, Jan. 1985.

75. SOLOW, B. The dentoalveolar compensatory mechanism: background and clinical implications. Brit. J. Orthodont., v.7, p.145-61, 1980.

76. SOLOW, B.; TALLGREN, A. Dentoalveolar morphology in relation to craniocervical posture. Angle Orthodont., v.47, n.3, p.157-64, July 1977.

77. SPEIDEL, T.D.; STONER, M.M. Variation of mandibular incisor axis in adult "normal" occlusion. Amer. J. Orthodont., v.30, n.10, p.536-42, Oct. 1944.

78. STEINER, C.C. Is there one best orthodontic appliance? Dent. Cosmos, v.75, p.3-17, Nov. 1933.

79. STEINER, C.C. Cephalometrics for you and me. Amer. J. Orthodont., v.39, n.10, p.729-55, Oct. 1953.

80. STEINER, C.C. Cephalometrics in clinical practice. Angle Orthodont, v.29, n.1, p.8-29, Jan. 1959.

81. STEINER, C.C. Instructions for using cephalometric measurements for treatment planning and assessment, as used in the Steiner analysis. Hawaiian Orthodont. Soc., Apr. 1959.

82. STEINER, C.C. The use of cephalometrics as an aid to planning and assessing orthodontic treatment. Amer. J. Orthodont., v.46, n.10, p.721 35, Oct. 1960. 
83. STEINER, C.C. Cephalometrics as a clinical tool. In: KRAUS, B.S.I.; RIEDEL,R.A. Vistas in Orthodont. Philadelphia, Lea\&Febige, 1962. p.131-61.

84. STEVENS, H.M. The intraoral pressure exerted on the maxillary and mandibular central incisors by the tongue and lips in Angle Class II, Division 1 cases. Amer. J. Orthodont. Dentofac. Orthop., v.42, n.12, p.937-8, Dec. 1956.

85. STRANG, R.H.W. Factors associated with successful orthodontic treatment. Amer. J. Orthodont., v.38, n.8, p.790-800, Aug. 1952.

86. STRANG, R.H.W. Axial inclination of teeth in extraction cases. Angle Orthodont., v.27, n.1, p.11-13, Jan. 1957.

87. TWEED, C.H. Indications for the extraction of teeth in orthodontic procedure. Amer. J. Orthodont. Oral Surg., v.30, n.8, p.405-28, Aug. 1944.

88. TWEED, C.H. A philosophy of orthodontic treatment. Amer. J. Orthodont. Oral Surg., v.31, n.2, p.74-103, Feb. 1945.

89. TWEED, C.H. The Frankfort - mandibular plane angle in orthodontic diagnosis, classification, treatment planning, and prognosis. Amer. J. Orthodont. Oral Surg., v.32, n.4, p.175-221, Apr. 1946.

90. TWEED, C.H. The frankfort - mandibular incisor angle (FMIA) in orthodontic diagnosis, treatment planning and prognosis. Angle Orthodont., v.24, n.3, p.121-69, July 1954.

91. TWEED, C.H. The diagnostic facial triangle. In: Clinical Orthodontics. Saint Louis, Mosby, 1966. p.6-12. 
92. TWEED. C.H. The diagnostic facial triangle in the control of treatment objectives. Amer. J. Orthodont. Dentofac. Orthop., v.55, n.6, p.651-67, June 1969.

93. UHDE, M.D.; SADOWSKY, C.; BEGOLE, E.A. Long-term stability of dental relationships after orthodontic treatment. Angle Orthodont., v.53, n.3, p.240-52, July 1983.

94. VAN DER LINDEN, F.P.G.M. Diferenças na forma e no crescimento facial. In: Crescimento e ortopedia facial. São Paulo, Quintessence, 1990. p. 184-8.

95. VILELLA, O.V.; MUCHA, J.N. Avaliação cefalométrica da estabilidade dos incisivos inferiores pós-contenção ortodôntica. Ortodontia, v.29, n.1, p.48-52, jan./abr. 1996.

96. VION, P.E. Anatomia telerradiográfica em norma lateralis. In: Anatomia cefalométrica. São Paulo, Ed. Santos, 1994. p.5-91.

97. WEINSTEIN, S.; HAACK, D.C.; MORRIS, L.Y.; SNYDER, B.B.; ATTAWAY, H.E. On an equilibrium theory of tooth position. Angle Orthodont., v.33, n.1, p.1-26, Jan. 1963.

98. WILLIAMS, R. Eliminating lower retention. J. Clin. Orthodont., v.19, n.5, p.342-9, May 1985.

99. WILLIAMS, R.; HOSILA, F.J. The effect of different extraction sites upon incisor retraction. Amer. J. Orthodont., v.69, n.4, p.388-410, Apr. 1976.

100. WILLIAMS, S.; ANDERSEN, C.E. Incisor stability in patients with anterior rotational mandibular growth. Angle Orthodont., v.65, n.6, p.431-42, 1995. 
101. WYLIE, W.L. The mandibular incisor - its role in facial esthetics. Angle Orthodont., v.25, n.1, p. 32-41, Jan. 1955. 
ABSTRACT 
FIVE YEARS EVALUATION OF CEPHALOMETRIC MEASUREMENTS IN

PATIENTS THAT DISPLAYED OVER THAN 4 DEGREES ANB ANGLE, TREATED

BY MEANS OF ORTHODONTIC APPLIANCES AND THE FOUR FIRST-

PREMOLARS EXTRACTION

The main objective of this study was to evaluate the long-term stability of the following cephalometric measurements: SNA, SNB, ANB, 1 .NA, $\underline{1}-\mathrm{NA}, \overline{1} . \mathrm{NB}, \overline{1}-$ NB, 1.ENP-ENA, IMPA, 1. $\overline{1}$. This analysis was carried out in orthodontically treated patients which had the four first pre-molars extracted. Alternatively, this study also determined the influence of the proposed treatment at the dento-basal arrangements by orthodontic mechanics and its preservation after five years of treatment completion. The sample of this study was comprised of twenty-seven patients that were assessed at the beginning $\left(T_{1}\right)$, at the end $\left(T_{2}\right)$ and five years later $\left(T_{3}\right)$. At the beginning of treatment the patients age averaged thirteen years and five months and all the subjects displayed an ANB angle over than 4 degrees. Among the studied sample, 14 subjects were classified as Angle Class II, Division 2 malocclusion, 12 subjects displayed Angle Class I, and 1 Angle Classe II, Division 2. All the subjects were orthodontically treated by means of edgewise appliances. During all the three phases of the study the radiological data were obtained through lateral cephalograms, which were performed manually, depicted eight angular and two linear measurements. The statistical analysis in which the data were processed included one way analysis of variance in order to identify the changes between the phases related to each studied measurement. As an adjunctive method, the Tukey test was conducted to indicate in which phases of the proposed study the statistically 
significant changes were occurring. The Pearson Product Moment Correlation was recorded to relate the $\underline{1} \cdot \overline{1}$ cephalometric measurements with all the remaining measurements obtained throughout the three phases of the study. According to the obtained results, all the studied measurements, between phases $T_{1}$ and $T_{2}$, significantly changed reflecting the influence of orthodontic mechanics on the dental movement. Between the $T_{2}$ and $T_{3}$ phases, all the measurements remained stable. By the end of the orthodontic treatment all the necessaries dental arrangements were performed and preserved in a long-term fashion. 
APÊNDICE 
TABELA 1 - Idade, em anos (a) e meses (m), dos pacientes da amostra no início, no final e 5 anos após o tratamento ortodôntico

\begin{tabular}{|c|c|c|c|c|c|}
\hline № & Arquivo & Gênero & $\begin{array}{c}\text { Idade ao } \\
\text { início }\end{array}$ & $\begin{array}{c}\text { Idade ao } \\
\text { final }\end{array}$ & $\begin{array}{l}\text { Idade pós- } \\
\text { tratamento }\end{array}$ \\
\hline 1 & 61D9 & $F$ & $11 \mathrm{a} 4 \mathrm{~m}$ & $12 \mathrm{a} 5 \mathrm{~m}$ & $17 \mathrm{a} 1 \mathrm{~m}$ \\
\hline 2 & 2D1 & $M$ & $18 \mathrm{a} 4 \mathrm{~m}$ & $21 \mathrm{a} 4 \mathrm{~m}$ & $25 a 3 m$ \\
\hline 3 & 6P1 & $\mathrm{F}$ & 13a8m & $16 a 2 m$ & $20 a 7 m$ \\
\hline 4 & 17D2 & $\mathrm{F}$ & $14 a 4 m$ & $16 a 1 m$ & 21a8m \\
\hline 5 & 33P4 & $M$ & $16 a 4 m$ & $18 a$ & 21a3m \\
\hline 6 & $42 S 8$ & $F$ & $12 \mathrm{a} 9 \mathrm{~m}$ & $13 a 6 m$ & $17 a 7 m$ \\
\hline 7 & 47S5 & M & $13 a 9 m$ & $15 \mathrm{a} 1 \mathrm{~m}$ & $19 a 7 m$ \\
\hline 8 & $49 L 7$ & $F$ & $12 a 3 m$ & $14 a 4 m$ & $18 a 8 m$ \\
\hline 9 & $51 S 7$ & M & $14 a$ & 15a11m & $20 a 7 m$ \\
\hline 10 & 60L9 & $F$ & $10 a$ & $12 \mathrm{a} 8 \mathrm{~m}$ & $17 a 2 m$ \\
\hline 11 & 68D8 & $\mathrm{F}$ & 12a10m & 13a6m & 18a1m \\
\hline 12 & 71L9/18 & $F$ & $12 \mathrm{a} 4 \mathrm{~m}$ & 13a9m & $18 a$ \\
\hline 13 & 75D5 & $M$ & $14 \mathrm{a} 9 \mathrm{~m}$ & $16 a 1 m$ & 21a1m \\
\hline 14 & $83 S 8$ & $M$ & $11 \mathrm{a} 6 \mathrm{~m}$ & $12 \mathrm{a} 10 \mathrm{~m}$ & $17 \mathrm{a} 4 \mathrm{~m}$ \\
\hline 15 & $85 S 6$ & M & 11a10m & $12 \mathrm{a} 6 \mathrm{~m}$ & $16 a 8 m$ \\
\hline 16 & $95 \mathrm{~A} 12$ & $M$ & 21a9m & $23 a$ & $27 \mathrm{a} 7 \mathrm{~m}$ \\
\hline 17 & 96R12 & M & $11 a$ & $13 a 6 m$ & $17 a 10 m$ \\
\hline 18 & $112 \mathrm{M} 10$ & $\mathrm{~F}$ & $12 a$ & 13a10m & $17 \mathrm{a} 11 \mathrm{~m}$ \\
\hline 19 & 139D16 & $\mathrm{F}$ & $12 a 8 m$ & 17a8m & $21 \mathrm{a} 11 \mathrm{~m}$ \\
\hline 20 & 145D20 & M & 10a10m & $12 \mathrm{a} 9 \mathrm{~m}$ & $16 a 11 m$ \\
\hline 21 & $178 C 24$ & M & $12 \mathrm{a} 11 \mathrm{~m}$ & $14 a 9 m$ & 19a2m \\
\hline 22 & 186M22 & M & $14 a 9 m$ & $15 \mathrm{a} 5 \mathrm{~m}$ & $20 a 3 m$ \\
\hline 23 & 196D24 & $\mathrm{M}$ & $12 \mathrm{a} 5 \mathrm{~m}$ & 15a3m & 20a3m \\
\hline 24 & $211 \mathrm{M} 23$ & $\mathrm{~F}$ & $14 \mathrm{a} 7 \mathrm{~m}$ & $16 a 6 m$ & 21a1m \\
\hline 25 & $255 C 31$ & $\mathrm{~F}$ & $12 \mathrm{a} 11 \mathrm{~m}$ & $15 a$ & $20 a$ \\
\hline 26 & 258M32 & $\mathrm{F}$ & $16 a$ & $18 \mathrm{a} 2 \mathrm{~m}$ & 23a2m \\
\hline 27 & 259M32 & $M$ & 13a1m & $14^{\mathrm{a}} 11 \mathrm{~m}$ & 19a2m \\
\hline
\end{tabular}

$\mathrm{F}=$ Gênero feminino $\quad \mathrm{M}=$ Gênero masculino 
TABELA 2 - Medidas Cefalométricas auferidas no início, no final e 5 anos após o tratamento ortodôntico

\begin{tabular}{|c|c|c|c|c|c|c|c|c|}
\hline PACIENTE & SNA-I & SNA-F & SNA-5 & SNB-I & SNB-F & SNB-5 & ANB-I & ANB $F$ \\
\hline 1 & 81 & 81 & 81 & 74 & 73 & 73 & 7 & 8 \\
\hline 2 & 83 & 84 & 84 & 76 & 76 & 76 & 7 & 8 \\
\hline 3 & 79 & 78 & 79 & 72 & 71 & 71 & 7 & 7 \\
\hline 4 & 82 & 83 & 83 & 75 & 74 & 75 & 7 & 9 \\
\hline 5 & 88 & 82 & 86 & 74 & 74 & 77 & 14 & 8 \\
\hline 6 & 85 & 81 & 84 & 75 & 74 & 75 & 10 & 7 \\
\hline 7 & 77 & 77 & 76 & 72 & 71 & 72 & 5 & 6 \\
\hline 8 & 78 & 72 & 75 & 70 & 68 & 69 & 8 & 4 \\
\hline 9 & 84 & 82 & 83 & 79 & 78 & 80 & 5 & 4 \\
\hline 10 & 81 & 79 & 77 & 74 & 72 & 71 & 7 & 7 \\
\hline 11 & 81 & 78 & 77 & 75 & 71 & 70 & 6 & 7 \\
\hline 12 & 88 & 86 & 87 & 81 & 80 & 81 & 7 & 6 \\
\hline 13 & 82 & 81 & 81 & 76 & 75 & 75 & 6 & 6 \\
\hline 14 & 86 & 82 & 83 & 80 & 79 & 80 & 6 & 3 \\
\hline 15 & 85 & 83 & 81 & 80 & 80 & 79 & 5 & 3 \\
\hline 16 & 74 & 73 & 73 & 69 & 68 & 68 & 5 & 5 \\
\hline 17 & 82 & 79 & 79 & 77 & 76 & 77 & 5 & 3 \\
\hline 18 & 82 & 82 & 82 & 77 & 79 & 79 & 5 & 3 \\
\hline 19 & 86 & 86 & 89 & 80 & 79 & 81 & 6 & 7 \\
\hline 20 & 83 & 79 & 80 & 74 & 73 & 74 & 9 & 6 \\
\hline 21 & 81 & 78 & 79 & 76 & 75 & 76 & 5 & 3 \\
\hline 22 & 85 & 84 & 84 & 76 & 77 & 77 & 9 & 7 \\
\hline 23 & 81 & 78 & 78 & 75 & 77 & 77 & 6 & 1 \\
\hline 24 & 80 & 77 & 78 & 75 & 73 & 74 & 5 & 4 \\
\hline 25 & 76 & 73 & 72 & 70 & 68 & 67 & 6 & 5 \\
\hline 26 & 85 & 84 & 83 & 78 & 79 & 78 & 7 & 5 \\
\hline 27 & 83 & 79 & 78 & 77 & 76 & 77 & 6 & 3 \\
\hline
\end{tabular}




\begin{tabular}{|c|c|c|c|c|c|c|c|}
\hline PACIENTE & ANB-5 & $\underline{1} \cdot N A-I$ & $\underline{1} \cdot N A-F$ & 1.NA-5 & 1-NA-I & 1-NA-F & 1-NA-5 \\
\hline 1 & 8 & 39 & 10 & 21 & 10 & 1 & 2 \\
\hline 2 & 8 & 30 & 8 & 8 & 10 & 3 & 2 \\
\hline 3 & 8 & 22 & 19 & 19 & 5 & 2 & 1 \\
\hline 4 & 8 & 29 & 17 & 24 & 8 & 1 & 4 \\
\hline 5 & 9 & 29 & 12 & 8 & 4 & -3 & -5 \\
\hline 6 & 9 & 23 & 11 & 13 & 6 & 1 & 2 \\
\hline 7 & 4 & 16 & 12 & 17 & 4 & 2 & 4 \\
\hline 8 & 6 & 24 & 18 & 19 & 6 & 4 & 1 \\
\hline 9 & 3 & 25 & 23 & 23 & 7 & 4 & 4 \\
\hline 10 & 6 & 37 & 18 & 23 & 7 & 2 & 5 \\
\hline 11 & 7 & 21 & 11 & 14 & 4 & 0 & 2 \\
\hline 12 & 6 & 17 & 21 & 19 & 4 & 4 & 4 \\
\hline 13 & 6 & 37 & 19 & 16 & 11 & 3 & 3 \\
\hline 14 & 3 & 19 & 20 & 14 & 3 & 1 & 0 \\
\hline 15 & 2 & 23 & 17 & 19 & 4 & 1 & 3 \\
\hline 16 & 5 & 35 & 13 & 11 & 7 & -3 & -3 \\
\hline 17 & 2 & 19 & 25 & 24 & 4 & 4 & 6 \\
\hline 18 & 3 & 29 & 26 & 23 & 8 & 4 & 5 \\
\hline 19 & 8 & 28 & 12 & 9 & 6 & 1 & 0 \\
\hline 20 & 6 & 26 & 18 & 16 & 9 & 4 & 5 \\
\hline 21 & 3 & 25 & 29 & 28 & 8 & 4 & 4 \\
\hline 22 & 7 & 14 & 16 & 17 & 3 & 2 & 3 \\
\hline 23 & 1 & -2 & 34 & 29 & -1 & 5 & 6 \\
\hline 24 & 4 & 28 & 25 & 25 & 7 & 6 & 6 \\
\hline 25 & 5 & 25 & 11 & 8 & 7 & 1 & 1 \\
\hline 26 & 5 & 12 & 29 & 24 & 2 & 1 & 1 \\
\hline 27 & 1 & 40 & 33 & 46 & 6 & 4 & 7 \\
\hline
\end{tabular}




\begin{tabular}{|c|c|c|c|c|c|c|c|c|}
\hline PACIENTE & 1.NB-I & 1.NBF & 1.NB-5 & 1-NB-I & 1-NB-F & 1-NB-5 & 1. $M x P-I$ & $\underline{1} . M \times P-F$ \\
\hline 1 & 23 & 23 & 30 & 7 & 8 & 7 & 125 & 97 \\
\hline 2 & 32 & 32 & 30 & 9 & 7 & 7 & 119 & 97 \\
\hline 3 & 29 & 24 & 22 & 7 & 7 & 6 & 115 & 111 \\
\hline 4 & 39 & 28 & 35 & 13 & 11 & 11 & 116 & 106 \\
\hline 5 & 31 & 23 & 22 & 8 & 6 & 5 & 125 & 104 \\
\hline 6 & 33 & 23 & 26 & 9 & 7 & 9 & 122 & 109 \\
\hline 7 & 28 & 24 & 24 & 7 & 7 & 7 & 105 & 100 \\
\hline 8 & 37 & 27 & 28 & 8 & 5 & 6 & 112 & 103 \\
\hline 9 & 24 & 24 & 22 & 6 & 6 & 5 & 115 & 116 \\
\hline 10 & 29 & 24 & 29 & 7 & 6 & 7 & 126 & 104 \\
\hline 11 & 27 & 20 & 29 & 8 & 6 & 8 & 111 & 100 \\
\hline 12 & 28 & 28 & 25 & 6 & 7 & 7 & 111 & 116 \\
\hline 13 & 34 & 24 & 25 & 10 & 8 & 8 & 127 & 110 \\
\hline 14 & 27 & 15 & 17 & 5 & 3 & 2 & 112 & 111 \\
\hline 15 & 35 & 21 & 18 & 8 & 4 & 3 & 118 & 112 \\
\hline 16 & 27 & 19 & 19 & 7 & 4 & 4 & 124 & 104 \\
\hline 17 & 18 & 25 & 20 & 6 & 5 & 5 & 110 & 118 \\
\hline 18 & 23 & 27 & 25 & 6 & 6 & 6 & 118 & 115 \\
\hline 19 & 29 & 29 & 27 & 6 & 5 & 5 & 125 & 108 \\
\hline 20 & 34 & 27 & 27 & 10 & 8 & 8 & 119 & 110 \\
\hline 21 & 35 & 20 & 24 & 11 & 6 & 6 & 117 & 121 \\
\hline 22 & 36 & 30 & 33 & 11 & 8 & 8 & 106 & 108 \\
\hline 23 & 14 & 24 & 21 & 2 & 3 & 3 & 84 & 118 \\
\hline 24 & 38 & 28 & 29 & 9 & 8 & 8 & 115 & 110 \\
\hline 25 & 28 & 26 & 28 & 7 & 4 & 4 & 113 & 99 \\
\hline 26 & 29 & 30 & 28 & 7 & 4 & 5 & 106 & 121 \\
\hline 27 & 25 & 21 & 22 & 8 & 5 & 5 & 129 & 120 \\
\hline
\end{tabular}




\begin{tabular}{|c|c|c|c|c|c|c|c|}
\hline PACIENTE & 1.MxP-5 & 1.MP-I & $1 . M P-F$ & $1 . M P-5$ & $1.1-I$ & $11-F$ & $1.1-5$ \\
\hline 1 & 110 & 82 & 84 & 90 & 112 & 140 & 122 \\
\hline 2 & 98 & 114 & 114 & 114 & 111 & 133 & 135 \\
\hline 3 & 105 & 99 & 93 & 91 & 122 & 129 & 137 \\
\hline 4 & 112 & 97 & 86 & 94 & 106 & 126 & 114 \\
\hline 5 & 103 & 97 & 87 & 90 & 106 & 137 & 140 \\
\hline 6 & 112 & 99 & 88 & 91 & 115 & 139 & 134 \\
\hline 7 & 107 & 95 & 90 & 92 & 131 & 139 & 136 \\
\hline 8 & 107 & 100 & 92 & 93 & 112 & 131 & 128 \\
\hline 9 & 115 & 90 & 90 & 89 & 128 & 127 & 132 \\
\hline 10 & 111 & 93 & 87 & 93 & 107 & 133 & 122 \\
\hline 11 & 104 & 91 & 82 & 89 & 127 & 144 & 131 \\
\hline 12 & 112 & 92 & 93 & 91 & 130 & 126 & 130 \\
\hline 13 & 105 & 98 & 87 & 89 & 102 & 131 & 133 \\
\hline 14 & 106 & 99 & 86 & 93 & 129 & 143 & 146 \\
\hline 15 & 113 & 100 & 86 & 87 & 116 & 139 & 141 \\
\hline 16 & 98 & 93 & 85 & 87 & 114 & 143 & 145 \\
\hline 17 & 117 & 89 & 96 & 95 & 138 & 127 & 134 \\
\hline 18 & 112 & 94 & 98 & 95 & 122 & 123 & 128 \\
\hline 19 & 105 & 98 & 98 & 96 & 117 & 132 & 136 \\
\hline 20 & 109 & 100 & 93 & 94 & 112 & 130 & 131 \\
\hline 21 & 120 & 109 & 85 & 90 & 115 & 127 & 125 \\
\hline 22 & 110 & 105 & 99 & 100 & 120 & 127 & 124 \\
\hline 23 & 111 & 93 & 104 & 100 & 161 & 121 & 129 \\
\hline 24 & 110 & 98 & 87 & 88 & 109 & 123 & 123 \\
\hline 25 & 95 & 100 & 95 & 99 & 122 & 138 & 139 \\
\hline 26 & 117 & 93 & 98 & 96 & 133 & 117 & 123 \\
\hline 27 & 132 & 92 & 87 & 88 & 109 & 123 & 112 \\
\hline
\end{tabular}


TABELA 3 - Comportamento das medidas cefalométricas nos pacientes componentes da amostra

\begin{tabular}{cccc}
\hline SNA & $=$ & $>$ & $<$ \\
\hline $\mathbf{T}_{1}-\mathbf{T}_{2}$ & 4 & 2 & $21^{*}$ \\
$\mathbf{T}_{2-} \mathbf{T}_{3}$ & 9 & 11 & 7 \\
\hline
\end{tabular}

\begin{tabular}{cccc}
\hline SNB & $=$ & $>$ & $<$ \\
\hline $\mathrm{T}_{1}-\mathrm{T}_{2}$ & 3 & 4 & $20^{*}$ \\
$\mathrm{~T}_{2}-\mathrm{T}_{3}$ & 8 & 14 & 5 \\
\hline
\end{tabular}

\begin{tabular}{cccc}
\hline ANB & $=$ & $>$ & $<$ \\
\hline $\mathbf{T}_{1}-\mathbf{T}_{2}$ & 4 & 7 & $16^{*}$ \\
$\mathbf{T}_{2}-\mathbf{T}_{3}$ & 15 & 5 & 7 \\
\hline
\end{tabular}

\begin{tabular}{cccc} 
1.NA & $=$ & $>$ & $<$ \\
\hline $\mathbf{T}_{1}-\mathrm{T}_{2}$ & 0 & 7 & $20^{*}$ \\
$\mathbf{T}_{2} \mathbf{T}_{3}$ & 4 & 10 & 13 \\
\hline
\end{tabular}

\begin{tabular}{cccc}
\hline 1-NA & $=$ & $>$ & $<$ \\
\hline $\mathrm{T}_{1}-\mathrm{T}_{2}$ & 2 & 1 & $24^{*}$ \\
$\mathrm{~T}_{2} \mathrm{~T}_{3}$ & 8 & 13 & 6 \\
\hline
\end{tabular}

\begin{tabular}{cccc}
\hline 1.NB & $=$ & $>$ & $<$ \\
\hline $\mathrm{T}_{1} \mathrm{~T}_{2}$ & 5 & 4 & $18^{*}$ \\
$\mathrm{~T}_{2} \mathrm{~T}_{3}$ & 3 & 12 & 12 \\
\hline
\end{tabular}

\begin{tabular}{cccc}
\hline $1-N B$ & $=$ & $>$ & $<$ \\
$\mathrm{T}_{1}-\mathrm{T}_{2}$ & 4 & 3 & $20^{*}$ \\
$\mathrm{~T}_{2}-\mathrm{T}_{3}$ & 16 & 5 & 6 \\
\hline
\end{tabular}


continuação

\begin{tabular}{cccc} 
1.ENP-ENA & $=$ & $>$ & $<$ \\
\hline $\mathrm{T}_{1}-\mathrm{T}_{2}$ & 0 & 6 & $21^{*}$ \\
$\mathrm{~T}_{2}-\mathrm{T}_{3}$ & 0 & 12 & 15 \\
\hline & & & $<$ \\
\hline IMPA & $=$ & $>$ & $18^{*}$ \\
\hline $\mathrm{T}_{1}-\mathrm{T}_{2}$ & 3 & 6 & 8 \\
$\mathrm{~T}_{2} \mathrm{~T}_{3}$ & 1 & 18 & \\
\hline & & & $<$ \\
\hline 1.1 & $\mathbf{1}$ & $22^{*}$ & 5 \\
\hline $\mathrm{T}_{1}-\mathrm{T}_{2}$ & 0 & 16 & 10 \\
$\mathrm{~T}_{2-} \mathrm{T}_{3}$ & 1 & & \\
\hline
\end{tabular}

